\title{
CAN (CONTROLLER AREA NETWORK): UMA ABORDAGEM PARA AUTOMAÇÃO E CONTROLE NA ÁREA AGRÍCOLA
}

\section{Rafael Vieira de Sousa}

Dissertação apresentada à Escola de Engenharia de São Carlos da Universidade de São Paulo, como parte dos requisitos para obtenção do título de Mestre em Engenharia Mecânica

ORIENTADOR: Prof. Dr. Ricardo Yassushi Inamasu

São Carlos

2002 
A Sérgio e Rosa,

meus dedicados e amorosos pais. 


\section{AGRADEÇO}

Ao Professor Ricardo Yassushi Inamasu pelo companheirismo e pela brilhante orientação.

A todos colegas, professores e funcionários do Departamento de Engenharia Mecânica da EESC/USP pela colaboração.

A todos colegas, pesquisadores e funcionários da Embrapa Instrumentação Agropecuária pela colaboração.

À Fundação de Amparo a Pesquisa do Estado de São Paulo pela bolsa de estudo concedida. 


\section{SUMÁRIO}

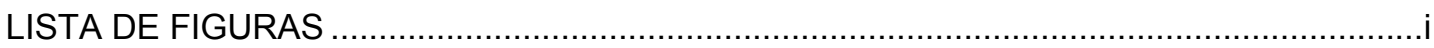

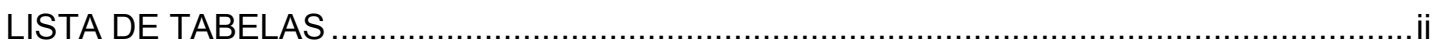

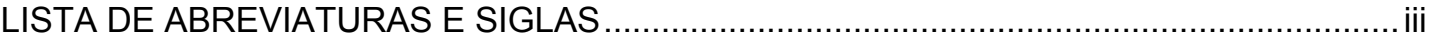

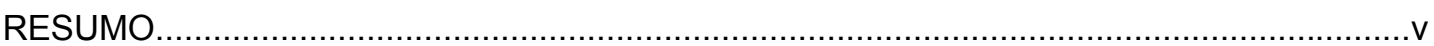

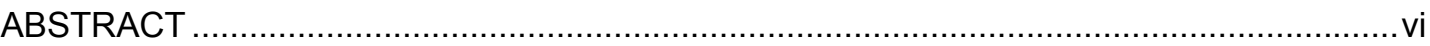

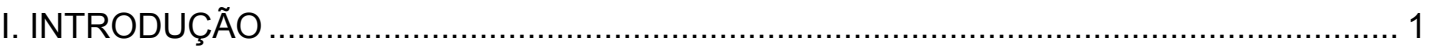

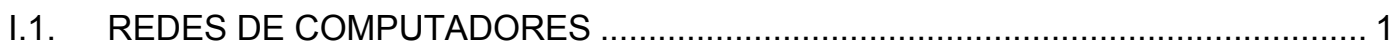

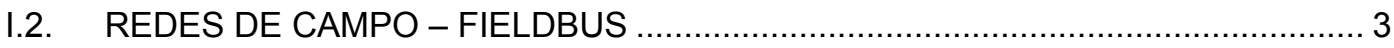

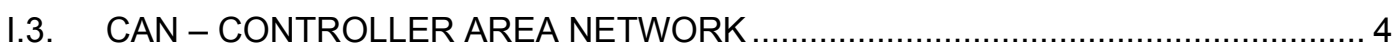

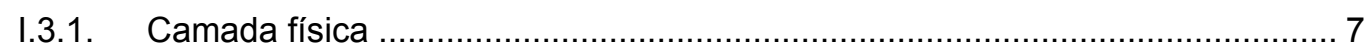

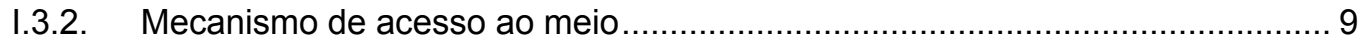

I.3.3. Tipos de quadros................................................................................ 10

I.3.4. Detecção e controle de erros ............................................................. 15

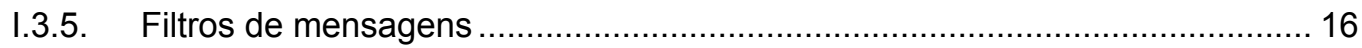

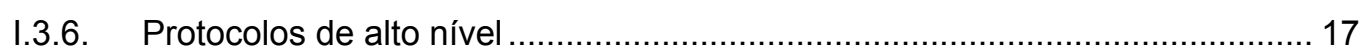

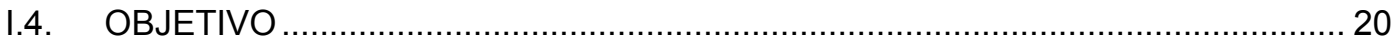

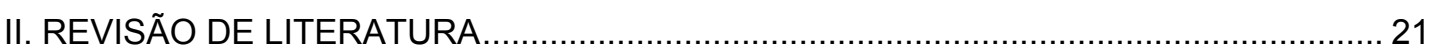

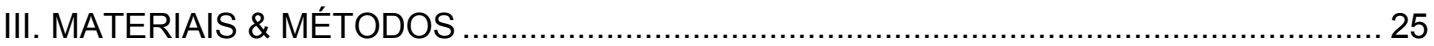

III.1. PESQUISA E SISTEMATIZAÇÃO DE PADRÕES ....................................... 25

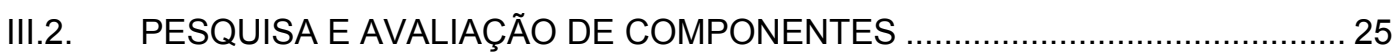

III.3. PESQUISA E AVALIAÇÃO DE INTERFACES ............................................. 26

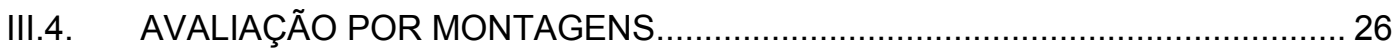

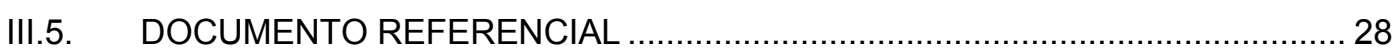

IV. RESULTADOS \& DISCUSSÕES - Documento Referencial ................................. 29

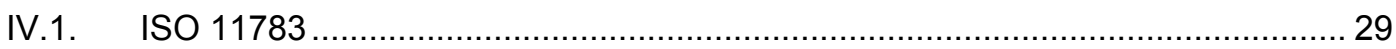

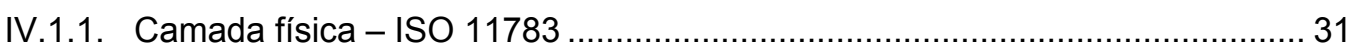

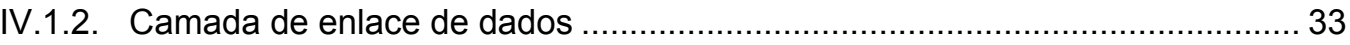

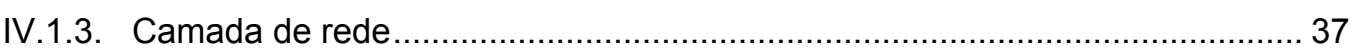

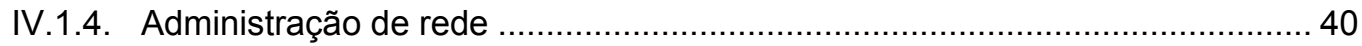

IV.1.5. Mensagens de implemento e mensagens automotivas .......................... 47

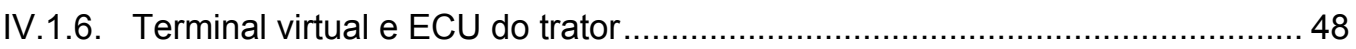

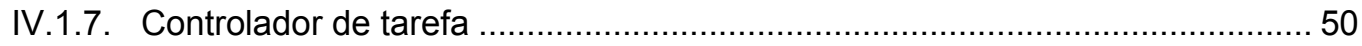

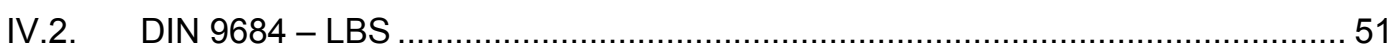

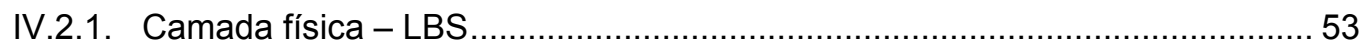

IV.2.2. Camada de enlace de dados e mensagens LBS .................................55

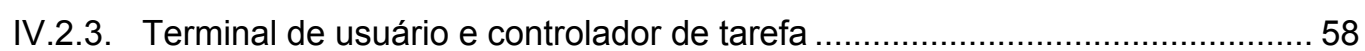




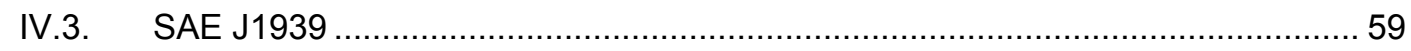

IV.4. CONSIDERAÇÕES SOBRE OS PADRÕES ISO 11783 E LSB ........................ 59

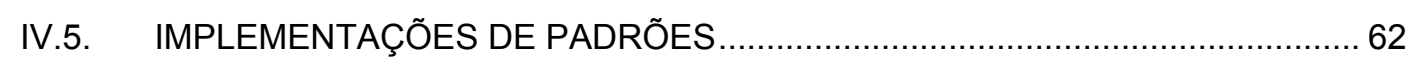

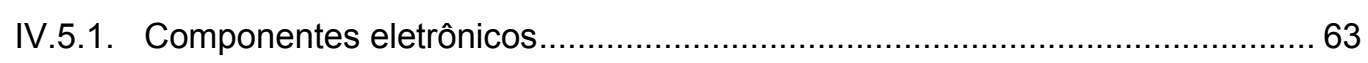

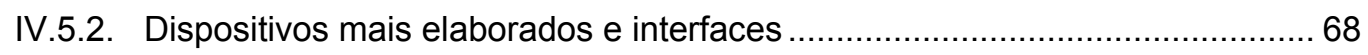

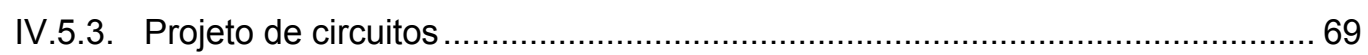

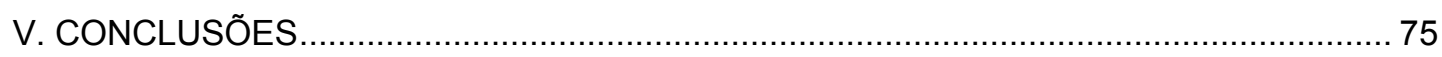

ANEXO

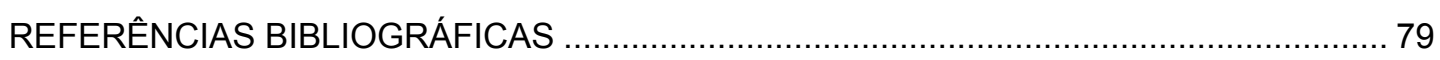

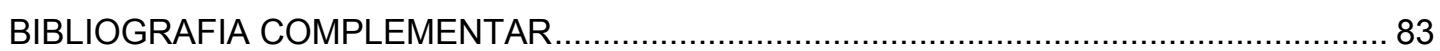




\section{LISTA DE FIGURAS}

FIGURA 1 - Ilustração do modelo ISO/OSI 2

FIGURA 2 - Fieldbus com dispositivos de campo e de controle............................................ 4

FIGURA 3 - Relação entre o modelo OSI e os padrões ISO 11898 e ISO 11519 ................. 6

FIGURA 4 - Formação da mensagem CAN a partir de quadro de bits do CAN ...................... 6

FIGURA 5 - Níveis de sinais elétricos especificados pelas normas ISO 11898 e ISO 115198

FIGURA 6 - Exemplo do processo de arbitragem do CAN ................................................ 9

FIGURA 7 - Formato do quadro de dados do CAN 2.0A …............................................ 11

FIGURA 8 - Formato do quadro de dados do CAN 2.0B ................................................. 13

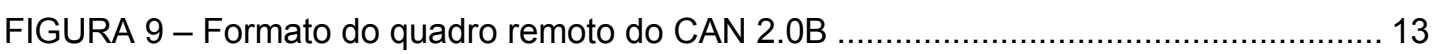

FIGURA 10 - Estados de erro possíveis para um dispositivo CAN ................................... 16

FIGURA 11 - Implementação de protocolos de alto nível utilizando quadro CAN ................ 18

FIGURA 12 - MCP2510 Kit e interface-protótipo RS232-C/CAN....................................... 27

FIGURA 13 - Metodologia para geração do documento referencial...................................... 28

FIGURA 14 - Ilustração de uma rede ISO 11783 ............................................................ 30

FIGURA 15 - Topologia de cabos e dimensões limites do barramento ISO 11783 .............. 31

FIGURA 16 - Exemplo de esquema de interconexão de sub-redes ISO 11783 ................... 33

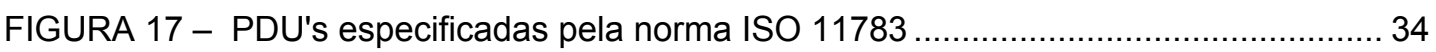

FIGURA 18 - Exemplo de mensagem do protocolo de transporte da ISO 11783 ................. 36

FIGURA 19 - Exemplo de rede ISO 11783 composta por sub-redes conectadas por NIU's 39

FIGURA 20 - Exemplo de uma NAME definida pela norma ISO 11783 ............................ 41

FIGURA 21 - Modelo do processo de inicialização de ECU autoconfigurável ..................... 45

FIGURA 22 - Simulação do modelo do processo de inicialização de ECU's ........................ 46

FIGURA 23 - Exemplo de uma mensagem definida pela ISO 11783 ................................ 47

FIGURA 24 - Estrutura de mensagem para controle de processo ....................................... 48

FIGURA 25 - Ilustração da comunicação de um MIS com o barramento ISO 11783. ..........51

FIGURA 26 - Ilustração de uma rede LBS....................................................................... 53

FIGURA 27 - Exemplo de topologia de rede LBS............................................................ 54

FIGURA 28 - Estrutura dos identificadores para os grupos de mensagens LBS ................. 56

FIGURA 29 - Relação entre os componentes físicos de um nó CAN e os protocolos .......... 64

FIGURA 30 - Interface RS232-C/CAN para instrumentos mais elaborados ........................ 70

FIGURA 31 - Fluxograma simples da rotina para teste da interface-protótipo...................... 71

FIGURA 32 - Diagrama ilustrativo da interface RS232-C/CAN - opticamente isolada ........ 72 


\section{LISTA DE TABELAS}

TABELA 1 - Padrões mais importantes desenvolvidos baseados no CAN. 19

TABELA 2 - Síntese da documentação da norma ISO 11783. 29

TABELA 3 - Partes componentes da documentação da norma DIN 9684 versão 2. 52

TABELA 4 - Partes componentes da documentação da norma SAE J1939..... 59

TABELA 6 - Transceptores CAN. 65

TABELA 7 - Controladores CAN 65

TABELA 8 - Microcontroladores com controlador CAN 67 


\section{LISTA DE ABREVIATURAS E SIGLAS}

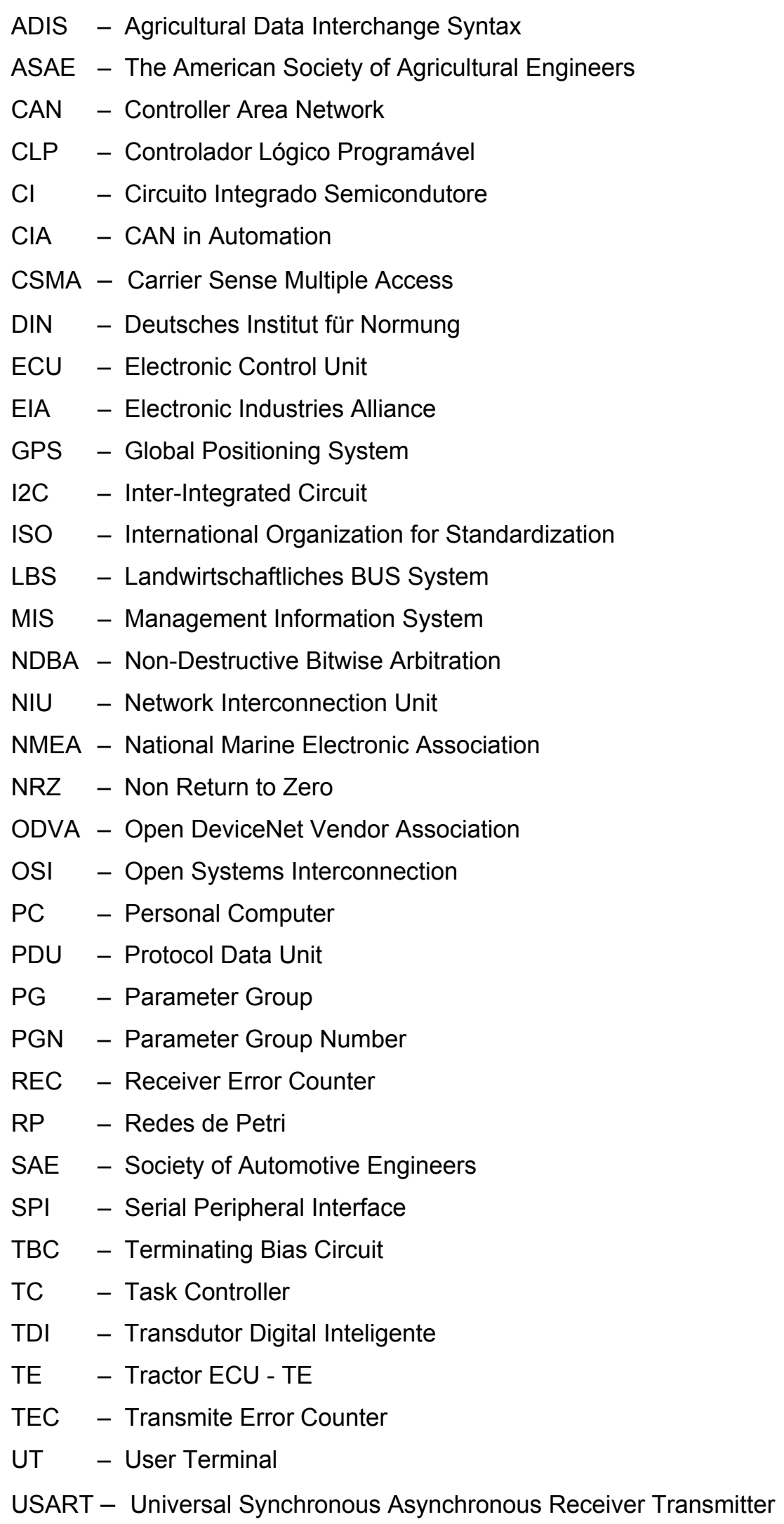


USB - Universal Serial Bus

VT - Terminal Virtual

$\mu \mathrm{C} \quad$ - Microcontroladores 
SOUSA, R. V. (2002). CAN (Controller Area Network): uma abordagem para automação e controle na área agrícola. São Carlos, 2002. 84p. Dissertação (Mestrado) - Escola de Engenharia de São Carlos, Universidade de São Paulo.

Padrões internacionais baseados no protocolo de comunicação digital serial CAN - Controller Area Network - têm sido elaborados e adotados em aplicações que utilizam eletrônica embarcada em máquinas e implementos agrícolas. No Brasil, a aplicação do CAN é restrita a máquinas e implementos importados. Verifica-se também, a necessidade de fornecer subsídios e auxílio às pequenas e médias indústrias nacionais de equipamentos agrícolas, para que estas possam oferecer equipamentos compatíveis no mercado, através da implementação desses padrões em seus produtos. Este trabalho apresenta a pesquisa de circuitos integrados, transceptores, dispositivos de instrumentação mais elaborados (receptores GPS, computadores embarcáveis, computadores portáteis, rádios digitais e atuadores e sensores inteligentes) e protocolos de alto nível para o desenvolvimento de sistemas baseados no CAN. A sistematização dos resultados origina um documento referencial prático do CAN para projetos de máquinas e implementos agrícolas, e para automação de sistemas agrícolas, como estufas, sistemas de irrigação e criadouros.

Palavras-chave: Protocolo CAN; Automação de Máquinas Agrícolas; Padrões. 


\section{ABSTRACT}

SOUSA, R. V. (2002). CAN (Controller Area Network): an approach to automation and control on agricultural area. São Carlos, 2002. 84p. Dissertação (Mestrado) Escola de Engenharia de São Carlos, Universidade de São Paulo.

International standards based on the digital data communication protocol CAN - Controller Area Network - are being developed and applied to embedded electronics in agricultural and environmental area to integrate different devices. In Brazil, the application of CAN is restricted to imported machines. Small and medium manufactures also need some support to apply this technology and offer compatible equipment to the market. This work present the searching of integrated circuits, transducers, elaborated devices (GPS receivers, embedded computers, handled computers, digital radios and intelligent sensors and actuators) and high level protocols for the development CAN based systems. The systematization of the results generate a practical reference documentation of CAN for agricultural machinery (tractor, combine and implements) designs and agricultural automation designs, such as irrigation, greenhouse and livestock systems.

Keywords: CAN Protocol; Agricultural Machinery Automation; Standards. 


\section{INTRODUÇÃO}

O desenvolvimento de sistemas computacionais e o desenvolvimento de redes computacionais para integração destes sistemas foram conquistas tecnológicas marcantes do século $X X$, que influenciam direta ou indiretamente os diversos setores de atividade humana.

Pesquisas em diversas áreas da ciência têm possibilitado o surgimento de novas tecnologias que ampliam as definições clássicas de sistema computacionais e de redes computacionais. Sistemas computacionais baseados em dispositivos ópticos, ou ainda, baseados em interações moleculares são exemplos da diversidade destas novas tecnologias.

Neste trabalho, um sistema computacional, ou simplesmente computador, em sua forma mais elementar, deve ser entendido como um conjunto formado por unidade de processamento, unidade de armazenamento e unidade de interface de entrada e saída para interação com sistemas externos. Tais unidades são compostas por circuitos elétricos analógicos e/ou digitais e por programas computacionais. Por sua vez, uma rede computacional, ou simplesmente rede, deve ser entendida como um conjunto computadores com circuitos elétricos analógicos e/ou digitais e programas computacionais de interface, que permitam a comunicação entre estes computadores, através de um ou mais meios físicos, utilizados para propagação de informação.

\section{I.1. REDES DE COMPUTADORES}

Com a finalidade de facilitar a compreensão, o projeto e a implementação de redes de computadores, a estrutura de uma rede é dividida em níveis ou camadas que têm a função de oferecer determinado serviço à camada imediatamente superior. Assim uma camada é constituída por um conjunto circuitos eletrônicos e/ou programas que implementam determinados serviços a uma camada superior, formando uma interface transparente entre as camadas, ou seja, a camada superior utiliza os serviços de uma camada inferior, sem a necessidade de esta camada superior ter informações sobre a implementação dos serviços pela camada inferior. A divisão em camadas e a implementação de serviços transparentes permitem que uma determinada camada em um computador se comunique com uma camada análoga em outro computador, trocando informações sem a necessidade de conhecerem a forma que as camadas inferiores implementam a comunicação. 
O conjunto de regras e convenções que uma camada utiliza para se comunicar com a camada análoga em outra máquina é denominado Protocolo. Uma camada pode ser constituída por um ou mais protocolos que são definidos de forma a implementarem os serviços de cada camada.

A ISO - International Organization for Standardization - propôs um modelo para a estrutura de camadas de uma rede. Esse modelo é denominado Modelo de Referência OSI (Open Systems Interconnection), ou simplesmente modelo OSI, e foi sugerido com o intuito de padronizar internacionalmente o projeto de redes. $\mathrm{O}$ modelo OSI foi definido com sete camadas, que são: Física, Enlace de Dados, Redes, Transporte, Sessão, Apresentação e Aplicação. A FIGURA 1 ilustra as sete camadas definidas para o modelo, as interfaces de serviço e a arquitetura de protocolos.

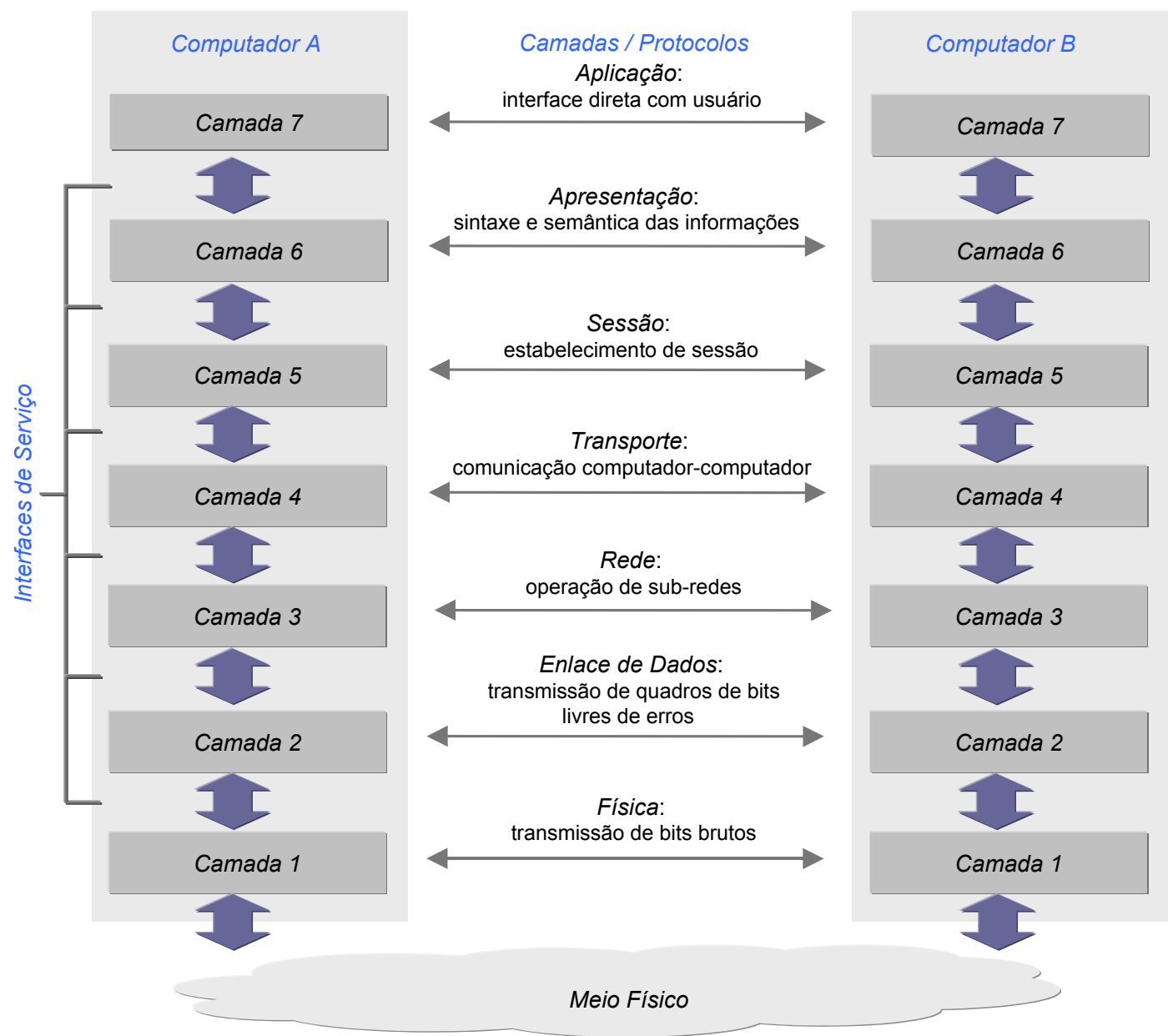

FIGURA 1 - Ilustração do modelo ISO/OSI

Indústrias, universidades, associações de normas e outros grupos interessados em integrar sistemas computacionais em redes específicas para 
aplicações próprias, têm desenvolvido Padrões que utilizam os conceitos do modelo OSI. Muitos destes padrões são desenvolvidos com apenas alguns protocolos ou camadas, proporcionando a cada usuário desenvolver outros protocolos e camadas, para criar, desta forma, uma rede adequada à aplicação desejada. Existe um número grande de padrões para atender as necessidades de aplicações diversas, como por exemplo, em redes de computadores pessoais, sistemas de comunicação de voz e imagem, sistemas de posicionamento, sistemas de instrumentação e sistemas de automação e controle em veículos, plantas industriais e residências.

\section{I.2. REDES DE CAMPO - FIELDBUS}

No setor de automação industrial se destaca uma classe de rede denominada Barramento de Campo ou Fieldbus. Um Barramento é um conjunto formado por fios, conectores e dispositivos de potência para promover a interconexão de dispositivos e permitir a comunicação entre estes. A definição tradicional para fieldbus foi de uma rede digital serial multiponto para conexão de dispositivos de campo (sensores e atuadores) e de controle (computadores industriais, controles lógicos programáveis - CLP's - e terminais de configuração, manutenção e supervisão), ou seja, uma rede com dispositivos de campo e de controle que compartilham um único meio para comunicação digital de dados. Esse conceito ampliou-se com o surgimento de novas tecnologias baseadas em novos protocolos de comunicação, que permitem implementar essa classe de redes com controle distribuído, utilizando dispositivos com maior capacidade de processamento, frequentemente denominados Transdutores Digitais Inteligentes (TDI's). A FIGURA 2 ilustra uma rede fieldbus com dispositivos de campo e de controle utilizados em plantas industriais. 


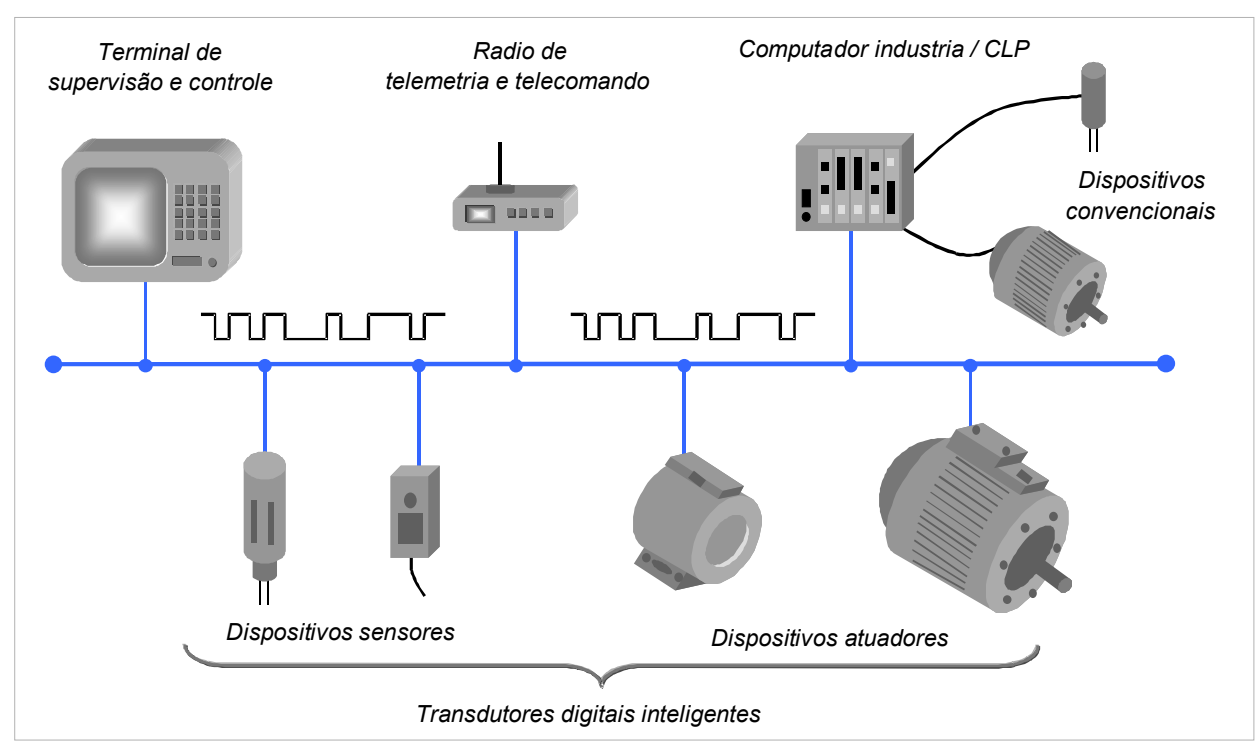

FIGURA 2 - Fieldbus com dispositivos de campo e de controle

As tecnologias de redes fieldbuses, inicialmente utilizadas em automação de plantas industriais, tem se expandido para outras áreas. Estas tecnologias têm sido empregadas em sistemas de automação e controle em aplicações diversas, como por exemplo, em veículos, residências e laboratórios.

\section{I.3. CAN - CONTROLLER AREA NETWORK}

Sob os conceitos de fieldbus foi desenvolvido o protocolo de comunicação digital serial CAN - Controller Area Network - ou Rede de Área de Controle. O CAN foi desenvolvido na década de oitenta por Robert Bosh Gmb (ROBERT, 2002) para promover a interconexão entre dispositivos de controle em automóveis, mas em poucos anos esta tecnologia migrou para outras áreas. Atualmente encontram-se padrões baseados no CAN em outros tipos de veículos, como caminhões, ônibus, barcos, satélites, máquinas agrícolas, máquinas da construção civil e máquinas militares. Outros padrões com o CAN foram desenvolvidos para automação de plantas industrias, aplicações na área de robótica e para aplicações em instrumentação, como em instrumentação médica e agrícola.

A crescente popularidade de aplicações com CAN em sistemas de automação e controle é sustentada, entre outros fatores, por este possuir, em relação a outros padrões, características muito próprias para tais sistemas, das quais ressaltam-se:

$>$ Possibilidade de configurações para operar com taxas de comunicação de poucos $\mathrm{Kb} / \mathrm{s}$ até $1 \mathrm{Mb} / \mathrm{s}$; 
> Comunicação de dados utilizando dois fios, o que reduz o custo e complexidade da implementação física, e promove proteção à interferências eletromagnéticas;

> Tamanho de dados por quadro otimizado, que permite a transmissão de dados comuns a dispositivos de sistemas de controle, com pequeno tempo de ociosidade para cada dispositivo;

> Utilização de um método de arbitragem para acesso ao meio para transmissão de dados que evita colisões e permite uma resposta rápida à necessidade de transmissão;

> Possibilidade de implementação de rede com comunicação ponto-a-ponto (entre dois dispositivos), por multidifusão (de um dispositivo para um grupo de dispositivos) ou por difusão (de um para todos dispositivos);

> Mecanismos de identificação de erros e de tolerância a faltas que permitem a implementação de redes bastante robustas;

$>$ Flexibilidade para adição, remoção e mudança de dispositivos, que favorecem operações de manutenção e alterações no sistema;

O protocolo CAN, como desenvolvido por Robert Bosch $\mathrm{GmbH}$, foi padronizado e documentado internacionalmente pela ISO, gerando a Norma ISO 11898, para aplicações de alta velocidade, e a Norma ISO 11519, para aplicações de baixa velocidade. Estes padrões apresentam camada física e camada de enlace de dados em acordo com o modelo OSI. A FIGURA 3 mostra as camadas desenvolvidas para o CAN relacionando-as com as camadas do modelo OSI. 
Modelo OSI

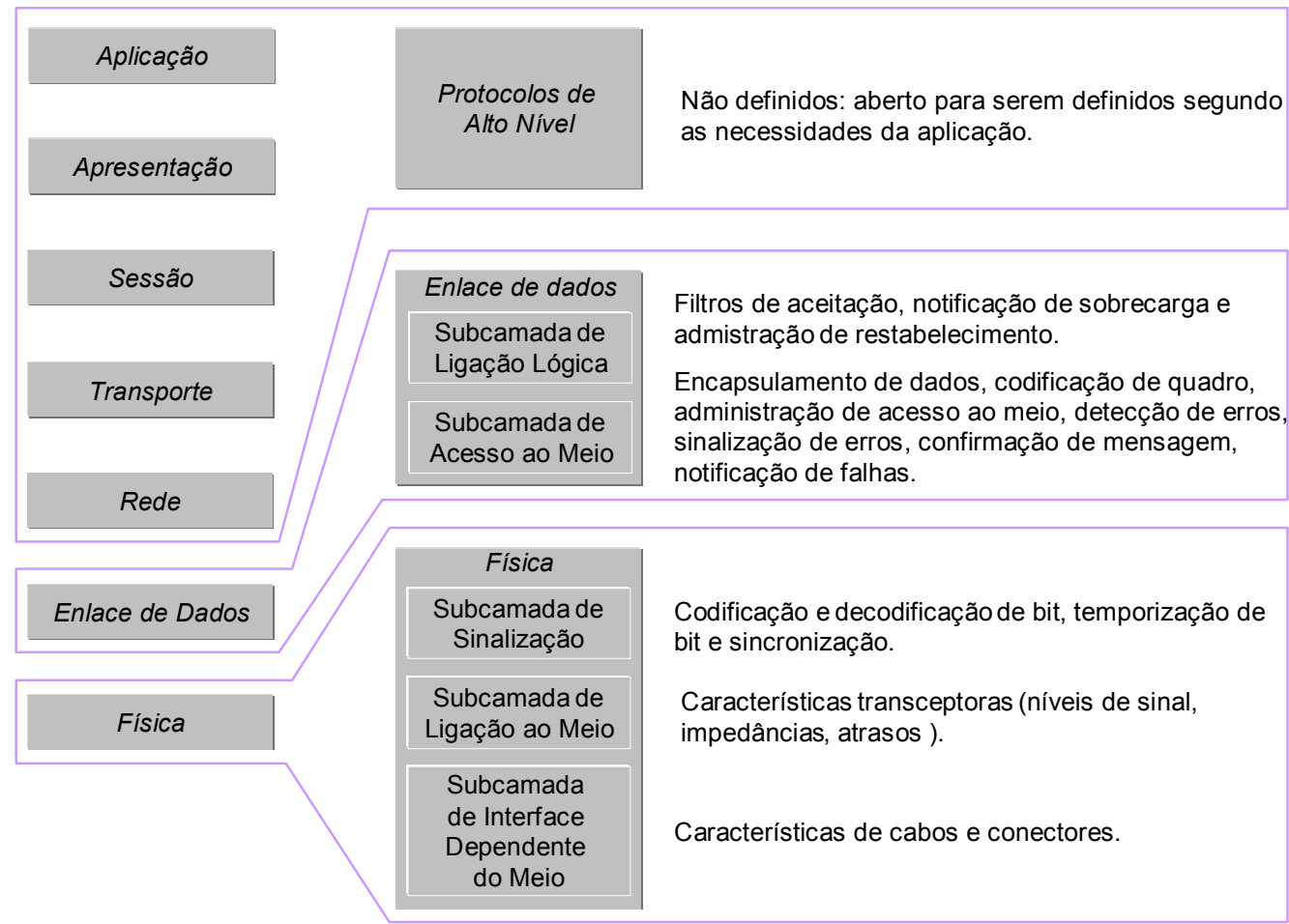

FIGURA 3 - Relação entre o modelo OSI e os padrões ISO 11898 e ISO 11519

Como pode ser visto na FIGURA 3, as camadas acima da camada de enlace de dados não são definidas pelas normas ISO 11898 e ISO 11519, ficando aberto para que cada usuário ou grupo de usuários desenvolva o próprio padrão, baseado em protocolos de camadas superiores, denominados Protocolos de Alto Nível (Higher Layer Protocols), com especificações que atendam as necessidades de cada aplicação.

A comunicação de dados em uma rede com protocolo CAN é baseada em mensagens, que são transportadas em quadros de bits, que por sua vez, são formados por campos de bits, que são conjuntos de bits com determinada função no quadro. A FIGURA 4 ilustra uma mensagem CAN e o quadro para transmissão de dados do CAN formado por diferentes campos de bits.

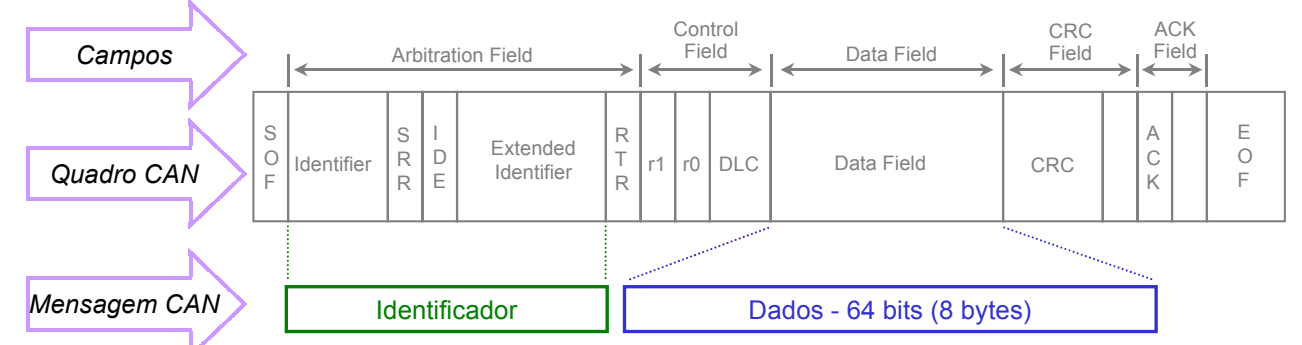

FIGURA 4 - Formação da mensagem CAN a partir de quadro de bits do CAN 
A FIGURA 4 mostra que a mensagem CAN é formada por campo de dados denominado Data Field, ao qual está associado outro campo que caracteriza a mensagem. No caso do CAN, este campo identificador que caracteriza a mensagem é denominado Identifier. Este campo define também a prioridade de cada mensagem. $O$ valor do identificador das mensagens de cada nó é exclusivo em uma rede CAN, e quanto mais baixo o valor do identificador, maior é a prioridade das mensagens desse nó. Utilizando um identificador, os vários nós fazem o escalonamento do acesso ao meio. Na recepção, quando os nós recebem a mensagem transmitida por um determinado nó, estes realizam o teste de aceitação e verificam se a mensagem tem interesse para esse nó ou não, através do identificador.

Existem duas versões do protocolo CAN, que diferem pelo formato do quadro de bits. Estas duas versões são: o Standard CAN (CAN 2.0A), com o identificador composto por 11 bits, e o Extended CAN (CAN 2.0B), com identificador composto por dois campos, um com 11 bits e outro com 18 bits (total de 29 bits). Ambas versões definem um campo de dados do quadro de dados composto por 64 bits ( 8 bytes), além de outros campos de controle e verificação.

A seguir são descritas algumas características gerais do CAN, baseadas nas normas ISO 11898 e ISO 11519, e são descritos alguns protocolos de alto nível.

\section{I.3.1. Camada física}

O barramento CAN utiliza a codificação NRZ (Non Return to Zero), regra de violação de bits - Bit-Stuffing - para assegurar o sincronismo, e sinal elétrico diferencial para comunicação de dados em um barramento a dois fios (geralmente par trançado).

A técnica de bit-stuffing definida para o CAN impede a transmissão de mais que 5 bits consecutivos idênticos. Esta técnica permite que existam blocos de 6 em 6 bits com características previsíveis. Estes blocos são usados pelos nós receptores para verificar erros de transmissão e para ressincronização.

É possível o funcionamento da rede utilizando adaptadores de sinais elétricos, denominados Transceptores, específicos para o CAN, ou utilizando outro tipo de adaptador, como por exemplo, os utilizados para o padrão RS485 da EIA (Electronic Industries Alliance). O único pré-requisito para a utilização de um meio 
diferente é a possibilidade de poder obter-se níveis recessivos e níveis dominantes nesse meio. As normas da ISO recomendam que os transceptores de interface sejam desenvolvidos de maneira que a comunicação possa continuar mesmo que um dos dois fios do barramento esteja rompido ou curto-circuitado à fonte de alimentação, ou ainda curto-circuitado à referência (ao terra).

Os sinais elétricos digitais do CAN são representados pelos níveis recessivo e dominante. Quando presentes um nível recessivo e um nível dominante no meio é sempre o nível dominante que prevalece. É este princípio que possibilita o mecanismo de acesso ao meio utilizado pelo CAN. A FIGURA 5 ilustra os níveis de sinal do CAN, considerando as duas linhas de transmissão do CAN - CAN_H e CAN_L.

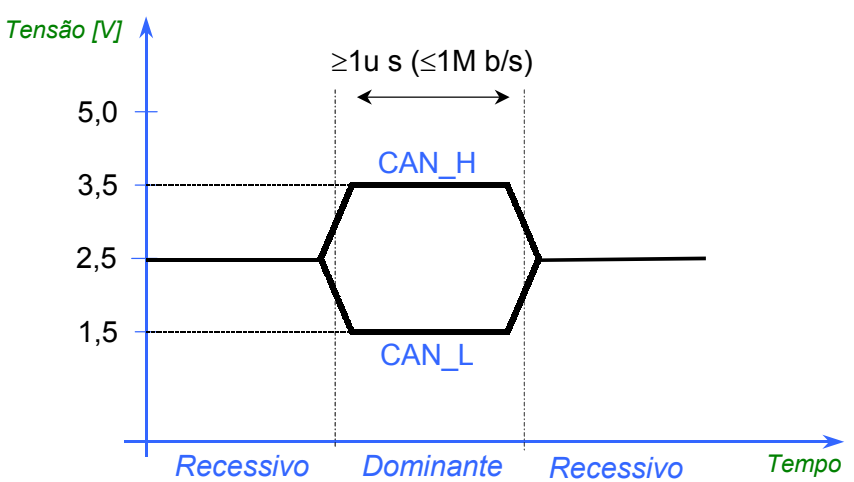

FIGURA 5 - Níveis de sinais elétricos especificados pelas normas ISO 11898 e ISO 11519

Como ilustra a FIGURA 5, a tensão elétrica nominal para o bit recessivo é 2,5V, tanto para CAN_H como para CAN_L, assim a diferença entre as tensões elétricas nominais para o bit recessivo no barramento é $0 \mathrm{~V}$. A tensão elétrica nominal para o bit dominante é 3,5V para CAN_H e 1,5V para CAN_L, assim a diferença entre as tensões elétricas nominais para o bit dominante é $2 \mathrm{~V}$. Este tipo de sinalização, utilizando a diferença entre dois sinais elétricos, é denominado sinalização balanceada, e minimiza interferência eletromagnética na comunicação, pois a interferência afeta igualmente as duas linhas com grande probabilidade, mantendo desta forma a diferença entre as tensões que representam cada bit.

As normas da ISO especificam ainda características elétricas de conectores e cabos. Especificam tempos de bit e formas de sincronização para diferentes taxas de transmissão, assim como as dimensões do barramento para estas diferentes taxas. 


\section{I.3.2. Mecanismo de acesso ao meio}

O mecanismo de acesso ao meio para comunicação de dados é feito através do método CSMA/NDBA - Carrier Sense Multiple Access with NonDestructive Bitwise Arbitration (Acesso Múltiplo com Detecção de Portadora com Arbitragem Não Destrutiva por Operação Lógica Bit-a-Bit). O CSMA define que para um nó transmitir, este deve aguardar que o barramento esteja desocupado. Estando desocupado, o nó inicia a transmissão bit-a-bit, verificando se no mesmo instante outro nó também iniciou uma transmissão, através dos sinais no barramento. O processo de NDBA soluciona os problemas de colisões através de uma lógica "E" por fios, quando dois ou mais nós iniciam a transmissão simultaneamente. Neste método os bits são relacionados com estados, sendo que o estado 0 sobrepõe-se a um estado 1 . Sendo assim, o nó com mensagem com Identificador de menor valor terá maior prioridade na transmissão da mensagem, estabelecendo um processo de acesso ao meio denominado Arbitragem. A FIGURA 6 ilustra com um exemplo a disputa entre dois nós para acessar o meio.

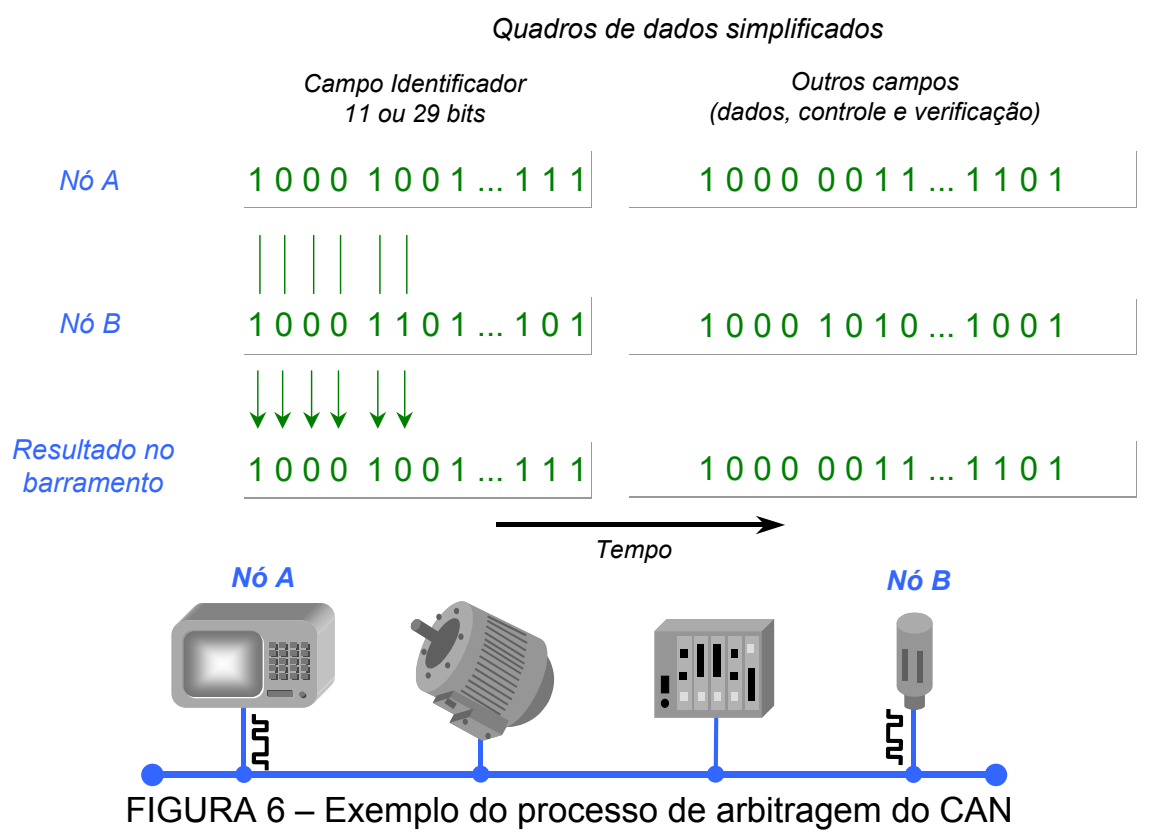

No exemplo da FIGURA 6 o Nó A tenta transmitir um quadro, referente a uma mensagem, com identificador 1000 1001.. 111 e o Nó B tenta transmitir outro quadro com o identificador 1000 110...111. Como pode ser visto na FIGURA 6, os nós prosseguem transmitindo seus identificadores que são iguais até o sexto bit, e verificam o resultado no barramento a cada bit. No momento da transmissão do sexto bit, o Nó A transmite 0 (bit dominante) e o Nó B transmite 1 (bit recessivo), 
logo, devido às propriedades da arbitragem da rede CAN, o Nó B irá detectar um bit dominante, quando havia transmitido um bit recessivo, então sai do meio e torna-se nó receptor, enquanto o Nó A prossegue transmitindo normalmente até o fim do quadro.

O mecanismo completo de acesso ao meio é o seguinte: os nós que vão transmitir aguardam barramento estar desocupado e em seguida transmitem um bit dominante, de modo a sincronizar a comunicação com os outros nós. Depois estes nós transmitem os seus respectivos identificadores. Os nós que tentam ter acesso ao meio, também monitoram os sinais elétricos no barramento, e quando detectam a presença de um bit dominante tendo transmitido um bit recessivo, saem do meio e esperam até que o barramento esteja de novo em repouso e se possa iniciar um novo período de arbitragem. Os nós que saíram do meio por terem perdido o direito de acesso durante o processo de arbitragem, passam a ser nós receptores, que no final da mensagem deverão, tal como todas as outras, confirmar que a mensagem foi recebida sem qualquer erro.

\section{I.3.3. Tipos de quadros}

Um quadro de dados segundo a versão CAN 2.0A, denominado Standard Frame (Quadro Padrão), permite a existência de 2048 mensagens (identificador com 11 bits: $2^{11}$ ), já um quadro de dados segundo a versão CAN 2.0B, denominado Extended Frame (Quadro Estendido), permite a existência de aproximadamente 500 milhões de mensagens (identificador com 29 bits: $2^{29}$ ). Esta característica do CAN permite que as mensagens trocadas sejam vistas como informações com prioridades diferentes e independentes dos nós que as produzem. Estas informações, uma vez produzidas, podem ser consumidas por qualquer nó ligado ao barramento. Os nós consumidores podem utilizar filtros de aceitação de mensagens. Estes filtros podem ser configurados de modo a interromper o processador do nó, ou CPU (Central Processing Unit - Unidade Central de Processamento) do nó, apenas quando chegam mensagens de interesse para esse nó. O número de filtros de aceitação é limitado e varia com a implementação de cada circuito controlador de protocolo.

Os quadros de bits estão relacionados com especificações de camada de enlace de dados. Para o CAN são definidos quatro tipos de quadros de bits: 
> Data Frame (Quadro de Dados);

> Remote Frame (Quadro Remoto);

$>$ Error Frame (Quadro de Erro);

> Overload Frame (Quadro de Sobrecarga);

Além dos quadros citados anteriormente, há um conjunto de bits composto por 3 bits recessivos que formam um campo denominado Intermission. Estes bits sucedem o final de cada um dos tipos de quadros citados e antecedem a condição de barramento livre (Bus Idle), na qual o barramento é mantido em estado recessivo.

A seguir é apresentada uma descrição dos quatro tipos de quadros.

a) Quadro de Dados

Nas duas versões do CAN, o quadro de dados possui o campo de dados que permite a transmissão de 0 a 8 bytes (64 bits), o campo identificador e outros campos de controle e verificação. A FIGURA 7 ilustra o quadro de dados da versão CAN 2.0A.

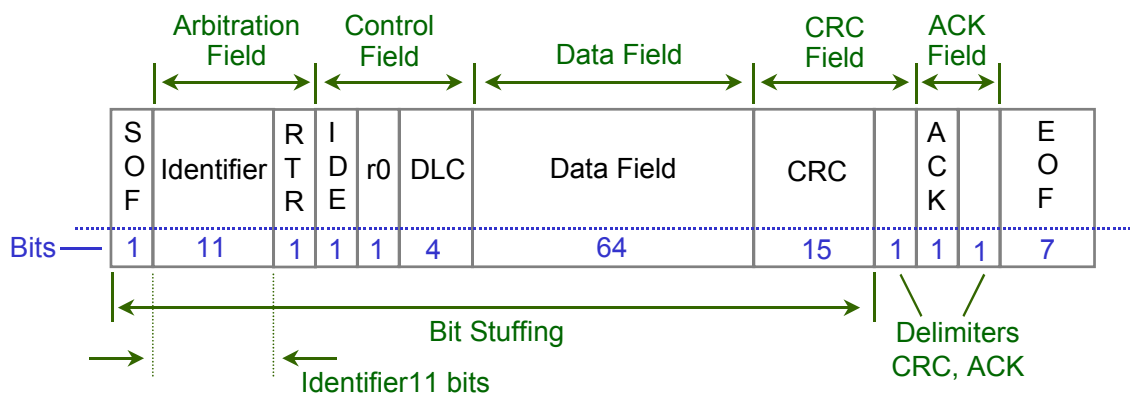

FIGURA 7 - Formato do quadro de dados do CAN 2.0A

Na FIGURA 7 os campos (fields) de bits do quadro de dados têm os seguintes significados e funções:

SOF (Start of Frame) Field (Campo de Início de Quadro): composto por um bit dominante que indica início de quadro;

Arbitration Field (Campo de Arbitragem): campo relacionado com o processo de arbitragem. Contém o identificador e um bit denominado RTR (Remote Transmission Request). Se o RTR for 0 , o quadro é do tipo quadro de dados, caso seja 1 , indica que o quadro é do tipo quadro remoto; 
$>$ Control Field (Campo de Controle): contém 6 bits de controle. O primeiro bit é o IDE (Identifier Extended Bit), que sinaliza se o quadro é padrão (se o bit for dominante) ou estendido (se o bit for recessivo). O bit seguinte, $\mathrm{r} 0$, é reservado para novas aplicações em futuras versões do CAN. Os quatro últimos bits deste campo formam um conjunto denominado DLC (Data Length Code), que indica o número de bytes no campo de dados;

> Data Field (Campo de Dados): contém 8 bytes (64 bits) com o bit mais significante do primeiro byte de dados sendo transmitido primeiro. Os bytes podem representar diversas informações, uma informação ou partes de uma informação;

> CRC (Cyclic Redundance Check) Field (Campo de Verificação de Redundância Cíclica): possui 15 bits utilizados para implementação do código de detecção de erros e um bit recessivo delimitador deste campo. O código é calculado de acordo com um polinômio específico definido para o CAN, e utiliza os 4 primeiros campos do quadro de dados (SOF, Arbitration Field, Control Field e Data Field) para o cálculo. Este código introduz uma redundância suficiente para permitir que receptores deduzam que houve um erro durante a transmissão;

ACK (Acknowledge) Field (Campo de Confirmação): consiste em dois bits, um bit denominado $A C K$, recessivo, que é sobrescrito por bits dominantes transmitidos de um outro nó que recebe a mensagem com sucesso, confirmando o recebimento. $O$ segundo bit é recessivo delimitador;

EOF (Enf of Frame) Field (Campo de Fim de Quadro): possui 7 bits recessivos, indicando o fim do quadro.

O quadro estendido diferencia-se do quadro padrão por possuir o campo de arbitragem com os 29 bits do identificador divididos em dois blocos, um de 11 bits, como no quadro padrão, e outro com 18 bits. Na versão estendida, o bit IDE faz parte do campo de arbitragem e não do campo de controle, como na versão padrão. Ainda no campo de arbitragem da versão estendida, é adicionado um bit denominado SRR (Substitute Remote Request), que deve sempre ser transmitido como recessivo para garantir que o quadro estendido tenha prioridade menor em relação a um quadro padrão, em uma rede CAN com nós com diferentes versões do protocolo. Outra diferença entre o quadro de dados estendido e o padrão, é que 
o campo de controle do quadro estendido não contém o bit IDE, que está no campo de arbitragem, e em seu lugar está presente mais um bit reservado (r1). FIGURA 8 ilustra o quadro de dados da versão CAN 2.0B.

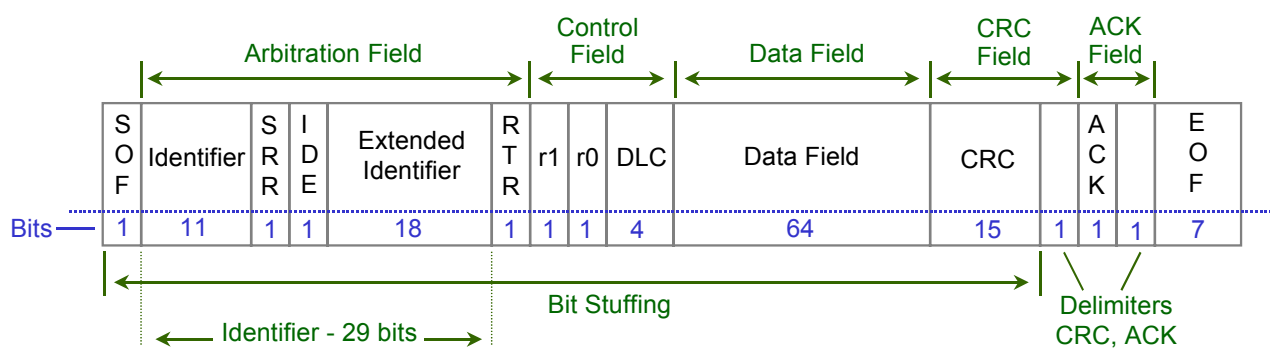

FIGURA 8 - Formato do quadro de dados do CAN 2.0B

b) Quadro Remoto

O quadro remoto permite de forma eficiente e rápida, que um nó cliente possa solicitar a um outro nó receptor remoto (servidor), o envio de um quadro de dados com o mesmo Identificador do quadro remoto. A estrutura do quadro remoto difere da estrutura do quadro de dados, por não apresentar o campo de dados. Os outros campos são iguais. A FIGURA 9 ilustra o quadro remoto definido pela versão CAN 2.0B.

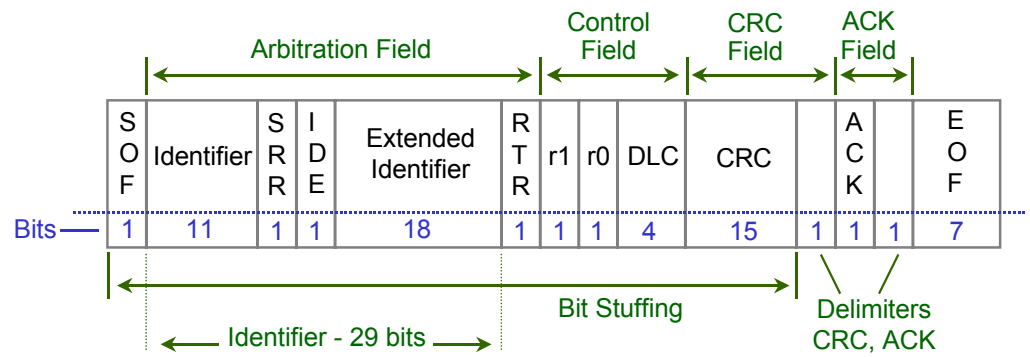

FIGURA 9 - Formato do quadro remoto do CAN 2.0B

O bit RTR deverá ser recessivo e o campo DLC poderá ter qualquer valor entre 0 a 8.

Após a recepção de um quadro remoto, o servidor deve enviar a resposta de forma automática sem interromper a CPU.

c) Quadro de Erro

O quadro de erro é gerado por qualquer nó que detecte um erro no barramento. Este tipo de quadro consiste de dois campos, um campo sinalizador de erro, denominado Erro Flag, e um campo delimitador, denominado Error Delimiter. 
O campo sinalizador de erro pode ser de dois tipos, dependendo do valor dos contadores de erros de transmissão ou recepção especificados para o CAN.

Um nó ao detectar um erro envia um quadro constituído por seis bits consecutivos, o que viola a regra de bit-stuffing e leva a que os outros nós transmitam também um quadro de erro. Deste modo, pode existir sobreposição de quadros transmitidos por todos os nós. Os níveis dos bits que são transmitidos pelo nó dependem do estado em que este nó se encontra, e que, por sua vez, esta relacionado com os valores dos contadores de erro. Um nó pode encontrar-se em estado Error-Passive, Error-Active ou Bus-Off, que são descritos com mais detalhes em seção posterior. Um nó que se encontra no estado Error-Passive transmite um quadro de erro com campo sinalizador de erro com 6 bits recessivos, seguidos por campos sinalizadores de erro de outros nós. Caso o nó se encontre em estado Error-Active o campo sinalizador de erro é constituída por 6 bits dominantes. $O$ delimitador do quadro de erro, para ambos os casos, é constituído por 8 bits recessivos, e é consecutivo aos campos sinalizadores.

Um quadro de erro só é transmitido quando ocorre um erro na transmissão ou na recepção de uma mensagem. Quando existe um erro na mensagem, o nó que tentou transmitir volta a tentar a sua transmissão, competindo pelo acesso ao meio com os outros nós. São efetuadas retransmissões até que o nó passe ao estado Bus-Off, que ocorre quando é atingido um número máximo baseado nas tentativas de retransmissão sem sucesso.

d) Quadro de Sobrecarga

O quadro de sobrecarga apresenta, assim como o quadro de erros, dois campos, um campo sinalizador de sobrecarga, denominado Overload Flag, e um campo delimitador, denominado Overload Delimiter. O campo sinalizador é composto por uma sequência de 6 bits recessivos, seguida de campos sinalizadores gerados por outros nós. O campo delimitador é composto por 8 bits recessivos e segue a sequência de campos sinalizadores. O quadro de sobrecarga é transmitido em duas situações:

$>$ Quando é detectado um bit dominante no campo Intermission entre dois quadros;

> Quando um receptor não está preparado para aceitar uma mensagem e precisa de mais algum tempo para se preparar. 


\section{I.3.4. Detecção e controle de erros}

As especificações do CAN disponibilizam alguns mecanismos de controle e administração de erros, de modo a impedir que um dispositivo que funcione mal provoque erros no barramento.

Em cada nó CAN existem dois contadores: o REC (Receiver Error Counter) de 7 bits, que guarda a contagem dos erros devidos a recepções erradas, e o TEC (Transmite Error Counter), que acumula os erros devidos às transmissões de mensagens por esse nó.

Existem 5 tipos de erros que o CAN pode identificar e que causam 0 incremento dos contadores. Os tipos de erros são os seguintes:

$>$ Bit Error (Erro de Bit): bit transmitido por um nó é diferente do bit presente no barramento monitorado pelo nó. Isto não é considerado erro na arbitragem. Nesta fase uma estação pode enviar um bit recessivo e detectar um bit dominante colocado no barramento por outro nó;

$>$ Stuff Error (Erro de Stuff): falta o bit de stuff, ou seja, mais de cinco bits transmitidos com o mesmo nível de tensão (violação da regra de bit-stuffing)

> Form Error (Erro no Quadro): um bit que deveria ter um valor esperado, prédefinido, não tem o valor correto;

> CRC Error (Erro no CRC): cálculo do CRC recebido por um nó, difere do valor transmitido junto aos dados, indicando erro no valor de um ou mais bits da mensagem;

$>$ ACK Error (Erro de Confirmação): o nó que acabou de transmitir não recebe qualquer confirmação dos outros nós.

São definidos estados de erro de um nó, e estes estados estão relacionados com o valor dos contadores de erro TEC e REC. A FIGURA 10 mostra os diferentes estados de erro relacionados com os valores dos contadores. 


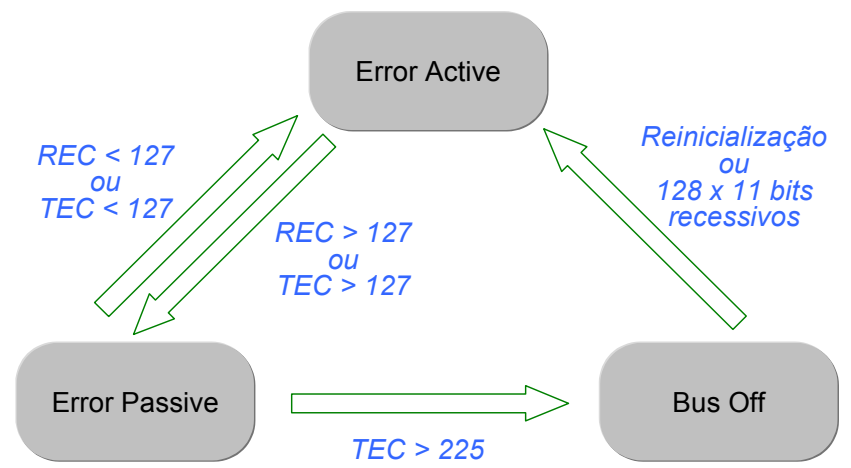

FIGURA 10 - Estados de erro possíveis para um dispositivo CAN

Os contadores TEC e REC são incrementados de 1 ou de 8 conforme a gravidade do erro detectado, e são decrementados de 1, sempre que se verifique uma transmissão ou uma recepção sem problemas.

Quando um nó, que se encontra no estado Error-Active, detecta um erro e o sinaliza através da transmissão de um quadro de erro constituído por seis bits dominantes, os outros nós irão detectar uma violação da regra de bit-stuffing, o que os leva a descartar os dados recolhidos até ao momento, e a transmitir também um campo sinalizador de erro, denominado Error Echo Flag. Um nó no estado ErrorActive esta em estado normal de operação, sendo permitido transmitir e receber dados sem restrições.

Se um nó detectar que o valor de um dos seus contadores excede o valor de 127 (TEC e REC>127), este passa para o estado Error-Passive. Neste estado, o nó passa a assumir que um erro no barramento pode, muito provavelmente, ser causado por ele, por isso, sempre que detecta um erro emite um quadro de erro constituído por seis bits recessivos. Neste estado ainda é permitido transmitir e receber dados sem restrições.

Um nó passa ao estado Bus-Off quando o número de erros de transmissão é igual a 255. Neste estado, um nó está completamente desligado do barramento, até que se efetue uma reinicialização do controlador do protocolo CAN do nó.

\subsubsection{Filtros de mensagens}

Os filtros de mensagens permitem separar, individualmente, em cada nó, as mensagens que lhe interessam das que não lhe interessam. Deste modo, haverá uma otimização na tarefa de processamento de mensagens pelo processador do nó, e este não tem que estar sempre sendo interrompido para processar mensagens. 
Existem dois tipos de filtros de mensagens:

$>$ Filtro de Aceitação: filtros que contêm valores configurados previamente que são comparados com os valores de identificadores de mensagens no barramento, para determinar se a mensagem será ou não carregada e processada pelo nó (tem ou não interesse para o nó);

> Máscara: permite definir quais bits de identificadores de mensagens no barramento serão comparados com os valores de filtros de aceitação, para determinar se a mensagem será ou não carregada e processada pelo nó.

\section{l.3.6. Protocolos de alto nível}

Os protocolos de alto nível são desenvolvidos utilizando a mensagem CAN, formado pelo campo identificador e pelo campo de dados dos quadros definidos pelo CAN (quadro padrão ou quadro estendido). No campo de dados são dispostos conjuntos bits representando as informações que se deseja transmitir, que podem ser, por exemplo:

$>$ Dados de controle para outros nós;

$>$ Dados coletados por sensores;

> Dados informando o estado do nó ou de dispositivos conectados ao nó;

> Solicitação de dados a determinados nós;

> Parâmetros de configuração para outros nós.

Os dados de uma mensagem podem conter também bits que representam características da informação, como: unidade de medida, precisão, se o dado está fragmentado e faz parte de um conjunto maior, ordenação, entre outros.

O identificador é utilizado para endereçamento e qualificação da mensagem. Os bits deste campo podem conter informações como: endereço de destino da mensagem, endereço de origem, se esta pertence a um determinado grupo de mensagens, entre outras.

A FIGURA 11 ilustra a forma de utilização de um quadro de dados CAN 2.0B para implementação de protocolos de alto nível. 


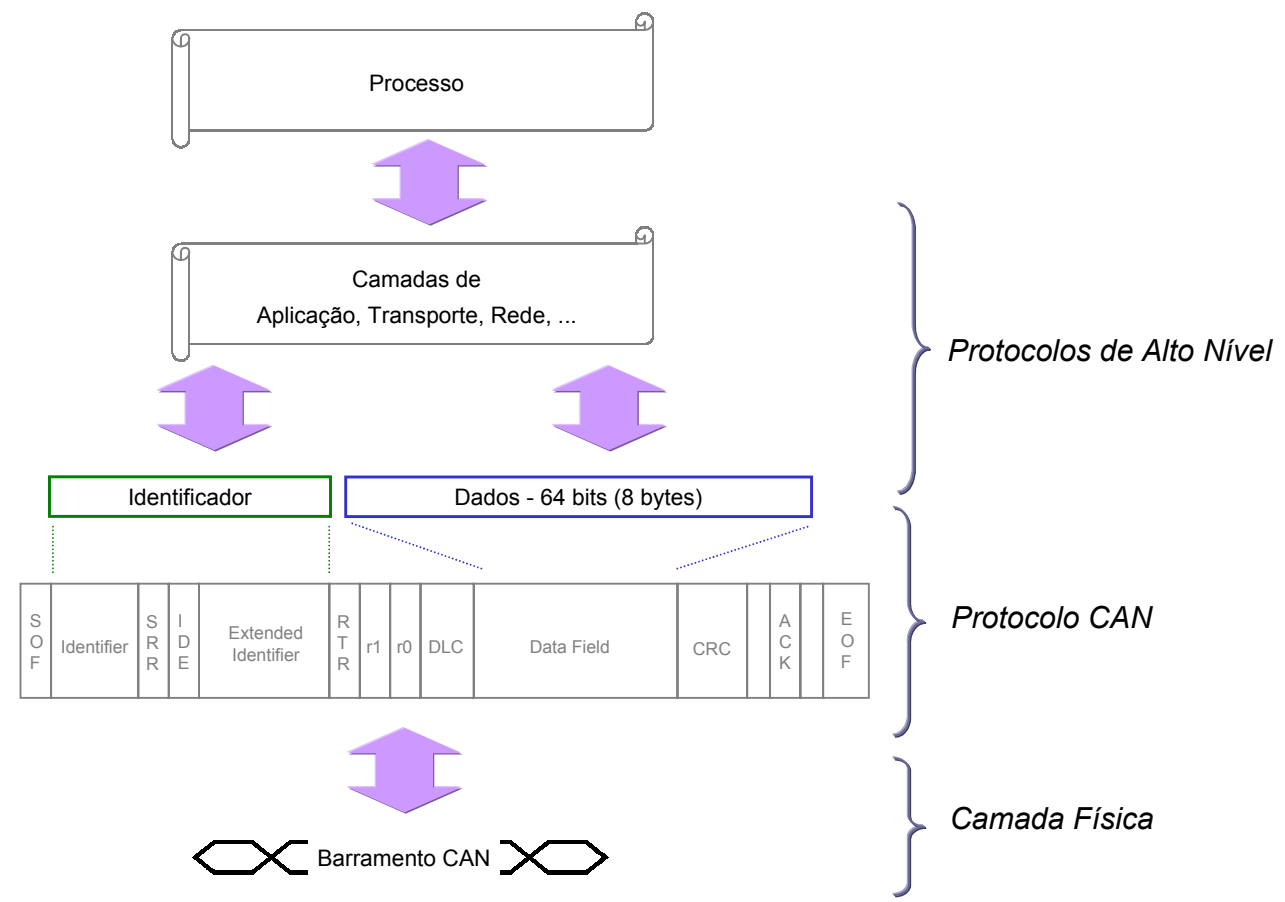

FIGURA 11 - Implementação de protocolos de alto nível utilizando quadro CAN

As aplicações mais expressivas do CAN têm sido em automação industrial e automação de veículos (automóveis, tratores, caminhões, embarcações e máquinas agrícolas). As diversas formas de implementar uma rede baseada no CAN dependem das necessidades identificadas por cada setor ou grupo, e variam de acordo com as estratégias adotadas para atender estas necessidades. A TABELA 1 mostra alguns dos padrões mais representativos presentes no mercado atual. 
TABELA 1 - Padrões mais importantes desenvolvidos baseados no CAN

\begin{tabular}{|c|c|}
\hline Padrão & Descrição \\
\hline $\begin{array}{l}\text { CAL (CAN } \\
\text { Application } \\
\text { Layer) }\end{array}$ & $\begin{array}{l}\text { Especificado por CAN in Automation (Cia) e publicado em 1993. Aplicação em } \\
\text { sistemas distribuídos na área industrial. }\end{array}$ \\
\hline CANopen & Subconjunto do CAL especificada pela Cia para automação industrial. \\
\hline DeviceNet & $\begin{array}{l}\text { Padrão desenvolvido pela Allen-Bradley e gerenciado por uma associação de } \\
\text { normas independente, a ODVA - Open DeviceNet Vendor Association. Aplicado } \\
\text { em automação fabril. }\end{array}$ \\
\hline CAN Kingdom & $\begin{array}{l}\text { Não é um padrão, mas um conjunto de regras que foram organizadas em um } \\
\text { programa que permite manipular conjunto de primitivas de protocolo e construir } \\
\text { um padrão final com protocolos personalizados para cada aplicação. Foi } \\
\text { desenvolvido pela firma sueca KVASER em conjunto com grupo CAN Textile } \\
\text { Users Group para automação fabril. }\end{array}$ \\
\hline $\begin{array}{l}\text { SDS (Smart } \\
\text { Distribution } \\
\text { Systems) }\end{array}$ & $\begin{array}{l}\text { É um padrão aberto desenvolvido pela empresa Honeywell Micro Switch. } \\
\text { Aplicado em automação industrial e foi desenvolvido especialmente para sistema } \\
\text { distribuído de sensores e atuadores ligados a dispositivos de lógica binária como } \\
\text { CLP's }\end{array}$ \\
\hline OSEK/VDX & $\begin{array}{l}\text { Originado de projeto conjunto de industrias automotivas, consiste em um padrão } \\
\text { aberto para sistemas de controle distribuído em veículos. }\end{array}$ \\
\hline NMEA 2000 & $\begin{array}{l}\text { Padrão desenvolvido por um grupo da National Marine Electronic Association } \\
\text { para redes de dispositivos eletrônicos em embarcações navais. É baseado nos } \\
\text { padrões ISO } 11783 \text { e SAE J1939. }\end{array}$ \\
\hline SAE J1939 & $\begin{array}{l}\text { Desenvolvido para aplicação em veículos de terra de grande porte como } \\
\text { caminhões, ônibus, tratores, incluindo máquinas e implementos agrícolas. }\end{array}$ \\
\hline DIN 9684 & $\begin{array}{l}\text { Especificado pela associação de normas da Alemanha DIN, para aplicações } \\
\text { agrícolas. É baseado na versão } 2.0 \mathrm{~A} \text { do CAN, e adotou e influenciou algumas } \\
\text { especificações de padrões da ISO. }\end{array}$ \\
\hline ISO 11783 & $\begin{array}{l}\text { As atividades de normatização pela ISO para este padrão para aplicações em } \\
\text { máquinas e implementos agrícolas estão sendo concluídas. Possui diversas } \\
\text { especificações iguais ao padrão SAE J1939 e ao DIN } 9684 \text {. }\end{array}$ \\
\hline
\end{tabular}

Como podem ser observados na TABELA 1, os padrões baseados no CAN mais importantes para a área agrícola atualmente são: DIN 9684 da associação de normas alemã DIN - Deutsches Institut für Normung, SAE J1939 da sociedade norte-americana SAE - Society of Automotive Engineers - e ISO 11783 da ISO. 


\section{I.4. OBJETIVO}

A importância do CAN na área agrícola é observável pelas padronizações internacionais para aplicações em máquinas e implementos agrícolas. No mercado internacional, máquinas agrícolas já possuem padrões baseados no CAN, mas no Brasil a presença desta tecnologia é restrita aos produtos importados. Também, observa-se no Brasil que pequenas e média industrias, muitas vezes, não possuem condições para manter uma equipe de desenvolvimento. Estas industrias necessitam de suporte para tornar seus produtos compatíveis com tais padrões, e para que haja possibilidade de competição com produtos importados (SOUSA, INAMASU \& TORRE-NETO, 2000).

O objetivo deste trabalho é sistematizar o CAN para o nível de projetistas de sistema de controle e automação de máquinas agrícolas através de três metas principais:

> Pesquisar e sistematizar o CAN e os padrões desenvolvidos baseados no protocolo CAN para a área agrícola, visando facilitar a aplicação desta tecnologia por empresas e instituições da área agrícola, sem a necessidade de conhecimento profundo de implementação do protocolo nos diversos níveis;

> Pesquisar e avaliar componentes eletrônicos para projetos de redes CAN para aplicações agrícolas, assim como pesquisar e avaliar interfaces de dispositivos mais elaborados para integração destes dispositivos a redes CAN para aplicações agrícolas;

- Gerar documento referencial prático para uso do CAN para aplicações agrícolas. 


\section{REVISÃO DE LITERATURA}

Tem-se verificado nas últimas décadas, um avanço vertiginoso da informática e automação em áreas como a indústria metal mecânica, química, biomédica entre outros, contribuindo para uma melhoria das condições de trabalho, do meio ambiente e promovendo a qualidade, a produtividade e a competitividade.

$\mathrm{Na}$ agropecuária, podem ser observados esforços no sentido de se obter benefícios em escala semelhante através de inovações criativas em controle da irrigação, estufas, máquinas agrícolas, criadouros entre outras aplicações. Entre os temas, o que tem demandado um expressivo número de desenvolvimento de instrumentos para automação é a Agricultura de Precisão, como apresentado por BALASTREIRE (1998) e MANTOVANI, QUEIROZ \& DIAS (1998). Uma das principais necessidades indicadas pela ASAE (1997) e reafirmada por SARAIVA \& CUGNASCA (1998) nessa área, é a compatibilidade de programas computacionais e de equipamentos. Uma tendência verificada para suprir essa necessidade tem sido a adoção de protocolo de comunicação Controller Area Network - CAN (HOFSTEE \& GOENSE, 1999; JAHNS \& SPECKMANN, 1999).

Os crescimentos de aplicações baseadas no CAN têm levado ao surgimento de novos produtos para CAN e fabricantes de Circuitos Integrados Semicondutores (Cl's) para CAN, com características diversas para diferentes aplicações. Hoje existem mais que 50 semicondutores controladores do protocolo (controladores CAN) e mais que 15 fabricantes de semicondutores, segundo a sociedade que congrega empresas de negócios no tema CAN in Automation - Cia (CIA, 2002). Ainda, segundo Cia, foram vendidos até 1999 no mercado cerca de 150 milhões de sensores, atuadores, terminais computacionais e outros tipos de sistemas computacionais com protocolo CAN, também denominados Nós CAN. Estes dados justificam o otimismo encontrado nas literaturas em relação ao CAN, e sugerem que o crescimento do uso do CAN tem levado ao aumento da disponibilidade de componentes no mercado a um custo baixo, e também de ferramentas e de serviços de avaliação e de desenvolvimento para aplicação em projetos, apesar da sofisticada tecnologia embutida, como relatado por BARBOSA, FARSI, \& RATCLIFF (1999).

$\mathrm{Na}$ área agrícola do Brasil o emprego de redes CAN é ainda restrito a produtos importados, como em colheitadeiras combinadas de grande porte. No 
Brasil, são encontradas algumas implementações com fieldbus em comunicação digital em sistemas de aquisição de dados, de telemetria e de telecomando na agricultura, como os sistemas apresentados por TORRE-NETO (1995) e CORONA (1996). Embora não sejam implementações do CAN, são encontrados nesses trabalhos os relatos da necessidade de desenvolvimento de meios de comunicação de dados robustos, próprios para ambientes agressivos. STRAUSS (1999) apresenta uma análise dos padrões de comunicação de dados mais comuns em dispositivos utilizados atualmente na agricultura, e destaca que apesar dos padrões RS232-C e RS485-C da EIA - Electronic Industries Alliance (EIA, 2001) serem os mais utilizados, não têm atendido os requisitos dos dispositivos eletrônicos desenvolvidos para atender a demanda crescentes de dispositivos para automação agrícola. É interessante observar que a maioria dos requisitos de robustez indicada pelos autores é atendida pelo CAN, como propriedades de detecção, sinalização e distinção de erros, detecção de faltas (e existência), além da possibilidade de continuar a comunicação em caso de rompimento de um dos dois fios do barramento ou curto-circuito com a fonte de alimentação (ou terra). Essa robustez conferida ao meio de transmissão de dados, aliada ao custo dos componentes, faz com que o uso do CAN seja potencialmente viável para a área agrícola.

A importância do CAN na área agrícola é observável pelas padronizações internacionais para aplicações em máquinas e implementos agrícolas, como relatado por JAHNS \& SPECKMANN (1999). No final da década de 80, na Europa, iniciou-se a elaboração da norma DIN 9684. JAHNS \& SPECKMANN (1999) e MUNACK \& SPECKMANN (2001) apresentam uma descrição das principais partes da versão 1 desta norma. O desempenho deste padrão, com respeito ao tempo de transferência de mensagens de dados, foi avaliado por HOFSTEE \& GOENSE (1997). Neste trabalho foram idealizados quatro barramentos CAN (trator e implementos) interligados por nós comuns conectados a sensores, atuadores e controladores. Foram introduzidas, para análise por simulação, mensagens com diferentes prioridades e diferentes distribuições de carga nos barramentos. Os resultados mostraram que os tempos de transmissão de mensagens são, na maioria dos casos, aceitáveis para processos de controle de implementos agrícolas, mas em certas configurações há possibilidade de atraso para o propósito considerado. 
Durante a década de 90 iniciou-se o desenvolvimento de sistemas e padrões para a área agrícola com o CAN nos Estados Unidos. STONE \& ZACHOS (1993) descrevem o desenvolvimento de mensagens para pulverizador baseado no padrão SAE J1939. STEPPER (1993) descreve as principais características das camadas físicas e de enlace de dados da norma SAE J1939 e as potenciais aplicações deste padrão em desenvolvimento na época. STONE (1997) apresenta um histórico do desenvolvimento destes padrões e relata a associação da SAE, da ASAE (The American Society of Agricultural Engineers) e da ISO para desenvolvimento internacional.

$\mathrm{Na}$ segunda metade da década de 90 surgiram aplicações com o padrão ISO 11783, apesar de este ainda não estar concluído. LANG (1999) apresenta o desenvolvimento de uma semeadora baseada no CAN e descreve o potencial do padrão ISO 11783 em aplicações como esta. STRAUSS (1999) descreve o projeto de uma plantadeira baseada no padrão ISO 11783. O desempenho deste padrão, com respeito ao tempo de transferência de mensagens de dados, foi avaliado por HOFSTEE \& GOENSE (1999) através de um programa de simulação, utilizando metodologia similar à apresentada por HOFSTEE \& GOENSE (1997).

Diante das vantagens oferecidas pelo protocolo CAN, algumas grandes empresas de máquinas agrícolas, como a AGCO (2002) em seu sistema denominado Fieldstar, já estão aplicando parte desta tecnologia em seus produtos. Também a TRIMBLE (2001), uma das empresas líderes no mercado de GPS (Global Positioning System), tem incorporado a tecnologia CAN em receptores GPS para controladores de implementos para aplicação em Agricultura de Precisão.

Pode-se inferir, portanto, que sistemas de controle distribuído podem ser projetados para a área agrícola na maioria dos casos com CAN. Entretanto, ainda há necessidade de estudos em relação aos vários parâmetros de projeto, que envolvem, por exemplo, a escolha de um padrão, a escolha de componentes (por exemplo, circuitos integrados, circuitos controladores, transdutores), a definição de prioridades para os dispositivos, a definição de topologia de rede, a definição de taxas de aquisição e de transmissão de dados, entre outros. Também, para alcançar a almejada compatibilidade, ainda há a necessidade de aplicativos (programas computacionais) e circuitos utilizarem protocolos de alto nível compatíveis, e estarem disponíveis para as pequenas e médias empresas fabricantes de implementos e acessórios de máquinas agrícolas. 
Tornando o CAN viável, considerando os custos envolvidos, outros sistemas como controladores de irrigação, fertirrigação, estufas, criadouros entre outros, podem se beneficiar, ampliando possibilidade de integração entre vários sistemas de controle e a acessibilidade pelos produtores agrícolas. 


\section{MATERIAIS \& MÉTODOS}

Os materiais e métodos aplicados neste trabalho são os típicos encontrados em metodologias de desenvolvimento de projetos em engenharia. A seguir são apresentados estes materiais e métodos em acordo com as metas descritas na Seção I.4.

\section{III.1. PESQUISA E SISTEMATIZAÇÃO DE PADRÕES}

Foram realizados levantamentos dos padrões desenvolvidos com o CAN para diversas áreas, mas, sobretudo com ênfase para a área agrícola. Foram pesquisados seriados, teses e revistas publicados pelo meio acadêmico e cientifico, disponíveis em bibliotecas e bancos de dados físicos e virtuais em universidades e instituições de pesquisa. Consultaram-se as fontes relacionadas com as associação de normas International Standards Organization (ISO, 2002), Deutsches Institut für Normung (DIN, 2002), Society of Automotive Engineers (SAE, 2002) e National Marine Electronic Association (NMEA, 2001), responsáveis por padronizações internacionais, e as associações de fabricantes e usuários KVASER (2001), CIA (2002) e ODVA (2002). Também foram consultados catálogos e revistas das empresas do setor agrícola DEERE (2002), AGCO (2002), NEW HOLLAND (2002), CASE (2001), AGROCOM (2001), AMAZONEN-WERKE (2001), MARCHESAN (2001) e BALDAN (2001). Realizaram-se consultas diretas a fabricantes de máquinas e implementos agrícolas e empresas que desenvolvem produtos com CAN para estas áreas, como no Agrishow em Ribeirão Preto.

Os principais trabalhos científicos que serviram de base para os levantamentos foram: BAKER, BRANDON \& FORMWALT (1994), HOFSTEE \& GOENSE (1997), HOFSTEE \& GOENSE (1999), JAHNS \& SPECKMANN (1999), STEPPER (1993), STONE (1997) e STONE (2001).

\section{III.2. PESQUISA E AVALIAÇÃO DE COMPONENTES}

Efetuou-se levantamento e avaliação de componentes em várias fontes, como as citadas na Seção III.1, mas principalmente das empresas fabricantes de componentes eletrônicos PHILIPS (2001), INTEL (2002), MOTOROLA (2001), INFINEON (2001), TEXAS (2001), ROBERT BOSCH GMBH (2002), NATIONAL (2001) e MICROCHIP (2002). Consultou-se também, os fabricantes de 
equipamentos e desenvolvedores de programas computacionais para CAN, KVASER (2001), VECTOR (2001), OMEGAS (2001), DEARBON (2001), TRIMBLE (2001). Os componentes avaliados foram transceptores CAN (interface física entre um controlador e o barramento CAN), controladores CAN (estabelecem o protocolo, controlam e gerenciam o barramento) e microcontroladores com ou sem controladores CAN integrados a estes (controle e processamento de dados, interface ou componente de interface com sensores, atuadores, terminais computacionais e outros). Os componentes foram avaliados tendo-se como orientação aplicações em ambientes agrícolas.

\section{III.3. PESQUISA E AVALIAÇÃO DE INTERFACES}

Foram pesquisadas e avaliadas as interfaces de dispositivos mais elaborados. Foram pesquisados e avaliados os seguintes dispositivos: transdutores (atuadores e sensores), rádios digitais, receptores GPS, computadores embarcáveis (como por exemplo, PC 104) e computadores portáteis (como por exemplo, Palm Computing e PC Notebook). Os levantamentos e avaliações foram realizados sob os seguintes enfoques: a disponibilidade de tais dispositivos com CAN e os padrões de comunicação digital mais comuns nestes dispositivos. Efetuou-se levantamento e avaliação destes dispositivos em várias fontes, como as citadas na Seção III.1 e na Seção III.2. Também foram consultados documentos das empresas de sistemas computacionais 3COM (2002) e JUMPTEC (2001), assim como documentos disponibilizados pelo consórcio internacional de computadores-embarcáveis PC104 (PC/104 CONSORTIUM, 2002).

\section{III.4. AVALIAÇÃO POR MONTAGENS}

Os resultados das pesquisas e avaliações descritas nas seções anteriores permitiram definir os circuitos que foram montados e os componentes e dispositivos que foram adquiridos.

Decidiu-se pelo projeto de interface-protótipo entre o CAN e o padrão RS232-C, que também é chamado simplesmente de padrão RS232, e cuja utilização é comum como interface externa na maioria das interfaces disponíveis nos dispositivos pesquisados e citados na Seção III.3, e como apresentado por SOUSA, INAMASU \& TORRE-NETO (2001c) e por GAZZIRO, SOUSA, INAMASU \& TORRE-NETO (2001) 
Os circuitos foram montados em placas de montagem (protboard) em laboratório. Os circuitos são baseados em microcontroladores, e as rotinas de programa para estes microcontroladores foram implementadas, testadas e refinadas, para cada circuito.

Foi adquirido um MCP2510 CAN Developer's Kit (MCP2510 Kit) da Microchip (MICROCHIP, 2002) para auxiliar nesta etapa de montagens e testes. Este conjunto é composto por placa de circuito com dois nós CAN, implementados com controlador CAN MCP2510, uma interface paralela para PC (Personal Computer) e programa para $\mathrm{PC}$, para controle e testes da placa e do barramento CAN em que o MCP2510 Kit esteja conectado. A FIGURA 12 mostra a placa com os nós CAN do kit, conectada a um PC e à interface-protótipo RS232-C / CAN que foi desenvolvida.

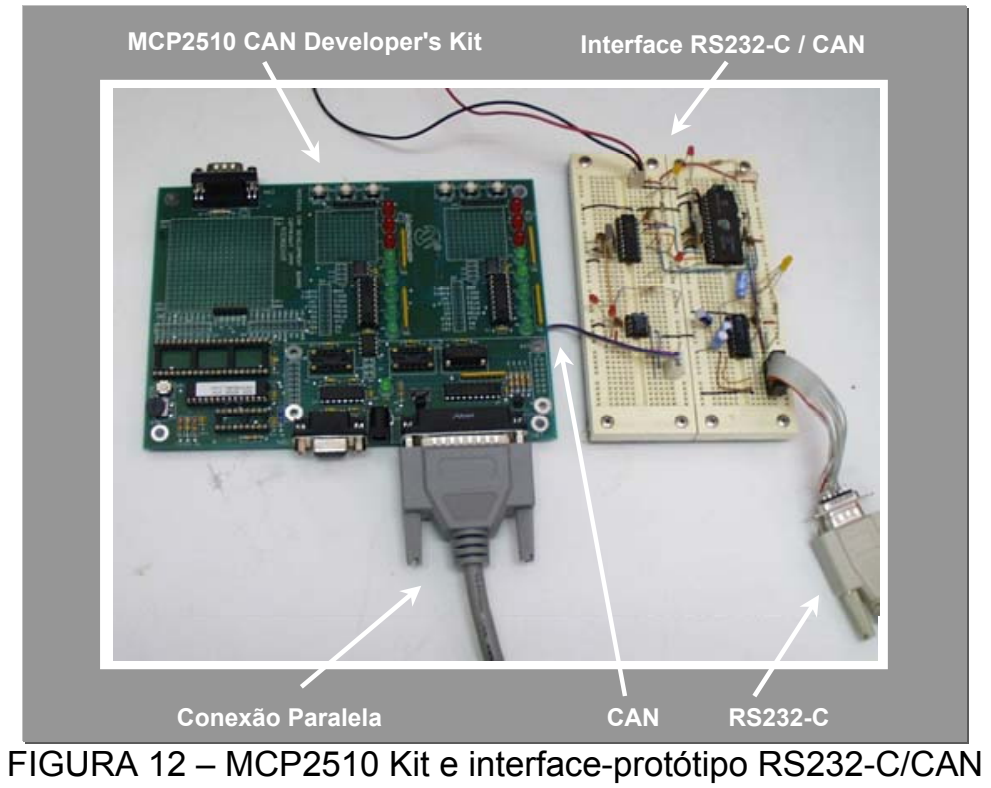

Escolheram-se os microcontroladores da família PIC18Cxx2 e controladores CAN MCP2510 da Microchip (MICROCHIP, 2002) para desenvolver os circuitos. Os transceptores CAN utilizados foram o 82C250 e o TJA1054 da Philips (PHILIPS, 2001). Os microcontroladores da família PIC18Cxx2 escolhida contêm periféricos, como interfaces SPI (Serial Peripheral Interface), USART (Universal Synchronous Asynchronous Receiver Transmitter) e I2C (Inter-Integrated Circuit), conversores $A D$ (analógicos digitais), comparadores, temporizadores e contadores internos. Contém boa capacidade de memória de programa (ROM) e de dados (RAM). Também têm disponível um compilador baseado em linguagem $C$, que facilita $O$ 
desenvolvimento de rotinas de programa para serem gravadas nestes componentes, posteriormente.

Foi elaborado também um programa de teste da interface RS232-C, no ambiente de desenvolvimento LabView ${ }^{\mathrm{TM}}$ da National Instruments (NATIONAL, 2001). Este programa é executado em um PC, e permite estabelecer comunicação entre o PC e o barramento CAN através da interface-protótipo.

\section{III.5. DOCUMENTO REFERENCIAL}

As informações e dados obtidos com a pesquisa dos padrões desenvolvidos e com a pesquisa e a avaliação de componentes e interfaces, foram confrontados, analisados e sistematizados para elaboração do documento referencial prático para uso do CAN aplicado à área agrícola. A FIGURA 13 ilustra a metodologia para geração do documento referencial.

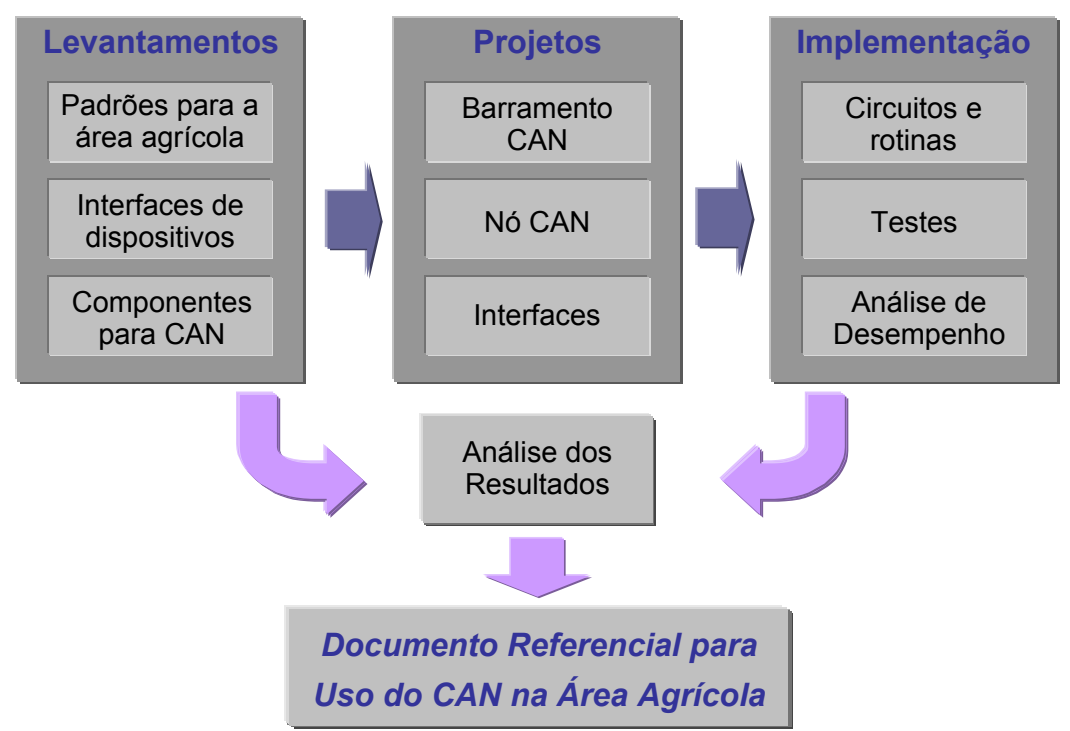

FIGURA 13 - Metodologia para geração do documento referencial

A documentação preliminar gerada ao longo do desenvolvimento do trabalho foi disponibilizada sob diversas formas, como publicações científicas, revistas relacionadas com a área agrícola, apresentações em eventos e contato com empresas e usuários. 


\section{RESULTADOS \& DISCUSSÕES - Documento Referencial}

A seguir são apresentados e discutidos os resultados do trabalho. São apresentados e discutidos de forma sistemática os padrões ISO 11783, LBS e SAE J1939 e a implementação de padrões baseados no CAN.

\section{IV.1. ISO 11783}

O comitê da ISO responsável pela norma ISO 11783 - Tractors and machinery for agriculture and forestry - Serial control and communications data network - é o TC23/SC19/WG1 e está com os trabalhos em fase de conclusão. Este padrão adota o CAN e algumas especificações desta norma foram baseadas na norma DIN 9684 e muitas outras foram baseadas na norma SAE J1939. A Tabela 2 apresenta as partes da documentação da norma ISO 11783 e uma síntese sobre cada parte.

TABELA 2 - Síntese da documentação da norma ISO 11783

\begin{tabular}{|c|c|c|}
\hline Parte & Título & Escopo \\
\hline Parte 1 & General Standard & Visão geral sobre o padrão e da aplicação de cada parte \\
\hline Parte 2 & Physical Layer & $\begin{array}{l}\text { Cabos, conectores, sinais elétricos e características } \\
\text { mecânicas e elétricas gerais do barramento }\end{array}$ \\
\hline Parte 3 & Data Link Layer & $\begin{array}{l}\text { Implementação do CAN e especificação da estrutura das } \\
\text { mensagens }\end{array}$ \\
\hline Parte 4 & Network Layer & Interconexão de sub-redes \\
\hline Parte 5 & $\begin{array}{l}\text { Network Management } \\
\text { Layer }\end{array}$ & Processo de inicialização e endereçamento de ECU's \\
\hline Parte 6 & Virtual terminal & Especificações do terminal de controle e operação \\
\hline Parte 7 & $\begin{array}{l}\text { Implement Messages } \\
\text { Application Layer }\end{array}$ & $\begin{array}{l}\text { Definição de mensagens básicas dos implementos e da } \\
\text { máquina }\end{array}$ \\
\hline Parte 8 & Power Train Message & Definição de mensagens automotivas \\
\hline Parte 9 & Tractor ECU & Especificações da Tractor ECU \\
\hline Parte 10 & $\begin{array}{l}\text { Task Controller and } \\
\text { Management Computer } \\
\text { Interface }\end{array}$ & $\begin{array}{l}\text { Especificação de interfaces para dispositivos e programas } \\
\text { computacionais de controle e administração com o } \\
\text { barramento }\end{array}$ \\
\hline Parte 11 & $\begin{array}{l}\text { Mobile Agricultural Data } \\
\text { Dictionary }\end{array}$ & Definições relativas a norma \\
\hline
\end{tabular}

O propósito do padrão ISO 11783 é prover um padrão aberto para interconexão de sistemas eletrônicos embarcáveis. O sistema eletrônico que promove a interconexão de um dispositivo ao barramento é denominado Electronic 
Control Unit (ECU) ou Unidade Eletrônica de Controle. Uma única ECU pode ser responsável pela conexão de um ou mais dispositivos a um barramento. Também um dispositivo pode ser conectado a um barramento por uma ou mais ECU's. O conjunto formado por ECU e dispositivo constitui um nó CAN. A FIGURA 14 ilustra um exemplo de rede segundo o padrão da ISO, disposto em um trator e com um implemento conectado.

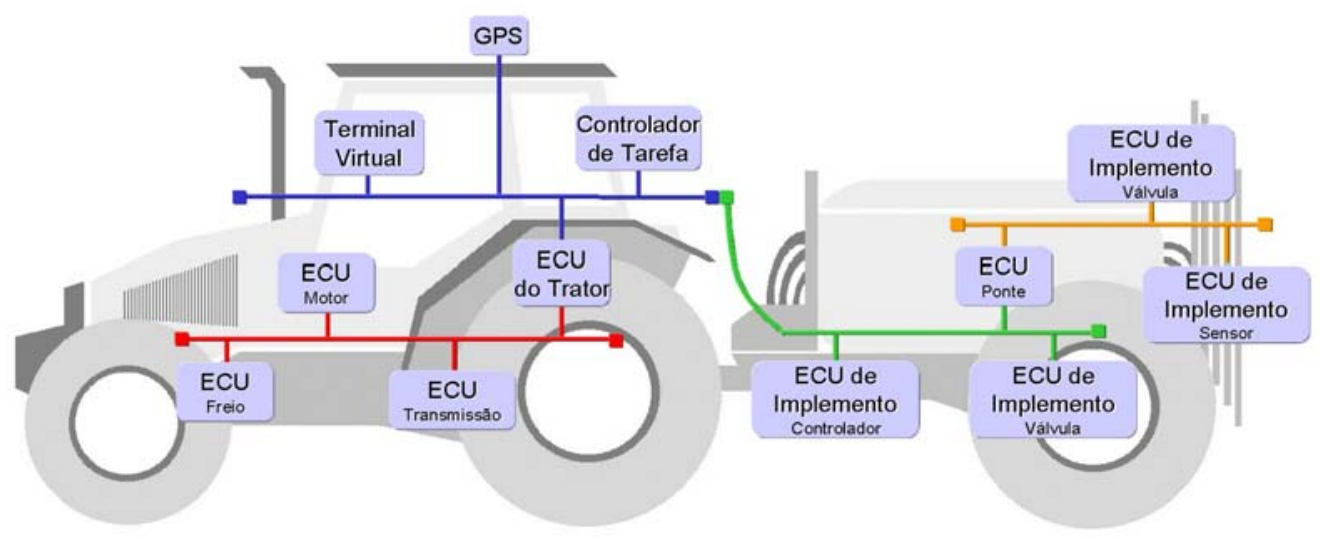

FIGURA 14 - Ilustração de uma rede ISO 11783

Neste padrão estão definidos três tipos de sub-redes, que são conectados por dispositivos denominados Network Interconnection Unit (NIU) ou Unidade de Interconexão de Rede. Estas NIUs podem ser Repeaters (Repetidores), Briges (Pontes), Routers (Roteadores) e Gateways (Portais), com funções semelhantes às funções destes elementos nas redes de PCs convencionais. Um tipo de sub-rede é a sub-rede do veículo, denominada Tractor Bus ou Barramento do Trator, onde podem estar conectadas ECU's relacionados com transdutores automotivos como, pode ser visto em vermelho na FIGURA 14. O outro tipo é a sub-rede principal de implementos, denominada Implement Bus ou Barramento de Implemento, que pode ser visto em azul e verde na FIGURA 14. A Tractor ECU (ECU do Trator) é uma NIU com funções especiais e faz a interconexão do barramento do trator com o barramento de implemento. O outro tipo de sub-rede, que está representado em laranja na FIGURA 14, pode ser qualquer fieldbus, desde que este possua uma NIU para adaptar o formato de transmissão dos dados entre os barramentos com diferentes padrões.

A seguir é apresentada uma sistematização das partes componentes da norma ISO 11783. 


\section{IV.1.1. Camada física - ISO 11783}

A Parte 1 da ISO 11783 define uma taxa de comunicação de $250 \mathrm{~kb} / \mathrm{s}$ e adota especificações da norma ISO 11898, como por exemplo, codificação NRZ, regra de violação de bits bit-stuffing e níveis de sinais elétricos, como descrito anteriormente na Seção I.3.1. São definidos o número máximo de nós igual a 30 por sub-rede e um comprimento máximo de barramento igual $40 \mathrm{~m}$ por sub-rede. A topologia de cabos e as dimensões limites por sub-rede são mostradas na FIGURA 15.

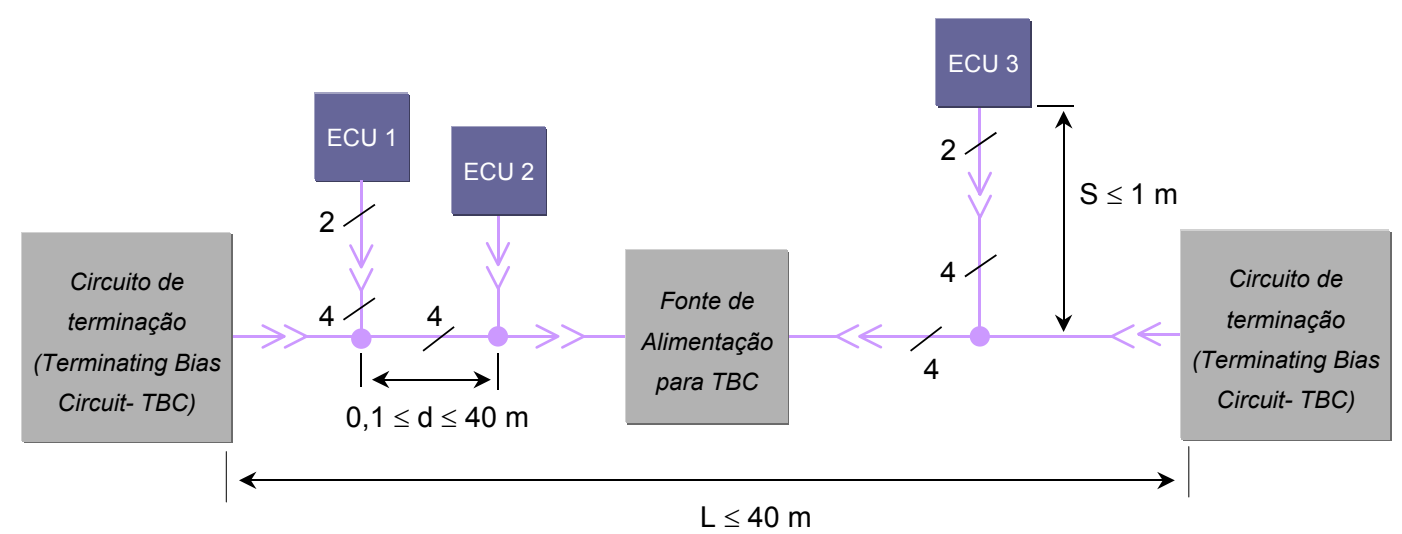

FIGURA 15 - Topologia de cabos e dimensões limites do barramento ISO 11783

O cabo para o barramento especificado é do tipo par trançado, não blindado e com quatro pares de condutores elétricos, como pode ser visto na FIGURA 15. Dois condutores são utilizados para sinalização elétrica digital na comunicação de dados (CAN_L e CAN_H), e os outros dois condutores alimentam eletricamente os circuitos de terminação do barramento (TBC_PWR e TBC_RTN). O circuito de terminação, denominado Terminating Bias Circuit (TBC), tem duas funções que são: prover uma terminação com casamento de impedância, para suprimir reflexões de sinal na linha de transmissão formada pelos condutores CAN_L e CAN_H, e prover tensão elétrica de referência de $2,5 \mathrm{~V}$ para os sinais elétricos do barramento, que corresponde ao estado recessivo e é o valor em torno do qual os sinais CAN_L e CAN_H variam, como pode ser visto na FIGURA 5 da Seção I.3.1.

São definidos três tipos principais de conectores que podem ser utilizados na implementação do barramento. Também se definem alguns conectores opcionais. Os principais tipos conectores são:

$>$ Bus Extension Connector (Conector de Barramento de Extensão): utilizado internamente na cabina do trator, no barramento de implemento, para prolongá- 
lo. Possui quatro pinos para conexão dos quatro condutores do par trançado especificado para o barramento.

> Implement Bus Breakaway Connector (Conector para Conexão Automática): utilizado no barramento do implemento para conexão de implementos com seus próprios barramentos. Possui nove pinos que são utilizados para conexão dos quatro condutores do par trançado especificado para o barramento e para conexão de condutores de alimentação elétrica para dispositivos de implemento conectado à máquina. Estes conectores devem estar associados a TBC's e devem permitir a conexão ou a desconexão automática destes, quando um implemento e seu barramento forem desconectados ou conectados ao trator.

Diagnostic Connector (Conector para Diagnóstico): utilizado para terminais de monitoramento e diagnóstico, através do barramento, de eventuais problemas. Possui nove pinos para conexão dos condutores de dados do barramento do implemento e do barramento do trator, e também para conexão dos condutores de alimentação elétrica;

Além das características citadas para cabos, conectores e TBC's, a documentação de camada física especifica também outras características elétricas e mecânicas para estes elementos, tais como: resistências e capacitâncias internas, níveis máximos de sinais elétricos suportados, atrasos de propagação de sinais elétricos, dimensões, limites de temperatura de operação, entre outras características.

Outras especificações de camada física tratadas pela norma são:

> Temporizações: tempo de bit, subdivisões do bit, amostragem de bit, sincronização e atrasos de transmissão;

Métodos de verificação de parâmetros elétricos do barramento, de ECU's e de TBC's. São apresentados alguns circuitos equivalentes referentes à aferição das grandezas elétricas que estes elementos devem apresentar;

Especificação da operação do barramento e das ECU's sob condições de faltas e falhas, tais como: curto-circuito entre os condutores do par trançado, curtocircuito de condutores do barramento e condutores de alimentação elétrica e rompimento de condutores. São previstas várias condições adversas de faltas e falhas em que o sistema deve manter a comunicação; 
- São apresentados circuitos elétricos equivalentes e esquemas elétricos de TBC's, circuitos transceptores e de circuitos de alimentação elétrica.

A FIGURA 16 apresenta o exemplo de um esquema de interconexão de uma rede formada por três sub-redes.

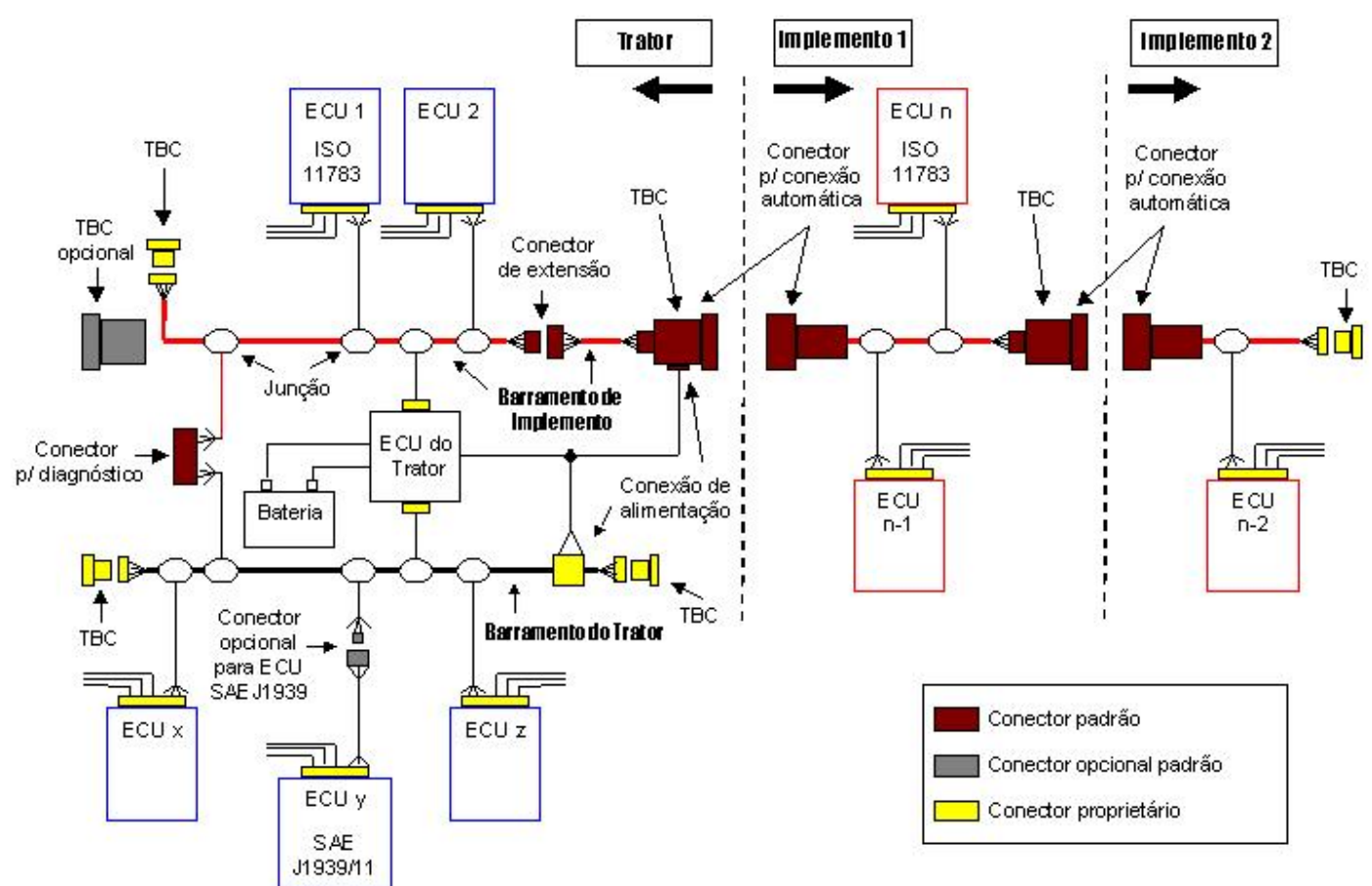

FIGURA 16 - Exemplo de esquema de interconexão de sub-redes ISO 11783

(LANDTECHNIK-VEREINIGUNG, 2002)

\section{IV.1.2. Camada de enlace de dados}

A camada de enlace de dados adota a versão CAN2.0B do protocolo CAN, como especificado pela ISO 11898 e como descrito na introdução da Seção I.3.

A Parte 3 da norma, que trata da camada de enlace de dados, define um esquema de uso de bits do identificador, que origina duas Unidades de Protocolo de Dados (Protocol Data Unit - PDU). Estas duas PDU's são estruturas de mensagem que permitem diferentes tipos de endereçamentos para uma mensagem. A estrutura denominada PDU1 permite que uma ECU envie uma mensagem diretamente para outra ECU. A estrutura denominada PDU2 permite que se identifique o tipo de dados da mensagem, mas não endereça a mensagem a uma ECU específica, podendo qualquer ECU conectada ao barramento, avaliar o conteúdo da mensagem pelo seu identificador, e, então, decidir pela recepção ou 
não desta mensagem. A FIGURA 17 mostra os dois tipos de PDU's especificadas pela norma.

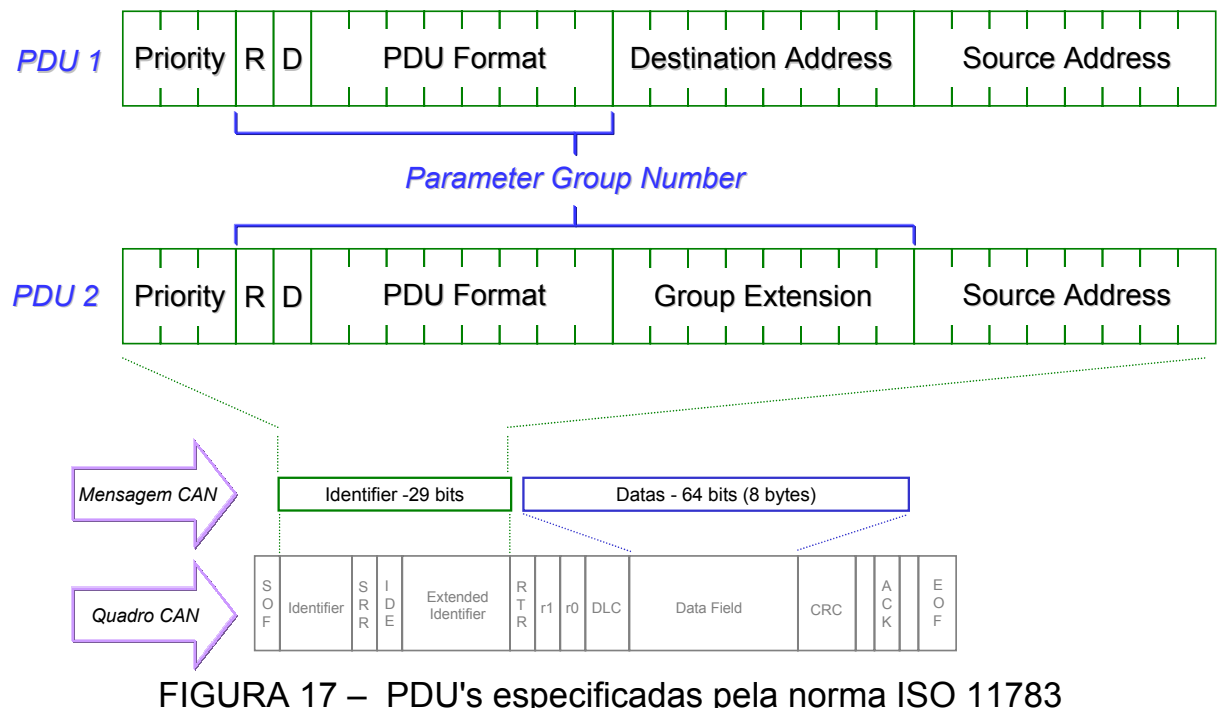

A norma define 256 ( 0 a 255 - 8 bits) endereços possíveis em uma rede, como pode ser verificado na FIGURA 17, pelos tamanhos dos campos Destination Address (Endereço de destino) e Source Address (Endereço de Origem), das duas estruturas possíveis para o identificador, denominadas PDU1 e PDU2. Destes 256 endereços, 253 podem ser atribuídos a dispositivos na rede. O endereço 255 é o endereço de destino global e o endereço 254 é um endereço nulo utilizado para administração da rede. Como pode ser visto na FIGURA 17, toda mensagem inclui o endereço do nó de origem da mensagem, e este endereço deve ser único na rede para que seja possível o correto mecanismo de acesso ao meio definido para o CAN.

O campo PDU Format (Formato de PDU) do identificador, que pode ser visto na FIGURA 17, permite que as ECU's conectadas ao barramento possam identificar o tipo de PDU, PDU1 ou PDU2, que esta sendo utilizada na comunicação de uma mensagem por um determinado nó. Se o campo da PDU (1 byte) tiver valor igual ou superior a 240, a PDU é do tipo 2 (PDU2), senão esta será do tipo 1 (PDU1).

O campo de que informa o formato de PDU tem outra função, além de permitir a identificação do tipo de mensagem, este campo, associado aos dois bits $\mathrm{R}$ e $\mathrm{D}$, no caso da PDU1, formam um conjunto de 10 bits, denominado PGN ou Parameter Group Number (Número de Grupos de Parâmetros). No caso da PDU2, o PGN tem 18 bits, sendo formado pelo campo de formato de mensagem, pelos bits $\mathrm{R}$ e D e pelo campo Group Extension (Extensão de Grupo). Os campos Destination 
Address e Group Extension, também são referenciados como PDU Specific (Especificação de PDU) A FIGURA 17 ilustra a estrutura do PGN para PDU1 e PDU2.

A norma classifica os dados que podem ser transmitidos em dado medido, dado de estado ou dado de comando, e especifica parâmetros para caracterizar estes dados, como por exemplo, para um dado referente a variáveis contínuas mensuradas, especifica unidade de medida, precisão e resolução. Os conjuntos de parâmetros que possuem características semelhantes são agrupados para compor uma mensagem relativa a um determinado tema, como por exemplo, mensagem com parâmetros do motor ou mensagem parâmetros de navegação. Este grupo de parâmetros é denominado PG ou Parameter Group (Grupo de Parâmetro), e é definido um formato de mensagem para cada PG. O PGN implementa uma forma de indicar o conteúdo dos dados de uma mensagem, ou seja, está associado ao PG. São possíveis 8672 grupos de parâmetro, e este número elevado possibilita implementar diversos conjuntos de mensagens para atender as necessidades de comunicação de dados entre ECU's em uma máquina agrícola e seus implementos. Os formatos de mensagens e a relação destas com os PG's e PGN's serão melhor detalhadas em seção posterior.

Considerando os bits que compõem o PGN em cada de PDU, o bit R é reservado para ampliação do número de grupos de parâmetros, e seu valor deve ser 0 nesta condição.

Os primeiros três bits das PDU's formam o campo Priority (Prioridade), que é um campo de prioridade independente e permite que sejam definidas prioridades diferentes para uma mensagem, independente do restante do identificador, pois segundo o mecanismo de acesso ao meio definido pelo CAN, estes são os primeiros bits que a serem submetidos ao processo de arbitragem, como descrito na Seção I.3.2. Ressalta-se que este campo não é o único a ser utilizado no processo de arbitragem, pois é possível que duas ECU's tentem transmitir mensagens com estes campos iguais, e neste caso os outros campos do identificador serão verificados.

A Parte 3 da norma ISO 11783 contém definições de estruturas para o campo de dados de mensagens para confirmação (ACK - Acknowledgment) e para resposta (Request). Também especifica um protocolo de transporte, com regras definidas para o envio de dados com mais de 8 bytes (limite máximo para um 
quadro CAN). Este protocolo define estruturas para o campo de dados de forma a assegurar que dados com até 1785 bytes de uma ECU, possam ser fragmentados e enviados em diversos quadros $\mathrm{CAN}$, e que estes possam ser remontados na ordem correta e verificados por ECU's receptoras. As especificações deste protocolo de transporte permitem a comunicação ponto-a-ponto (ECU envia mensagens para outra ECU específica) e a comunicação por difusão (ECU envia mensagens que qualquer ECU pode receber). Na comunicação ponto-a-ponto é possível a ECU transmissora realizar o controle de fluxo de mensagens e o receptor controlar o número de mensagens enviadas em sequência.

Algumas estruturas do campo de dados são definidas para que se possa implementar o protocolo de transporte. A FIGURA 18 ilustra um exemplo de estrutura de uma mensagem definida para pedido de permissão para envio de dados segmentados por meio de comunicação por difusão.

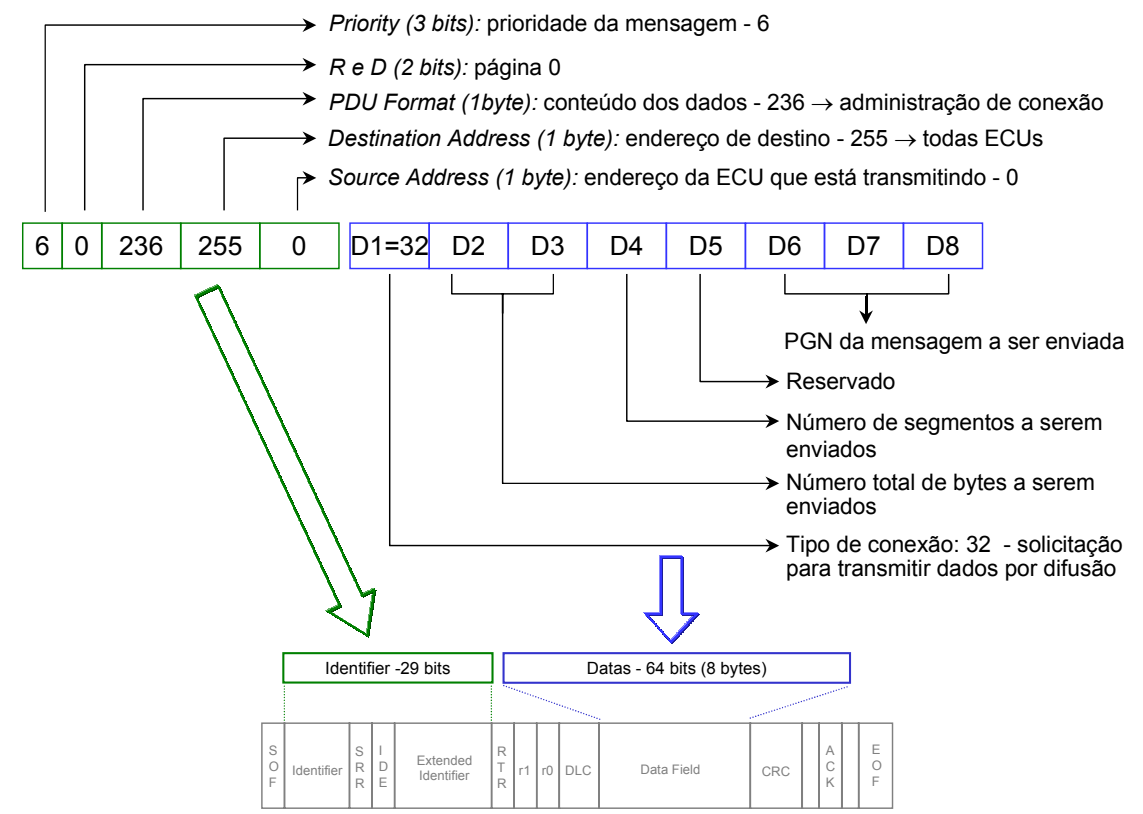

FIGURA 18 - Exemplo de mensagem do protocolo de transporte da ISO 11783

No exemplo da FIGURA 18 observa-se pelo identificador da mensagem que esta tem prioridade 6 , é uma mensagem de administração de conexão (tipo 236), é dirigida a todas ECU's (255 é definido como endereço global - comunicação por difusão) e a ECU que pretende enviá-la tem endereço 0 . No campo de dados desta mensagem o primeiro byte faz uma solicitação para enviar dados através de difusão (tipo 32), o segundo e terceiro bytes (D2 e D3) indicam o número de bytes a ser enviados, o quarto byte (D4) informa o número de sequências que serão necessárias para enviar estes dados, o quinto byte (D5) é reservado para 
implementações futuras da norma, e os três últimos bytes (D6, D7 e D8) informam o PGN dos dados a serem enviados.

A norma define os tempos limites para resposta de uma solicitação, espera por segmento de dado, espera por confirmação, entre outros tempos.

\section{IV.1.3. Camada de rede}

A Parte 4 da ISO 11783 contém definições de características e de serviços das ECU's para que estas possam comunicar-se através de diferentes sub-redes. Para interconexão de sub-redes são definidas ECU's especiais denominadas NIU's, como citado anteriormente na introdução da Seção IV.1. As funções principais das NIU são:

Encaminhamento de mensagens: consiste em receber uma mensagem de uma sub-rede e passar a outra sem alterá-la. Neste processo, para enviar mensagens acumuladas em uma fila, devem ser enviadas as mensagens obedecendo à prioridade de cada uma, ou seja, as que tiverem maior prioridade devem ser enviadas primeiro, e também obedecendo a um tempo de retardo máximo, que se atingido, a mensagem deve ser enviada independente da prioridade;

$>$ Filtragem de mensagens: consiste em selecionar as mensagens que devem ser encaminhadas. Com esta função é possível diminuir a taxa ocupação do barramento em uma sub-rede através do descarte de mensagens com determinados PGN's, proveniente de outra sub-rede, e que só tenham utilidade na sub-rede de onde provêem. A filtragem pode ser realizada de dois modos. Em um modo, uma NIU permite que todas mensagens sejam encaminhadas, exceto àquelas que possuam determinados PGN's configurados previamente. No outro modo, todas as mensagens são bloqueadas (descartadas), exceto aquelas que possuam determinados $\mathrm{PGN}$ 's configurados previamente;

> Translação de endereço: consiste na alteração de endereço de uma mensagem, para passá-la de uma sub-rede a outra. Esta função permite que seja utilizado um único endereço para referenciar determinada sub-rede. Uma NIU com esta função deve conter tabelas que associam endereços de origem com endereços de destino, e ao receber uma determinada mensagem, poderá decidir qual será o endereço de destino da mensagem na outra sub-rede; 
> Remontagem de mensagem: consiste em alterar o campo de dados de uma mensagem, adicionando-se outros dados, antes de transferi-la de uma sub-rede à outra. Esta função permite diminuir a taxa de ocupação do barramento em uma sub-rede, através da remontagem de uma mensagem com dados de outras mensagens destinadas a uma ECU, ou a um mesmo conjunto de ECU's, e provenientes de outra sub-rede;

Administração de base de dados: consiste em conjunto padrão de regras para que se possa acessar e configurar as bases de dados de NIU's em uma rede. Através de mensagens definidas, é possível configurar os filtros, obter informações de configuração e obter informações estatísticas, como por exemplo, ocupação do espaço de memória de dados, atrasos de transmissão e número de mensagens transmitidas.

A norma define cinco tipos de NIU's, como citado anteriormente na introdução da Seção IV.1. Estas NIU's são classificadas de acordo com as funções descritas anteriormente, e que elas possuem. Os cinco tipos de NIU's definidos e suas funções principais são:

$>$ Repeaters (Repetidores): encaminhamento de mensagens;

$>$ Briges (Pontes): encaminhamento e filtragem de mensagens;

$>$ Routers (Roteadores): encaminhamento, filtragem e translação de endereço de mensagens;

> Gateways (Portais): encaminhamento, filtragem, translação de endereço e remontagem de mensagens;

> Tractor ECU (ECU do Trator): encaminhamento, filtragem, translação de endereço e remontagem de mensagens, promovendo a interconexão do barramento do trator com o barramento do implemento. Esta NIU é especificada com detalhes na Parte 9 da norma.

A FIGURA 19 mostra um exemplo de rede composta por diversas sub-redes interconectadas por NIU's, segundo as especificações da norma. 


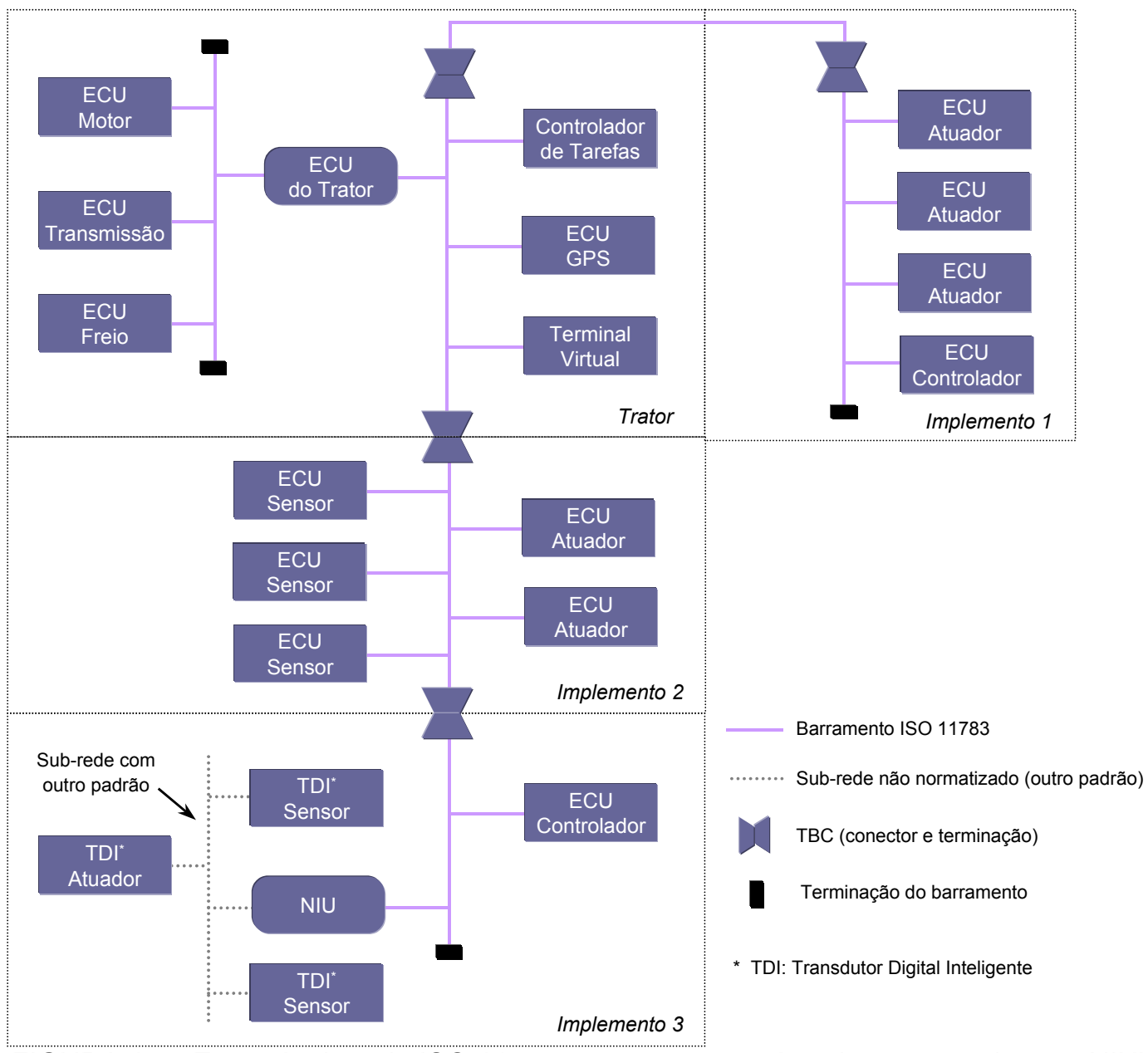

FIGURA 19 - Exemplo de rede ISO 11783 composta por sub-redes conectadas por NIU's (LANDTECHNIK-VEREINIGUNG, 2002)

Como pode ser visto na FIGURA 19, e descrito na introdução da Seção IV.1., a norma especifica a sub-rede do veículo denominada Tractor Bus (ou Barramento do Trator), onde podem estar conectadas ECU's relacionados com transdutores automotivos, como freios, transmissão, motor. O outro tipo de subrede é a sub-rede principal de implementos, denominada Implement Bus (Barramento de Implemento), onde podem estar conectadas ECU's de diversos tipos, como por exemplo, controladores de implemento, transdutores inteligentes, receptor GPS, computadores embarcáveis e terminais de operação e de manutenção. $O$ barramento de implemento pode ser segmentado através de conectores especiais (TBC's), permitindo que os implementos sejam trocados de acordo com o trabalho de campo a ser realizado. Outro tipo de sub-rede possível, que está também representado em laranja na FIGURA 14, pode ser qualquer fieldbus, desde que este possua uma NIU para adaptar os dados entre barramentos em diferentes padrões. 
A Parte 4 define as estruturas das mensagens de rede e os parâmetros transportados por estas mensagens, utilizados para administração das bases de dados das NIU's. Também são especificados nesta documentação, os tempos limites que envolvem a realização das funções de cada tipo de NIU.

\section{IV.1.4. Administração de rede}

A Parte 5 contém regras que definem a administração de endereços de origem das ECU's e a associação destes endereços com a identificação funcional do dispositivo conectado à rede pela ECU. Também define o processo conexão e inicialização de ECU's na rede. Nesta documentação são definidos os três tipos de ECU's previstos pela norma, que são:

$>$ ECU Padrão: ECU que não possui funções especiais, como as funções definidas para as NIU's, ou funções de monitoramento, análise e diagnósticos de problemas de uma rede;

> ECU de Diagnóstico ou de Desenvolvimento: ECU que é conectada ao barramento com propósito de monitorar e analisar a rede a que está conectada. Também pode ter a função de diagnosticar problemas ou ajudar na implementação de extensão de uma rede;

$>$ ECU de Interconexão de Redes: como descrito na Seção IV.1.3, é denominada de NIU, e tem as funções especiais que permitem a comunicação entre subredes componentes de uma rede.

São especificadas quatro formas distintas de configuração de endereços em uma ECU. Assim são caracterizados quatro tipos de ECU's segundo a forma atribuição de endereços:

ECU de Endereço Não Configurável: possui endereço atribuído pelo fabricante de acordo com a função da ECU e com outros parâmetros especificados na norma. Não permite configuração pelo usuário.

> ECU de Endereço Configurável em Manutenção: o endereço pode ser configurado manualmente por um usuário, através de um dispositivo que permita esta operação, ou através de comando específico definido pela norma para configuração pelo barramento, no modo de manutenção; 
> ECU de Endereço Configurável por Comando: o endereço pode ser configurado manualmente por um usuário, através de comando específico definido pela norma para configuração pelo barramento, em modo de operação normal;

$>$ ECU de Endereço Autoconfigurável: possui a capacidade de negociar o próprio endereço de origem no barramento através de um algoritmo interno, que permite a definição de um endereço e o anúncio do endereço definido no barramento. Se o endereço determinado já estiver sendo utilizado, a ECU é capaz de definir e anunciar outros endereços.

A norma define uma estrutura de campo de dados de mensagem denominada NAME. Esta estrutura é composta por 64 bits e possui as funções de prover uma descrição funcional de uma ECU, para outras ECU's conectadas a um barramento, e também, de fornecer um valor numérico para o processo de anúncio e de disputa de endereço de origem, na conexão e inicialização de ECU's a um barramento. A FIGURA 20 mostra a estrutura de uma NAME.

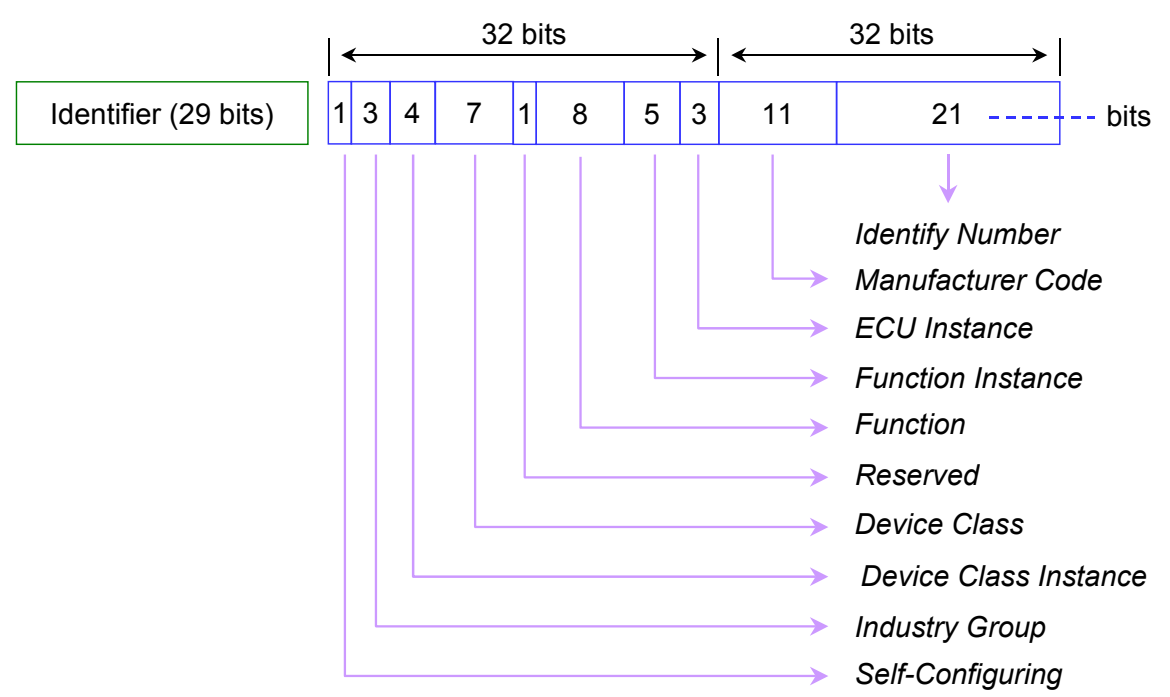

FIGURA 20 - Exemplo de uma NAME definida pela norma ISO 11783

Observa-se na FIGURA 20 a existência de dez campos de bits definidos para a NAME. A funções dos campos são:

> Self-Configuring (Autoconfiguração): indica se a ECU é de endereço autoconfigurável ou não;

> Industry Group (Grupo Industrial): associa a NAME a um dos grupos industriais definidos na Parte 1 da ISO 11783, e que são possíveis usuários deste padrão. 
> Device Class Instance (Indicação de Classe de Dispositivo): informa se existe mais de um tipo de classe de dispositivos conectados à rede pela mesma ECU;

> Device Class (Classe de Dispositivo): informa a que classe pertence o dispositivo conectado à rede. As diversas classes de dispositivos são definidas na Parte 1 da norma. Este campo, junto com o campo que informa o grupo industrial, formam um conjunto que informa as características gerais dos dispositivos conectados à uma rede, como por exemplo: Grupo Industrial Equipamentos Industriais - e Classe de Dispositivo - Plantadeira.

> Reserved (Reservado): campo reservado para definições futuras;

$>$ Function (Função): indica a que grupo funcional pertence o dispositivo conectado à rede. Os grupos funcionais são definidos pela norma, e aqueles com valores de representação de 0 a 127, não estão relacionados com valores de outros campos. Os valores de 128 a 255 estão relacionados com os campos que indicam o grupo industrial e a classe de dispositivo;

> Function Instance (Indicação de Função): informa sobre a existência de mais de uma função do mesmo dispositivo conectado na rede;

DECU Instance (Indicação de ECU): indica se existe mais de uma ECU associada a um grupo funcional;

> Manufacturer Code (Código de Fabricante): indica qual fabricante da ECU. O valor relacionado com cada fabricante é atribuído por comitê da ISO;

> Identify Number (Número de Identificação): atribui um valor de identificação para ECU. Deve ser a definido pelo fabricante da ECU.

Como se pode verificar pelos campos que compõem a NAME, esta estrutura implementa uma hierarquia de elementos de identificação funcional para um dispositivo conectado ao barramento. O elemento mais geral de identificação é a Device Class, em seguida a Function e por ultimo a identificação da ECU.

A estrutura NAME constitui a base para o processo de conexão e inicialização de ECU's em uma rede. Esta estrutura permite que uma ECU, ao ser conectada em uma rede, seja identificada pela sua função e obtenha um endereço de origem. No processo de inicialização em que o endereço de origem é negociado através de mensagens pelo barramento, esta estrutura tem importância ainda 
maior. Para esta negociação e para administração de rede são definidas quatro mensagens específicas. Estas mensagens são:

> Request for Address Claim (Solicitação de Anúncio de Endereço): utilizada por uma ECU para solicitar o endereço de origem e o NAME de outras ECU's conectadas à rede;

> Address Claim (Anúncio de Endereço): utilizada por uma ECU para responder a uma solicitação de anúncio de endereço, ou simplesmente, para anunciar o seu endereço de origem depois de sua conexão na rede;

> Commanded Address (Endereço por Comando): utilizada por NIU's e ECU's de diagnóstico e desenvolvimento para controlar endereços de origem de ECU's padrão. Este tipo de mensagem possui 9 (nove) bytes de dados e, sendo assim, é necessário utilizar o protocolo de transporte para a comunicação dos dados, como especificado pela norma;

> Cannot Claim (Anúncio Não Possível): utilizada por uma ECU para informar a impossibilidade de anúncio de endereço de origem.

São definidas regras para o processo de inicialização de ECU's, que utiliza as mensagens anteriores para definição de endereço de origem para uma ECU, pela troca de informações entre as ECU's já inicializadas e em operação normal com a ECU em processo de inicialização. A norma descreve estas regras e ilustra a comunicação de mensagens através de diagramas.

O desenvolvimento de ECU's autoconfiguráveis exige entendimento do processo de inicialização. Assim foi proposto e apresentado por SOUSA, INAMASU \& TORRE-NETO (2001a) a utilização da ferramenta Redes de Petri, que é uma ferramenta de modelamento gráfico e matemático, para construção de modelos do processo de inicialização e auxílio na implementação de redes CAN segundo a norma ISO 11783 ou a norma SAE J1939. O uso desta ferramenta tem-se destacado para modelagem de programação lógica, de protocolos de comunicação e de diversos sistemas distribuídos, concorrentes, de controle industrial e de manufatura (MURATA, 1989). O processo de endereçamento pode ser descrito em termos dos estados desse sistema e suas mudanças (condição/evento). Assim para modelar e simular este processo, utiliza-se uma RP definida pela quíntupla RP = (P,T,F,W,Mo) (MURATA, 1989), onde: 
$>P=\{p 1, p 2, \ldots \ldots, p m\}$ é um conjunto finito de lugares, representados graficamente por círculos e m é inteiro positivo;

$>T=\{t 1, t 2, \ldots . . . t n\}$ é um conjunto finito de transições, representadas graficamente por barras e n é inteiro positivo;

$>\mathrm{F} \subseteq(\mathrm{P} \times \mathrm{T}) \cup(\mathrm{T} \times \mathrm{P})$ é um conjunto de arcos (relação de fluxo), representados graficamente por setas;

$>\mathrm{W}: \mathrm{F} \rightarrow\{1,2,3, \ldots .$.$\} é uma função peso associada aos arcos;$

$>\mathrm{M} 0: \mathrm{P} \rightarrow\{0,1,2,3 \ldots\}$ é a marcação inicial, (estado inicial) representando recursos e representada graficamente por pontos - marcas - nos lugares;

$>\mathrm{P} \cap \mathrm{T}=\varnothing$ e $\mathrm{P} \cup \mathrm{T} \neq \varnothing$.

Para simular o comportamento dinâmico do processo, um estado ou marcação em uma Rede de Petri é alterado de acordo com a seguinte regra para transição (disparo):

> Uma transição está habilitada se cada lugar de entrada da transição possui quantidade de marcação pelo menos igual ao peso do arco ligando o lugar à transição.

> Uma transição habilitada pode ou não disparar (dependendo do evento realmente acontecer ou não);

> Um disparo de uma transição habilitada remove de cada lugar de entrada marcas, iguais em quantidade ao número do peso do arco que liga este lugar à transição, e adicionam marcas para cada lugar de saída, iguais ao número do peso dos arcos que ligam a transição a cada lugar de saída.

De acordo com o documento que especifica a administração de rede e com a RP definida, foi realizada a modelagem e posterior simulação do processo de endereçamento de uma ECU, utilizando o aplicativo Petri Net Tools 2000. Este aplicativo foi desenvolvido pelo Laboratório de Simulação do Núcleo Avançado de Manufatura e do Departamento de Engenharia Mecânica da USP de São Carlos. Ele possibilita a edição e simulação de RP.

Como descrito pelo documento de administração de rede, no começo do processo de inicialização a ECU seleciona um endereço predefinido pelo fabricante. 
Então envia uma mensagem anunciando seu endereço (Address Claim), e aguarda, por um período pseudo-randômico T por outra mensagem de anúncio de outra ECU que deseja utilizar o mesmo endereço, iniciando assim uma disputa. Se nenhuma mensagem de disputa é verificada nesse período T, a ECU estabelece comunicação normal no barramento. Mas se uma mensagem de disputa é recebida durante ou depois do período T, as ECU's comparam seus NAME's com o NAME recebido na mensagem e a ECU com menor valor de NAME (maior prioridade) adota o endereço e o anuncia novamente, enquanto que a ECU com maior NAME (menor prioridade) deve adotar outro endereço e reinicializar o processo, ou enviar uma mensagem informando da não possibilidade de anuncio de endereço (Cannot Claim). O modelo do processo descrito utilizando RP é apresentado na FIGURA 21.

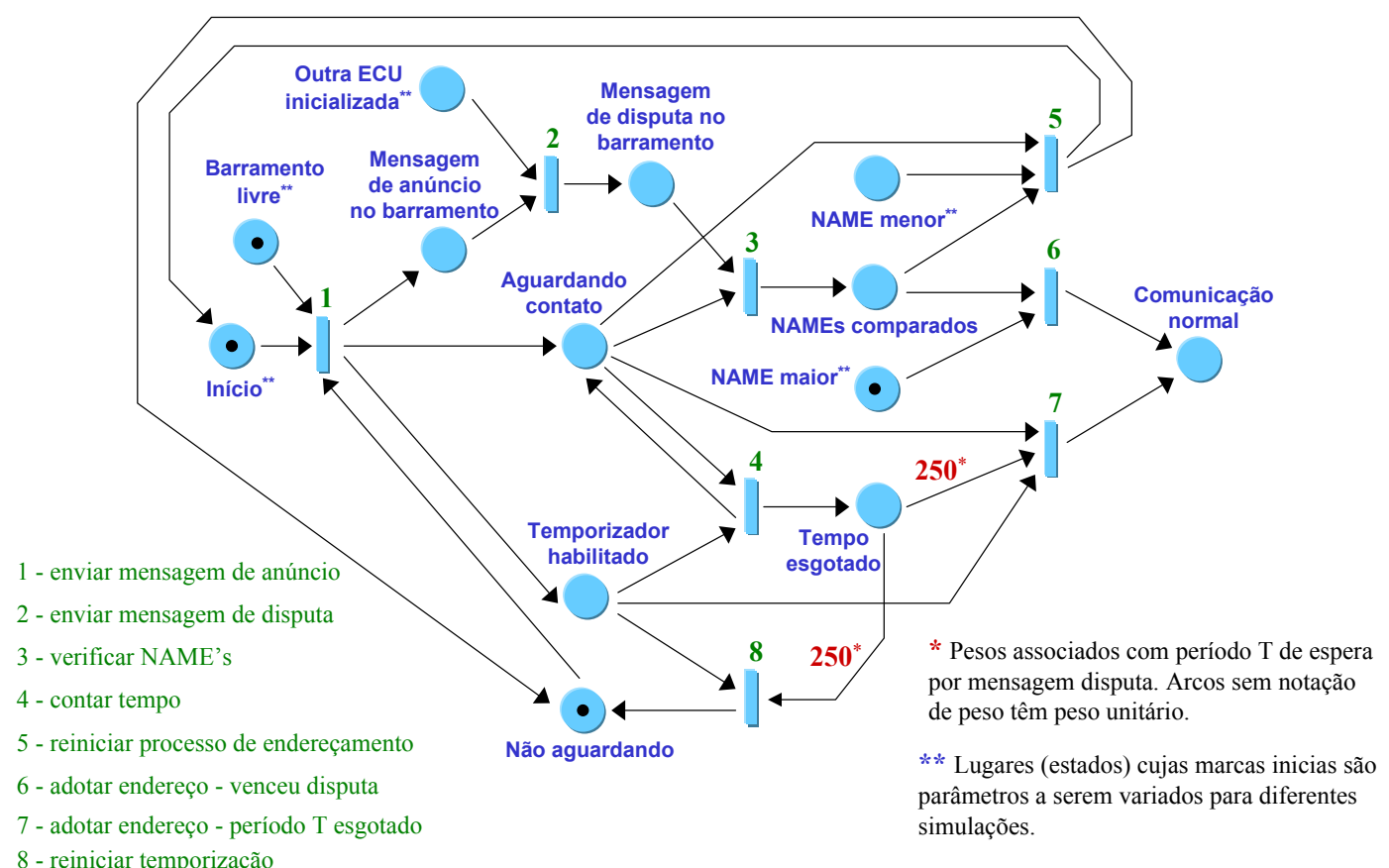

FIGURA 21 - Modelo do processo de inicialização de ECU autoconfigurável

Após a modelagem foi realizada a validação do modelo através de algumas simulações. Foram testadas as seguintes possibilidades:

> endereço anunciado/esgotamento do tempo de espera/adoção do endereço anunciado, cuja marcação inicial é a mesma apresentada na FIGURA 22;

> endereço anunciado/disputa com outro nó/disputa perdida/reinicialização do processo;

endereço anunciado/disputa com outro nó/disputa vencida/adoção de endereço anunciado. 


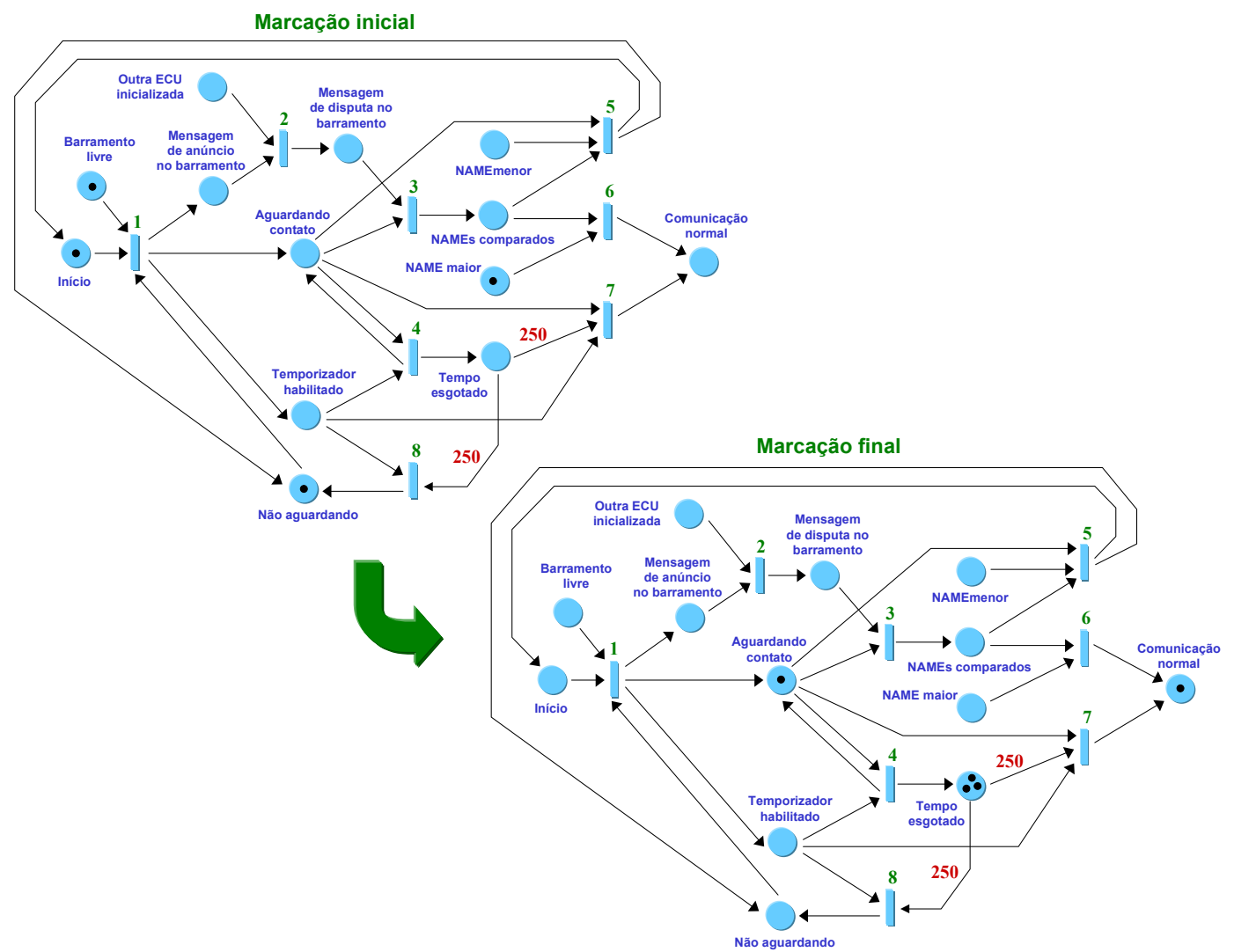

FIGURA 22 - Simulação do modelo do processo de inicialização de ECU's

Utilizando as simulações e recursos do Petri Net Tools foi possível determinar propriedades do modelo construído como: alcançabilidade, vivacidade, limitabilidade e reversibilidade (MURATA, 1989). Estas propriedades mostraram que certos estados desejados, como por exemplo, estabelecimento de comunicação normal pela ECU no barramento, retorno ao início do processo no caso de perda de disputa e adoções de endereços por disputa vencida ou fim de temporização, podem ser atingidos sem presença de travamentos.

Outros processos de inicialização são especificados pela norma, como por exemplo, inicialização de ECU's configuráveis utilizando mensagens do tipo Request for Address Claim e, também, inicialização de ECU's não configuráveis. Modelos destes outros processos podem ser construídos e simulados com algumas alterações no modelo desenvolvido e descrito anteriormente. Estes modelos podem, então, ser utilizados para orientar o desenvolvimento das rotinas computacionais de inicialização de ECU's segundo os padrões em questão. 


\section{IV.1.5. Mensagens de implemento e mensagens automotivas}

A Parte 7 especifica diferentes tipos de mensagens que podem ser utilizadas por ECU's conectadas ao barramento de implemento. A Parte 8 da norma especifica diferentes tipos de mensagens automotivas para comunicação de ECU's conectadas ao barramento do trator.

Como descrito na Seção IV.1.2, a norma classifica os dados que podem ser transmitidos e especifica parâmetros para caracterizar estes dados. Estes parâmetros são organizados em grupos, os PG's, , que dependem do tipo de dados a serem comunicados. Cada PG possui um número que o identifica, o PGN, que deve estar presente no identificador da mensagem. A FIGURA 23 ilustra o PG relacionado com a posição do veículo, e também o parâmetro latitude que compõe o campo de dados da mensagem referente a este grupo.

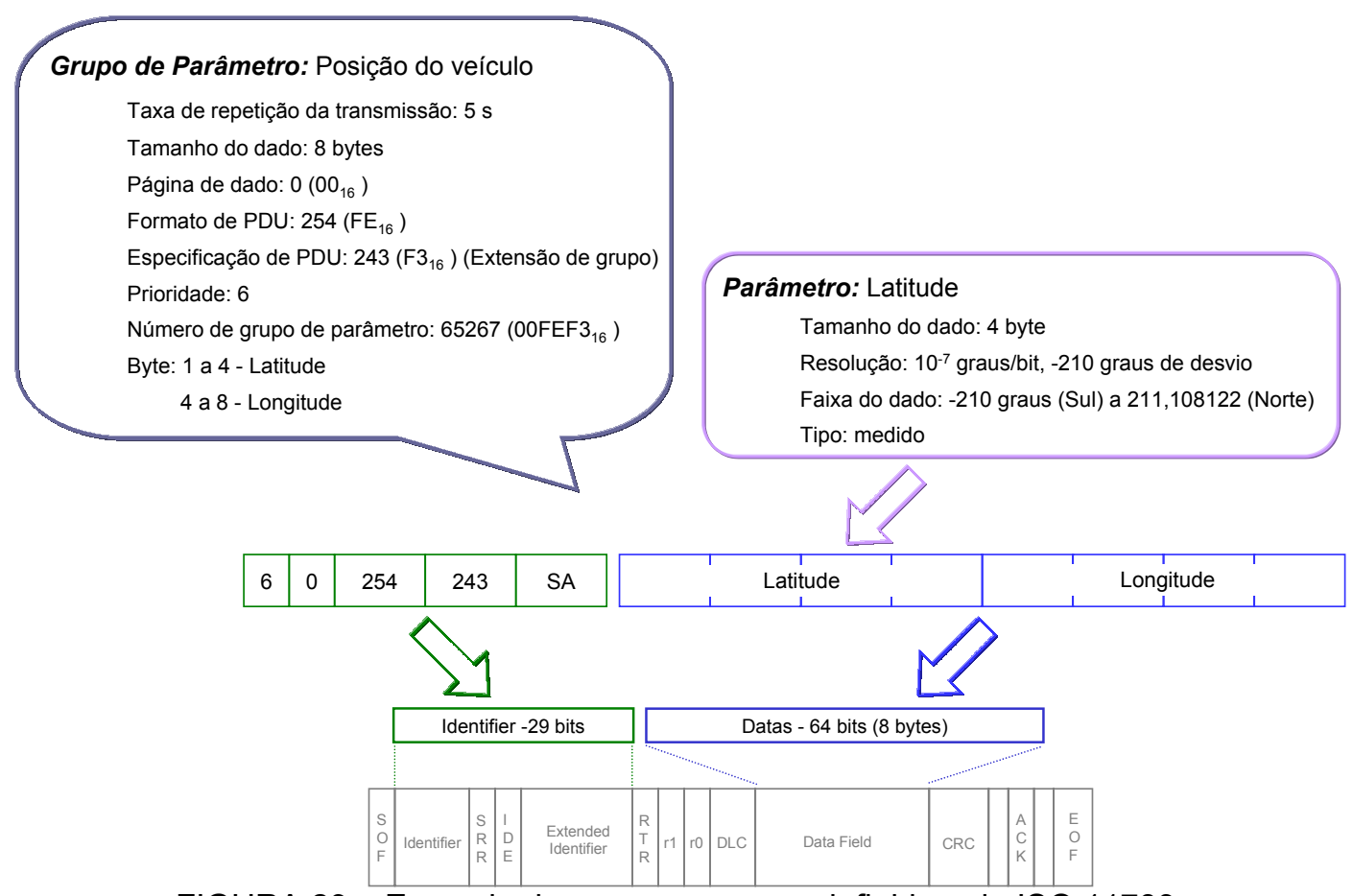

FIGURA 23 - Exemplo de uma mensagem definida pela ISO 11783

Nas Partes 7 e 8 são definidos diversos parâmetros e PG's para diferentes ECU's conectadas ao barramento de implemento (Parte 7) e ECU's conectadas ao barramento do trator (Parte 8). Também, a norma permite definição de novos parâmetros e PGs para mensagens de dispositivos não previstos pela norma.

Além das mensagens relacionadas com os PG's, a Parte 7 contém a definição de um outro tipo de mensagem denominado Process Data Message 
(Mensagem de Dado de Processo). Este tipo de mensagem é definido para comunicação com um ou mais controladores usados coletivamente para prover um determinado serviço, como por exemplo, fertilização, irrigação, plantio ou colheita. Para este tipo de mensagem é definida uma matriz de 16×16×16 (colunas, linhas e páginas), que contém a identificação (identificador) para cada grupo de dados de processo, para ser transmitido em uma mensagem relacionada com um determinado processo. Esta matriz é definida na Parte 11 (Mobile Agriculture Data Dictionary) para diferentes processos. A estrutura da mensagem de dado de processo pode se vista na FIGURA 24.

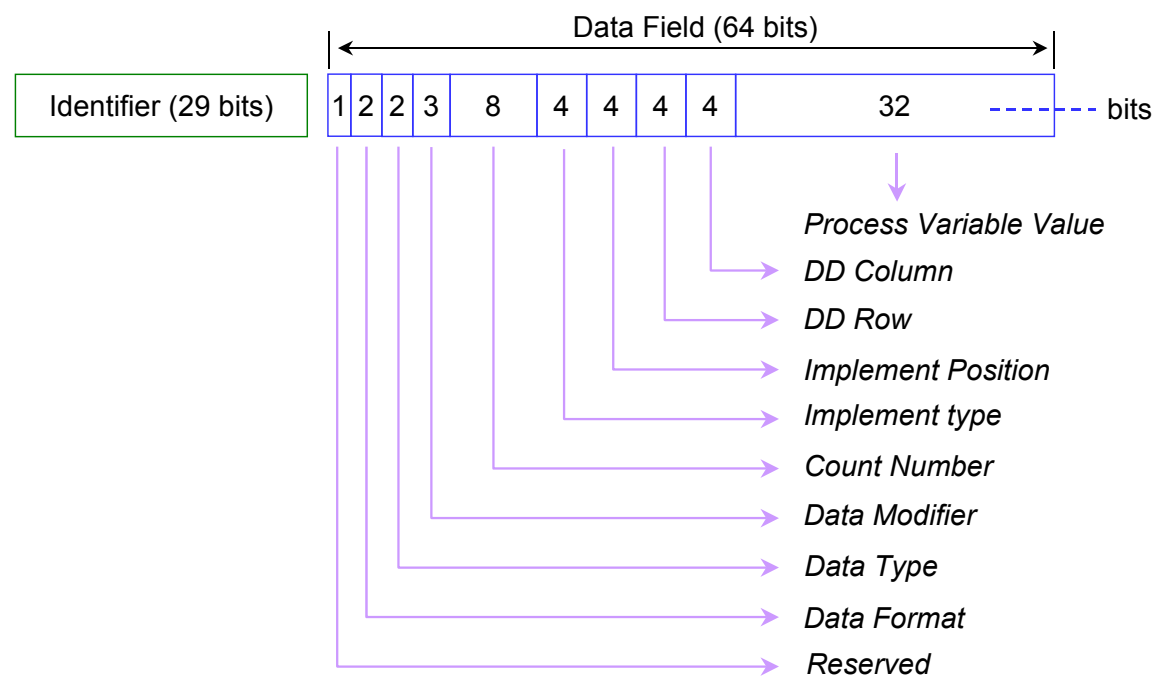

FIGURA 24 - Estrutura de mensagem para controle de processo

A mensagem de dado de processo tem grande potencial para ser utilizada na comunicação com implemento com muitos elementos endereçados, pois permite a comunicação de dados com diversas ECU's através de uma única mensagem.

\section{IV.1.6. Terminal virtual e ECU do trator}

Duas ECU's com funções especiais são especificadas pelas Partes 6 e 9 da ISO 11783. A Parte 6 especifica a ECU denominada Virtual Terminal - VT (Terminal Virtual), que é uma ECU com dispositivo que promove a interface entre a máquina (trator e implemento) e o operador (ser humano). A Parte 9 especifica a ECU denominada Tractor ECU - TE - (ECU do Trator), que é uma NIU para interconectar o barramento do trator com o barramento do implemento. A FIGURA 14, presente na introdução da Seção IV.1 ilustra a conexão destas ECU's no barramento de um trator com um implemento conectado. 
Para o VT são definidos dois tipos de mensagens: um tipo para envio de dados pelo VT para os outros dispositivos conectados na rede, e outro tipo para o envio de dados por dispositivos conectados na rede para o VT. Fisicamente o VT é constituído por uma tela (monitor) e teclas, botões ou outros tipos de dispositivos de entrada, que permitem a atuação do operador com telas virtuais (screens). As diferentes telas virtuais devem permitir ao operador visualizar diferentes tipos de variáveis de sistemas da máquina e de processos, trocar informações diretamente com ECU's ou grupos de ECU's, receber informações de estados do sistema, ser notificado sobre problemas (alarme), armazenar dados e configurações, e permitir a atuação do operador nos diferentes sistemas da máquina e processos em andamento. A atuação pode ser feita através escolha em menus ou por entradas de dados, utilizando dispositivos de entrada físicos, assim como, utilizando botões e teclas virtuais nas telas virtuais.

Para operação do VT são definidos recursos, que são telas virtuais com diferentes campos de visualização ou atuação. Estes recursos estão relacionados com grupos de funções predefinidos para execução de diferentes ações com o terminal, como por exemplo, configuração do VT, transmissão de comandos para ECU's, troca de textos entre o terminal e ECU's, e armazenamento de dados em memórias voláteis e não-voláteis.

As especificações do VT pela ISO 11783 foram baseadas nas especificações do mesmo tipo de terminal pela norma DIN 9684.

A TE possui diversas funções e a Parte 9 define com detalhes esta ECU. Além de possuir funções de um gateway, como descrito na Seção IV.1.3, também é responsável pelo controle de toda potência fornecida aos implementos e pelo controle do sistema de iluminação do trator e de implementos conectados ao trator. Esta ECU possui a capacidade de classificar as mensagens das ECU's conectadas ao barramento do trator, de acordo com classes predefinidas pela norma, e informar esta classificação ao operador, através do VT. Esta classificação permite identificar o conjunto mínimo de mensagens, em acordo com as Partes 7 e 8 , que o barramento do trator pode fornecer. O circuito eletrônico desta ECU é composto basicamente por dois nós CAN, um conectado ao barramento do trator e outro ao barramento de implemento, e módulos de controle de potência para os implementos e controle de iluminação geral. 
No exemplo da FIGURA 19 da Seção IV.1.3 pode ser observado as posições do VT e da TE em uma rede segundo a ISO 11783. No exemplo da FIGURA 16 da Seção IV.1.1, pode-se observar o esquema de conexão de uma TE em uma rede.

\section{IV.1.7. Controlador de tarefa}

A Parte 10 é responsável pela especificação de interface para troca de dados entre uma rede ISO 11783 e um Task Controller - TC - (Controlador de Tarefa). O TC é uma ECU especial, responsável pelo envio, recebimento e armazenamento de dados de processos. Estes dados de processos são os citados na Seção IV.1.5.

O TC pode conter uma interface proprietária (aberto para ser definida pelo fabricante), como por exemplo, transceptor de rádio ou suporte para cartões de memória, para comunicação de dados com um Sistema de Administração de Informação ou Management Information System (MIS). Um MIS é um sistema onde informações de um ou mais sistemas ou processos podem ser armazenadas e processadas, visando orientar a tomada de decisão para atuação nestes sistemas ou processos. Sob o contexto da área de aplicação do padrão, um MIS pode ser, por exemplo, um conjunto composto por um PC e por programas computacionais para agricultura, que permita através da manipulação de dados de produção, custos e variáveis físico-químicas de áreas de plantio, gerar orientações para tarefas em área de plantio, como pulverização, fertilização e colheita. O computador com esta finalidade é denominado Management Computer (Computador de Administração). A FIGURA 25 ilustra a comunicação entre o computador de administração e o TC conectado a um barramento ISO 11783. 


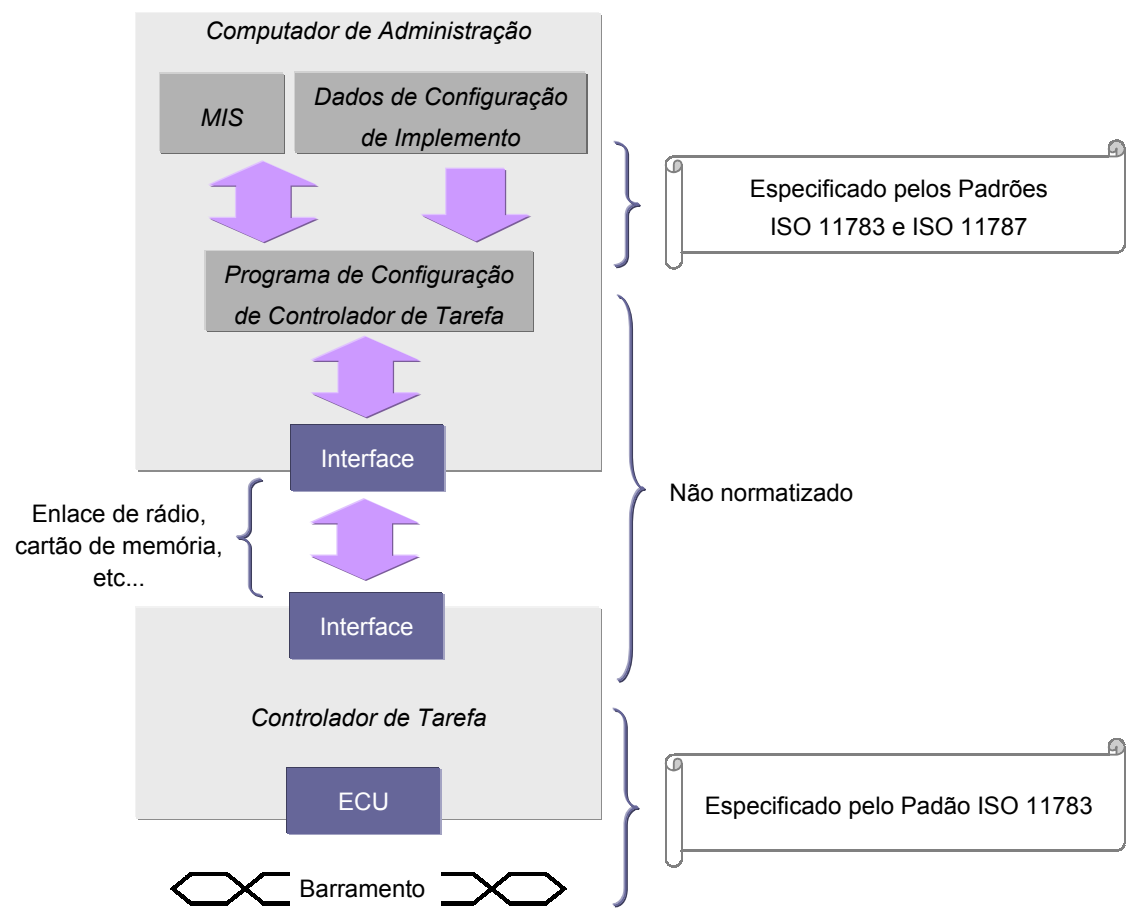

FIGURA 25 - Ilustração da comunicação de um MIS com o barramento ISO 11783.

A Parte 10 define um formato para os dados trocados entre o computador de administração e o TC baseado na Parte 11 e na definição de um formato de arquivo de dados pelo documento Data Interchange Syntaxe (ADIS - Agricultural Data Interchange Syntax) da ISO 11787 - Tractors and machinery for agriculture and forestry - Data interchange between management computer and process computer. Também é definido pela ISO 11783 o formato para mensagens enviadas para as ECU's pelo TC.

\section{IV.2. DIN $9684-$ LBS}

A norma DIN 9684 - Agricultural tractors and machinery - também referido como norma LBS (Landwirtschaftliches BUS System - Barramento Agrícola Móvel), foi desenvolvida na Alemanha com a participação de empresas e instituições da Alemanha e de outros grupos da Europa. A versão 1 da norma foi finalizada em 1997, e possui cinco partes, que são: Point to Point Connection, Serial Data BUS, System Functions and Identifier, User Station e Data Exchange with the Management Information System and Task Controller. As Partes 4 (User Station) e 5 (Task Controller) foram utilizadas como referência para elaboração de alguns documentos da ISO 11783. A versão 2 da norma DIN está em fase de elaboração e apresentará diversas mudanças em relação à versão 1. A TABELA 3 apresenta as 
partes componentes da documentação DIN 9684 versão 2 e uma síntese de cada parte.

TABELA 3 - Partes componentes da documentação da norma DIN 9684 versão 2

\begin{tabular}{|c|c|c|}
\hline Parte & Título & Escopo \\
\hline Capítulo 1 & $\begin{array}{l}\text { General Description and } \\
\text { Physical Layer }\end{array}$ & $\begin{array}{l}\text { Visão geral sobre o padrão e da aplicação de cada parte. } \\
\text { Especificação de cabos, conectores, sinais elétricos e } \\
\text { características mecânicas e elétricas gerais do barramento }\end{array}$ \\
\hline Capítulo 2 & $\begin{array}{l}\text { Identifier and System } \\
\text { Function }\end{array}$ & $\begin{array}{l}\text { Implementação do CAN, especificação da estrutura das } \\
\text { mensagens, definição de mensagens e especificação do } \\
\text { processo de inicialização e endereçamento de ECU's }\end{array}$ \\
\hline Capítulo 3 & User Terminal & Especificações do terminal de controle e operação \\
\hline Capítulo 4 & $\begin{array}{l}\text { Task Controller and } \\
\text { Data Interchange with } \\
\text { the Management } \\
\text { Information System }\end{array}$ & $\begin{array}{l}\text { Especificação de interfaces para dispositivos e programas } \\
\text { computacionais de controle e administração com o } \\
\text { barramento. }\end{array}$ \\
\hline Capítulo 5 & Explanation & Explicações e definições gerais relativas a norma \\
\hline
\end{tabular}

As principais alterações que podem ser observadas na versão 2 em relação a versão 1 até o momento são:

As Partes 4 (User Station) e 5 (Task Controller) da versão 1 foram revisadas e foram realizadas alterações. Estas Partes passaram a ser denominadas respectivamente Capítulo 3 - User Terminal - e Capítulo 4 - Task Controller and Data Interchange with the Management Information System;

Foi acrescentado o Capítulo 5 - Explanations - que contém explicações e definições para auxiliar e tornar clara a implementação das especificações do LBS;

> As Partes 1, 2 e 3 passaram por uma revisão editorial, e foram reorganizadas em dois documentos denominados Capítulo 1 - General Description and Physical Layer - e Capítulo 2 - Identifier and System Function.

Assim como o padrão ISO 11783 o padrão LBS tem a finalidade de prover um padrão aberto para interconexão de sistemas eletrônicos embarcáveis. O LBS também denomina ECU, o sistema eletrônico que promove a interconexão de um dispositivo ao barramento. Uma única ECU pode ser responsável pela conexão de um ou mais dispositivos a um barramento, assim como, um dispositivo pode ser conectado a um barramento por uma ou mais ECU's. A FIGURA 26 ilustra um 
exemplo de rede segundo a norma LBS, disposto em um trator e com um implemento conectado.

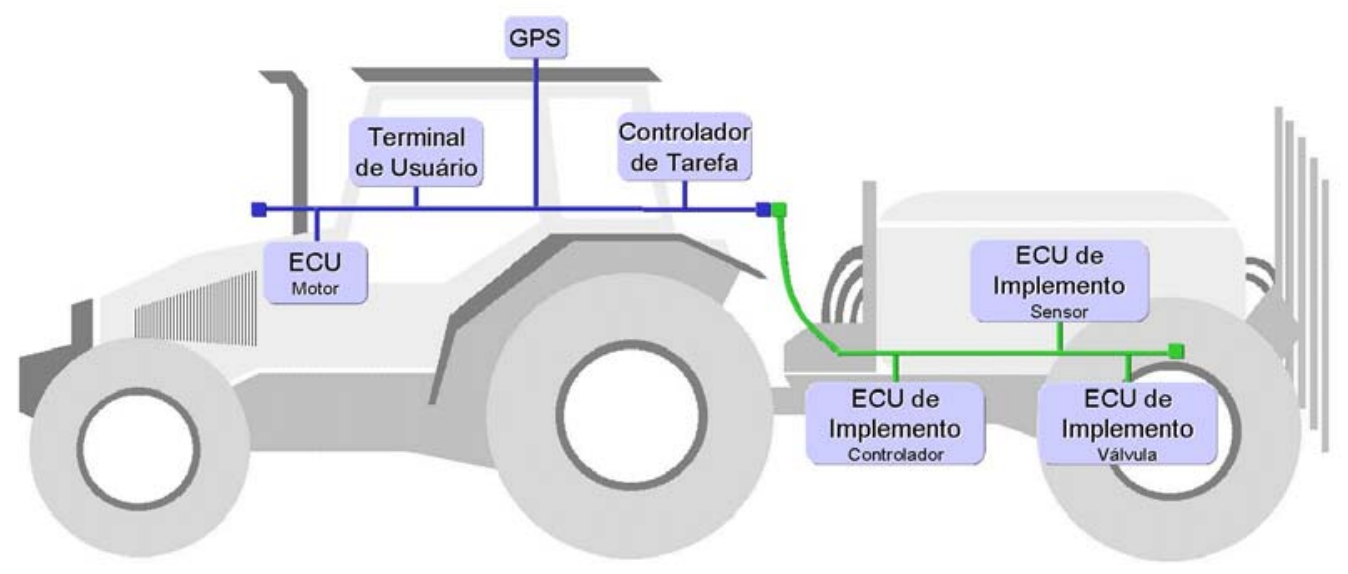

FIGURA 26 - Ilustração de uma rede LBS

A norma LBS especifica um barramento com possibilidade de extensão através da utilização de conectores próprios para isto. Nesta norma não são especificadas NIU's e sub-redes, mas é possível através da elaboração de especificações proprietárias implementar estes elementos em um barramento LBS. Desta forma, é possível integrar a um barramento LBS, através de NIU's proprietárias, fieldbuses segundo outros padrões, como a ISO 11783, ou até mesmo um outro barramento LBS.

A seguir é apresentada uma sistematização das partes componentes da norma LBS.

\section{IV.2.1. Camada física - LBS}

O Capítulo 1 da LBS define uma taxa de comunicação de $125 \mathrm{~kb} / \mathrm{s}$ e adota especificações da norma ISO 11898, como por exemplo, codificação NRZ, regra de violação de bits bit-stuffing e níveis de sinais elétricos, como descritas na Seção I.3.1. É definido o número máximo de nós igual a 20 e um comprimento máximo de barramento igual $40 \mathrm{~m}$.

O cabo para o barramento especificado é do tipo par trançado, não blindado e com quatro pares de condutores elétricos. Dois condutores são utilizados para sinalização elétrica digital na comunicação de dados - CAN_L e CAN_H - e os outros dois condutores alimentam eletricamente os circuitos de terminação do barramento - CAN_EN e CAN_GND. A linha de alimentação CAN_EN é utilizada para ativação ou desativação direta de ECU's. Os circuitos de terminação têm duas 
funções que são: prover uma terminação com casamento de impedância e de prover tensão elétrica de referência de $2,5 \mathrm{~V}$ para os sinais elétricos do barramento, que corresponde ao estado recessivo e é o valor em torno do qual os sinais CAN_L e CAN_H variam, como pode ser visto na FIGURA 5 da Seção I.3.1. Para permitir a expansão do barramento são especificados circuitos elétricos de terminação integrados a conectores, para permitirem a conexão automática de implementos. A FIGURA 27 mostra um exemplo de topologia de rede com o barramento LBS, ilustrando os conectores principais e as terminações.

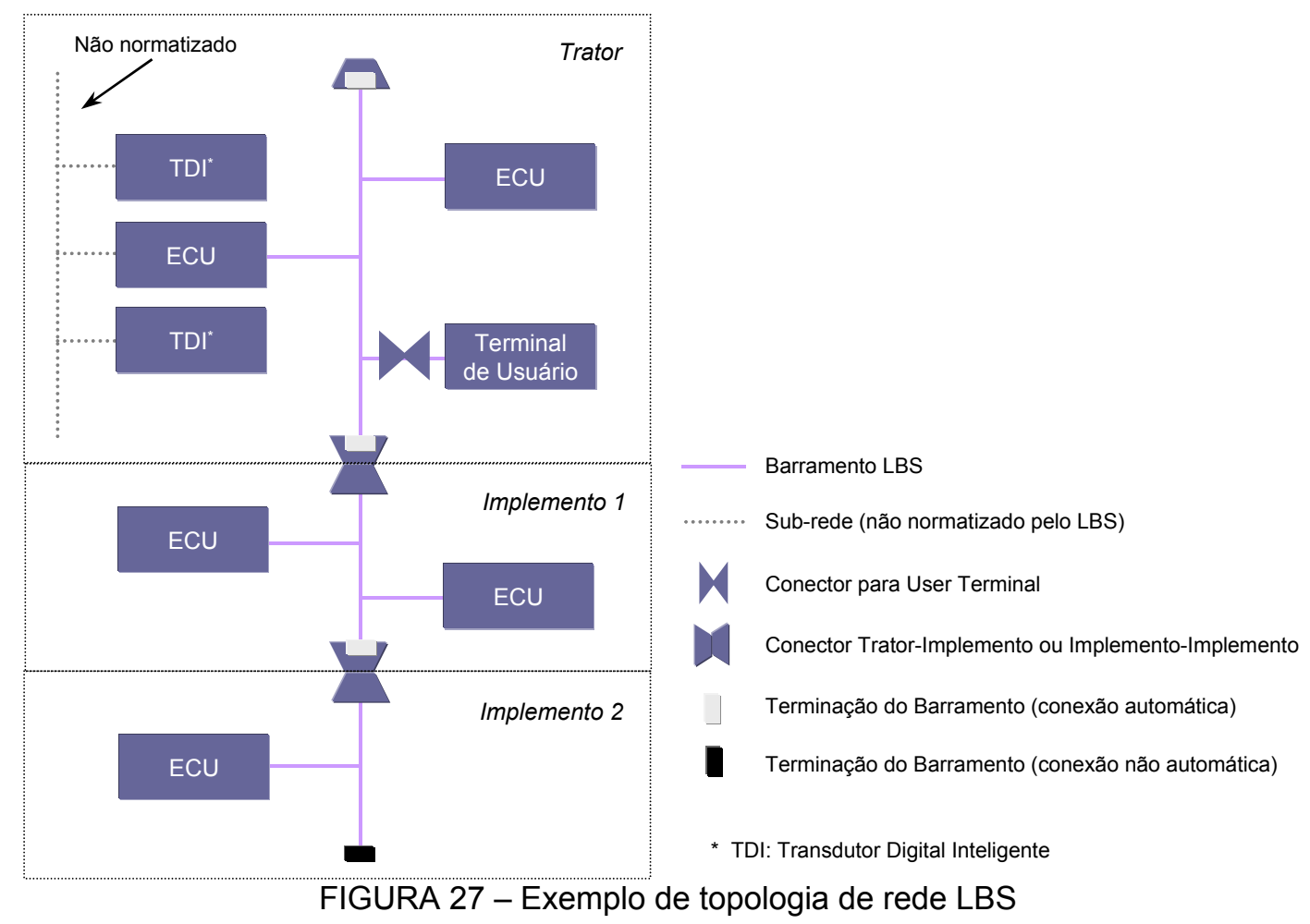

Na FIGURA 27 pode-se observar dois tipos principais de conectores que podem ser utilizados na implementação do barramento: um tipo de conector para conexão de implemento ao trator ou para conexão implemento ao outro implemento, e um outro tipo para conexão do User Terminal - UT - (Terminal de Usuário), que é um tipo de terminal igual ao VT definido pela ISO 11783. Os dois tipos de conectores possuem nove pinos, mas estes possuem funções diferentes em cada tipo de conector.

Além das características citadas para cabos, conectores e terminações, a documentação especifica também outras características elétricas e mecânicas para estes elementos, tais como: resistências e capacitâncias internas, níveis máximos 
de sinais elétricos suportados, atrasos de propagação de sinais elétricos, dimensões, limites de temperatura de operação, entre outras características.

\section{IV.2.2. Camada de enlace de dados e mensagens LBS}

Para a camada de enlace de dados da LBS é adotada a versão CAN 2.0A, como especificado pela ISO 11898 e ISO 11519, e como descrito na Seção I.3.3. Esta definição constitui uma das principais diferenças entre os padrões LBS e ISO 11783, pois na norma da ISO está definida a utilização da versão $2.0 \mathrm{~B}$ do CAN. Este fato é um dos principais fatores de incompatibilidade entre os dois padrões, pois a diferença de tamanho entre os identificadores de cada versão levou à especificação de diferentes estruturas de mensagem para cada padrão.

O LBS define oito grupos de mensagens, cada grupo com uma prioridade diferente para o processo de arbitragem. Estes oito grupos diferenciam-se pelos campos especificados para o identificador de 11 bits, que a versão 2.0A do CAN disponibiliza. Assim a estrutura do identificador estabelece a prioridade da mensagem e contém informações sobre o conteúdo de dados da mensagem. A FIGURA 28 mostra as estruturas do identificador dividido em diferentes campos, para formar os oito grupos de mensagens definidos. 


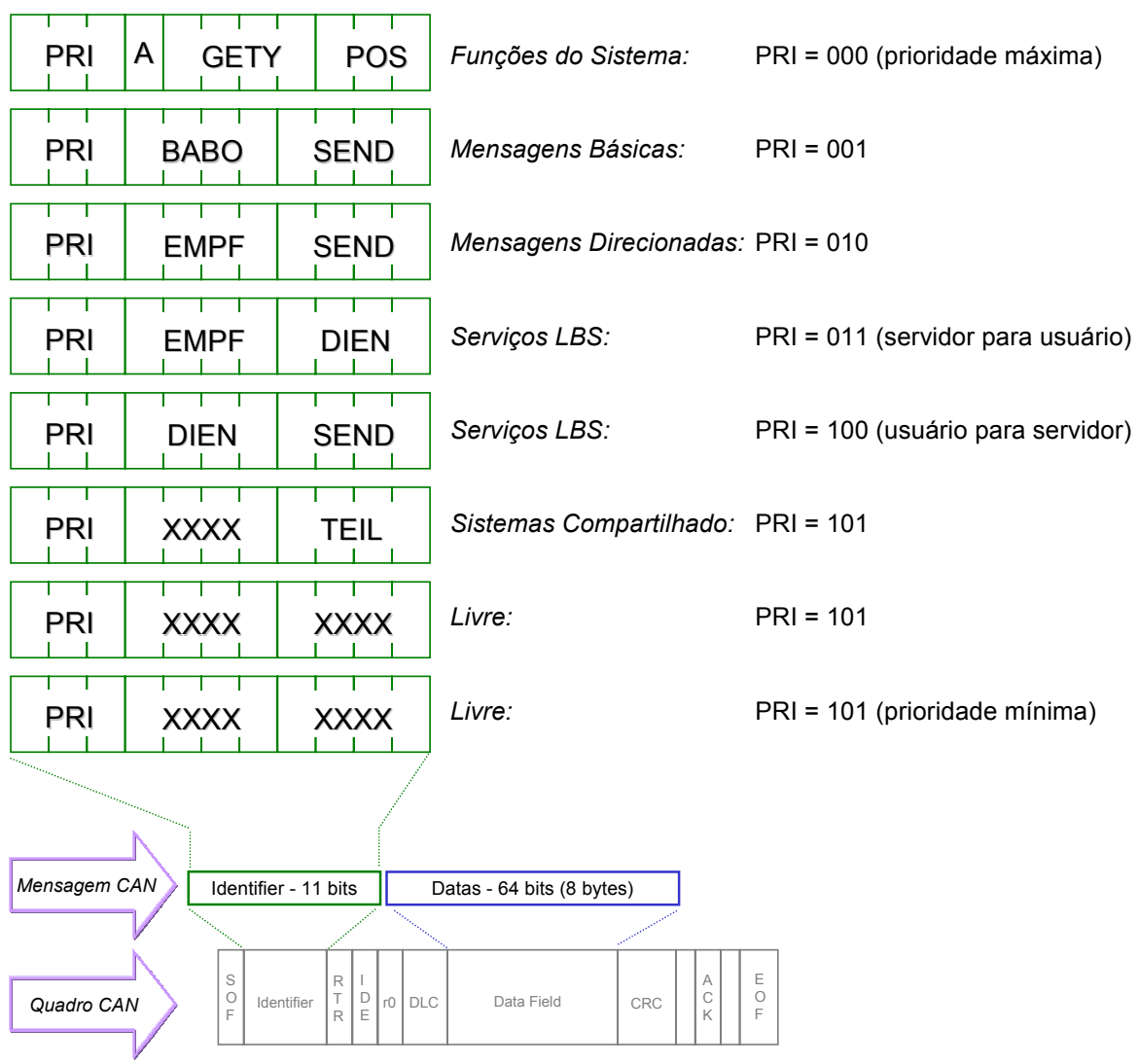

FIGURA 28 - Estrutura dos identificadores para os grupos de mensagens LBS

Os oito grupos, como pode ser visto na FIGURA 28, possuem o identificador com um campo de três bits denominado PRI, que é um campo de prioridade independente e define a prioridade das mensagens para cada grupo. Ressalta-se que este campo não é o único a ser utilizado no processo de arbitragem, pois é possível que duas ECU's tentem transmitir mensagens com estes campos iguais, e neste caso os outros campos do Identificador serão verificados.

$\mathrm{Na}$ FIGURA 28 pode-se observar que os grupos são formados por mensagens agrupadas de acordo suas funções. Os grupos de mensagens definidas pelos identificadores e as funções destes grupos são:

Funções do Sistema: grupo de mensagens relacionado com a configuração do sistema e com a administração de rede. A função de administração de rede relacionam-se com a administração de endereços das ECU's e a associação destes endereços com a identificação funcional do dispositivo conectado à rede pela ECU. Também se relaciona com o processo conexão e inicialização de ECU's na rede. $O$ bit $A$ do identificador define se a mensagem é uma mensagem de configuração $(A=1)$ ou é uma mensagem de administração de 
rede $(A=0)$. O campo GETY informa o tipo de função com que as ECU's estão relacionadas, baseando-se em valores predefinidos pela norma (ex.: fertilização - GETY=0101, irrigação - GETY=1010, atributos gerais - GETY=0000) . O campo POS informa a posição física da ECU, relacionada com a posição do implemento, baseando-se em valores predefinidos pela norma (ex.: atrás $\mathrm{POS}=000$, lateral $-\mathrm{POS}=010$ );

Mensagens Básicas: grupo de mensagens para comunicação por difusão (ECU envia mensagens que qualquer ECU pode receber) de dados de estado de dispositivos (ligado/desligado), dados relativos a medições ou dados de controle (atuação). São definidos subgrupos de mensagens, e o campo BABO do identificador é utilizado para informar a que subgrupo a mensagem pertence. $O$ campo SEND informa o endereço de origem da mensagem. Este tipo de mensagem também é utilizado para comunicação de dados de processo, ou seja, comunicação com um ou mais controladores usados coletivamente para prover um determinado serviço, como por exemplo, fertilização, irrigação, plantio ou colheita. Assim como na ISO 11783, esta mensagem é definida uma matriz de 16×16×16 (colunas, linhas e páginas), que contém a identificação para cada grupo de dados de processo para ser transmitido em uma mensagem relacionada um determinado processo;

Mensagem Direcionada: grupo de mensagens para comunicação ponto-a-ponto (ECU envia mensagens para outra ECU específica) de dados de estado de dispositivos, dados relativos a medições ou dados de controle. O campo EMPF constitui o endereço de destino e o campo SEND o endereço de origem;

> Serviços LBS: grupo de mensagens é utilizado para comunicação de dados relacionados de ECU's especiais ou servidoras, como por exemplo, o UT, ECU's de controle de tarefas ou ECU's para diagnóstico da rede. São definidos dois grupos com prioridades diferentes: um para envio de dados de ECU's especiais para ECU's comuns e outro para envio de dados de ECU's comuns para ECU's especiais. O campo DIEN indica o endereço de origem do servidor na mensagem enviada pelo servidor a ECU's comuns, e indica o endereço de destino da mensagem enviada por ECU's comuns a servidores. Os outros campos, SEND e EMPF, têm a mesma função que nas outras mensagens;

Sistemas Compartilhados: grupo de mensagens para comunicação de dados de sistemas compartilhados. Os sistemas compartilhados são conjuntos formados 
dispositivos conectados a uma ECU mestre, e que podem ser endereçados no barramento LBS. O campo TEIL indica o endereço de origem e os campos livres podem ser utilizados para compor o endereço de destino da ECU mestre e dos dispositivos compartilhados;

> Mensagens Livres: mensagens que podem ser utilizadas para implementações futuras ou para outros dispositivos não previstos pela LBS.

Para cada grupo são definidas diferentes mensagens com funções específicas dentro do grupo. Estes mensagens possuem estruturas do campo de dados diferentes para cada função.

As funções de administração de rede definidas pela norma LBS são semelhantes às da ISO 11783 descritas na Seção IV.1.4. São definidos procedimentos e mensagens para inicialização e endereçamento automático de ECU's. Os processos de inicialização de ECU's LBS também podem ser modelados e simulados, como proposto por SOUSA, INAMASU \& TORRE-NETO (2001a), utilizando Redes de Petri e descrito na Seção IV.1.4.

\section{IV.2.3. Terminal de usuário e controlador de tarefa}

O Capítulo 3 da norma especifica a ECU denominada User Terminal, que consiste em um dispositivo que promove a interface entre a máquina (trator e implemento) e o operador (ser humano). O Capítulo 4 especifica a interface para troca de dados entre uma rede LBS e um Task Controller - TC - (Controlador de Tarefa), e define um formato para os dados trocados entre um computador de administração contendo um MIS e o TC.

As especificações do UT, do TC e do formato da comunicação com um MIS são muito semelhantes às especificações destes mesmos elementos pela norma da ISO, que são descritas nas Seções IV.1.6 e IV.1.7. Estas semelhanças ocorrem porque a maioria das especificações do UT da LBS foi adotada pela ISO 11783 para definição do VT, e também o formato de comunicação com um MIS, especificado pela ISO 11787 e adotado pela ISO 11783, foi baseado em uma norma DIN adotada pela LBS. 


\section{IV.3. SAE J1939}

A norma SAE J1939 - Recommended Practice for Truck and Bus Control and Communications Network - foi desenvolvida pela pelo comitê SAE J1939 Truck and Bus Control and Communications Subcommittee para aplicação em veículospesados, como veículos da construção civil, ônibus e caminhões. Posteriormente este comitê da SAE juntou-se com um comitê da ASAE (American Society of Agricultural Engineers) para elaborações de novas partes para a norma, com especificações para aplicações em máquinas agrícolas e implementos. A TABELA 4 mostra as partes componentes da norma SAE.

TABELA 4 - Partes componentes da documentação da norma SAE J1939

\begin{tabular}{lll}
\multicolumn{1}{c}{ Parte } & \multicolumn{1}{c}{ Título } & \multicolumn{1}{c}{ Escopo } \\
\hline J1939 & General Standard & Visão geral sobre o padrão e da aplicação de cada parte \\
\hline J1939/11 & Physical Layer & $\begin{array}{l}\text { Cabos, conectores, sinais elétricos e características } \\
\text { mecânicas e elétricas gerais do barramento }\end{array}$ \\
\hline J1939/13 & Off-Board Diagnostic & Especificação de conexão para diagnóstico \\
& Connector & \\
\hline J1939/21 & Data Link Layer & Implementação do CAN e especificação da estrutura das \\
& & mensagens \\
\hline J1939/31 & Network Layer & Interconexão de sub-redes \\
\hline J1939/71 & Vehicle Application & Definição de mensagens automotivas \\
& Layer & \\
\hline J1939/73 & Application Layer - & Definição de mensagens básicas e de diagnóstico \\
& Diagnostics & \\
\hline J1939/81 & Network Management & Processo de inicialização e endereçamento de ECU's \\
& Layer & \\
\hline
\end{tabular}

Como citado anteriormente, a norma SAE 1939 influenciou fortemente a norma ISO 11783. Os documentos J1939/21 e J1939/71, vistos na TABELA 4 foram adotados pela norma da ISO. Os documentos J1939/11, J1939/31 e J1939/73 serviram de base para elaboração dos documentos sobre os mesmos assuntos da norma da ISO. As especificações destes documentos são semelhantes às descrições dos documentos da ISO apresentadas nas sub-seções da Seção IV.1.

\section{IV.4. CONSIDERAÇÕES SOBRE OS PADRÕES ISO 11783 E LSB}

Os padrões ISO 11783 e LBS são os padrões abertos baseados no CAN mais importantes para a área agrícola atualmente. 
O padrão da ISO, que ainda não está concluído, é aguardado com grande expectativa por diverso setores da área agrícola, principalmente dos Estados Unidos da América. Também existem esforços conjuntos de diversos grupos como fabricantes, universidades e associações de usuários, trabalhando para a elaboração deste padrão.

O padrão LBS não foi desenvolvido como está sendo desenvolvido o padrão da ISO, visando a conclusão de um padrão completo que abrange diversas camadas de protocolo. O padrão LBS foi apresentado em sua primeira forma com especificações principalmente de camada física e de camada de enlace de dados. Desde então, este padrão vem sendo aperfeiçoado continuamente, também contando com os esforços de diversos grupos, principalmente grupos europeus. A forma mais completa da norma LBS foi apresentada em 1997 e denominada de versão 1. Esta versão não é tão abrangente quanto a norma da ISO, mas tem sido utilizada por alguns fabricantes e grupos de pesquisa. As experiências práticas destas implementações têm inspirado outras especificações ou alterações para compor versões futuras.

Como pode ser observado pela descrição anterior na Seção IV.1, a norma ISO é bastante completa, possuindo protocolos de alto nível que abrangem diversos aspectos de arquitetura de rede. Esta abrangência torna a sua implementação mais sistemática em relação à norma LBS, que não possui especificações de protocolos de alto nível tão abrangentes.

A norma da ISO possui especificações de camada rede e de camada de transporte que definem diversos elementos de rede, as NIU's, assim como mensagens de configuração e operação de rede, que a norma LBS não possui. Estas especificações, como descrito nas Seções IV.1.2, IV.1.3 e IV.1.4, permitem a existência de sub-redes que possibilitam a expansão da rede e um número maior de ECU's. Também, estas especificações orientam o desenvolvimento de gateways para implementação de sub-redes com padrões diferentes.

Outras especificações que a norma ISO possui e norma LBS não, são as que tratam do sistema automotivo da máquina agrícola, como descrito na Seção IV.1.5. O padrão da ISO define uma NIU especial e mensagens específicas para implementação de uma sub-rede automotiva, que possibilita não só o monitoramento de elemento automotivos tais como motor, transmissão e freios, mas também possibilita o controle destes elementos. Esta característica de atuação 
sobre os elementos automotivos expande as possibilidades de operação da máquina agrícola, permitindo por exemplo a implementação de um sistema semiautônomo ou autônomo de navegação integrado a controladores de implemento, possibilitando aplicações diferenciada de insumos.

Um contra ponto da abrangência do padrão da ISO é que a sua implementação e operação tende a possuir uma complexidade computacional maior em relação ao padrão LBS. Mesmo que não se utilize todas as possibilidades que o padrão dispõe, existem muitas configurações a serem feitas para desabilitar as opções que não serão utilizadas em um determinado barramento. Também, para que haja total compatibilidade, as ECU's devem possuir rotinas computacionais mínimas para permitir o seu funcionamento em qualquer rede com o padrão. Estas rotinas devem cobrir todas as possibilidades de operação da rede, mesmo que existam algumas que não sejam utilizadas, e isto demanda processamento e memória dos seus sistemas computacionais.

A norma LBS, apesar de não possuir especificações tão abrangentes de camada de rede e de camada de transporte, e não possuir especificações de subrede automotiva, fornece suporte ao desenvolvimento e implementação destes elementos. Esta característica constitui uma vantagem do padrão LBS em relação ao padrão da ISO, pois permite a elaboração e implementação de barramentos com elementos mais simples. As ECU's podem possuir menor capacidade computacional direcionada à configuração e à operação do barramento, assim como o barramento pode possuir sequências de configuração e operação mais simples para o usuário. O problema que pode ocorrer com esta liberdade de desenvolvimento, é a incompatibilidade entre produtos de diferentes fabricantes, gerada por implementações que extrapolem os limites suportados pela norma.

Os padrões ISO 11783 e LBS não são totalmente compatíveis, como descrito anteriormente nas Seções IV.1 e IV.2, mas apresentam compatibilidade, senão completa, quase completa em algumas partes, como é o caso das especificações que tratam do terminal de operação, do controlador de tarefas e da administração de rede. As especificações que contribuem acentuadamente para não compatibilidade entre os padrões são as diferentes taxas de comunicação e as diferentes versões do protocolo CAN adotadas para os padrões.

Alguns trabalhos têm buscado soluções para esta incompatibilidade entre os dois padrões, principalmente trabalhos de grupos de pesquisa da Europa, como 
grupo IKB-Dürnast da universidade Technical University Munich (TUM, 2002) da Alemanha, que além de desenvolver bibliotecas com rotinas computacionais para implementação do padrão LBS, tem desenvolvido soluções para implementação de ECU's compatíveis com os dois padrões. Uma destas soluções constitui-se na utilização de Cl's controladores do protocolo CAN compatíveis com as duas versões do protocolo CAN, associada a implementação de rotinas computacionais nas ECU's que permitam a deteç̧ão automática da taxa de comunicação e do padrão que está sendo utilizado no barramento em que a ECU for conectada. Esta solução demanda uma capacidade computacional grande para ECU, pois esta deverá conter rotinas que implementem a solução e as especificações dos dois padrões.

Outra solução que pode ser explorada para permitir a compatibilidade entre os padrões é o desenvolvimento de gateways que permitam a interface entre uma sub-rede LBS e uma sub-rede ISO 11783, como descrito anteriormente nesta mesma Seção. Assim, por exemplo, o barramento interno de um trator com padrão LBS pode ser conectado a um barramento de implemento com o padrão LBS, ou através de um gateway, o barramento interno do mesmo trator (padrão LBS) pode ser conectado a um barramento de implemento com o padrão ISO 11783.

\section{IV.5. IMPLEMENTAÇÕES DE PADRÕES}

Para a tomada de decisão sobre qual padrão utilizar ou sobre o desenvolvimento de um padrão próprio, é importante considerar além de especificações técnicas, as necessidades associadas a fatores como: mercado alvo, custo de implementação e manutenção, nível de complexidade de implementação e operação, necessidade de integração com outros padrões e expansões futuras.

À partir da definição das necessidades que um sistema baseado no CAN deve atender, pode-se buscar as melhores especificações técnicas para desenvolvimento e implementação de uma norma. Com a definição das especificações, pode-se optar por um padrão existente no mercado, que melhor atenda a estas especificações, e contar com dispositivos existentes no mercado. Também se pode optar pelo desenvolvimento de um padrão próprio segundo as especificações definidas, ou ainda, adotar especificações de um padrão existente e adicionar outras especificações, criando um padrão misto. 
Para uma determinada aplicação a definição das especificações técnicas pode ser baseada em três itens, que são:

a) Definição dos parâmetros de livre escolha, previstos pelo protocolo, como por exemplo, versão do protocolo, taxa de comunicação, número de nós e tamanho do barramento;

b) Definição de parâmetros de camada física e de componentes eletrônicos, não definidos pelo protocolo, como por exemplo, conectores, cabos e circuitos transceptores e controladores;

c) Definição dos parâmetros de protocolo de alto nível, e que estão relacionados diretamente com a aplicação da rede CAN. Como exemplo desses parâmetros cita-se: necessidade de sub-redes, tipos de mensagens, tamanho de mensagens, interfaces com ser o humano para operação e manutenção, possibilidades de expansão e formas conexão e inicialização de nós à rede.

\section{IV.5.1. Componentes eletrônicos}

Muitos dos padrões presentes no mercado adotaram especificações das normas ISO 11898 e ISO 11519, que são constituídas por especificações de camada física e de enlace de dados. Também existem no mercado, muitos Cl's que obedecem as especificações destas normas. Desta forma, encontram-se no mercado muitos padrões com o CAN que diferem pelos protocolos de alto nível desenvolvidos para cada aplicação.

Na implementação de um padrão baseado no CAN, os nós são tipicamente constituídos por três módulos elementares, que são:

> Transceptor CAN: módulo responsável pela adaptação dos níveis de tensão entre circuito do nó e do barramento CAN. Também promove a adaptação de impedâncias e a proteção do nó à faltas.

> Controlador CAN: módulo central da implementação e do controle do protocolo.

Sistema Computacional Central: módulo constituído por CPU, memória, programas computacionais e interface com o controlador CAN e interfaces para outros dispositivos como sensores, atuadores e terminais de controle. Através desse módulo são implementados os protocolos de alto nível. 
A FIGURA 29 ilustra um nó CAN e seus módulos constituintes. Também ilustra a forma de utilização de um quadro de dados CAN 2.0B para implementação de protocolos de alto nível.

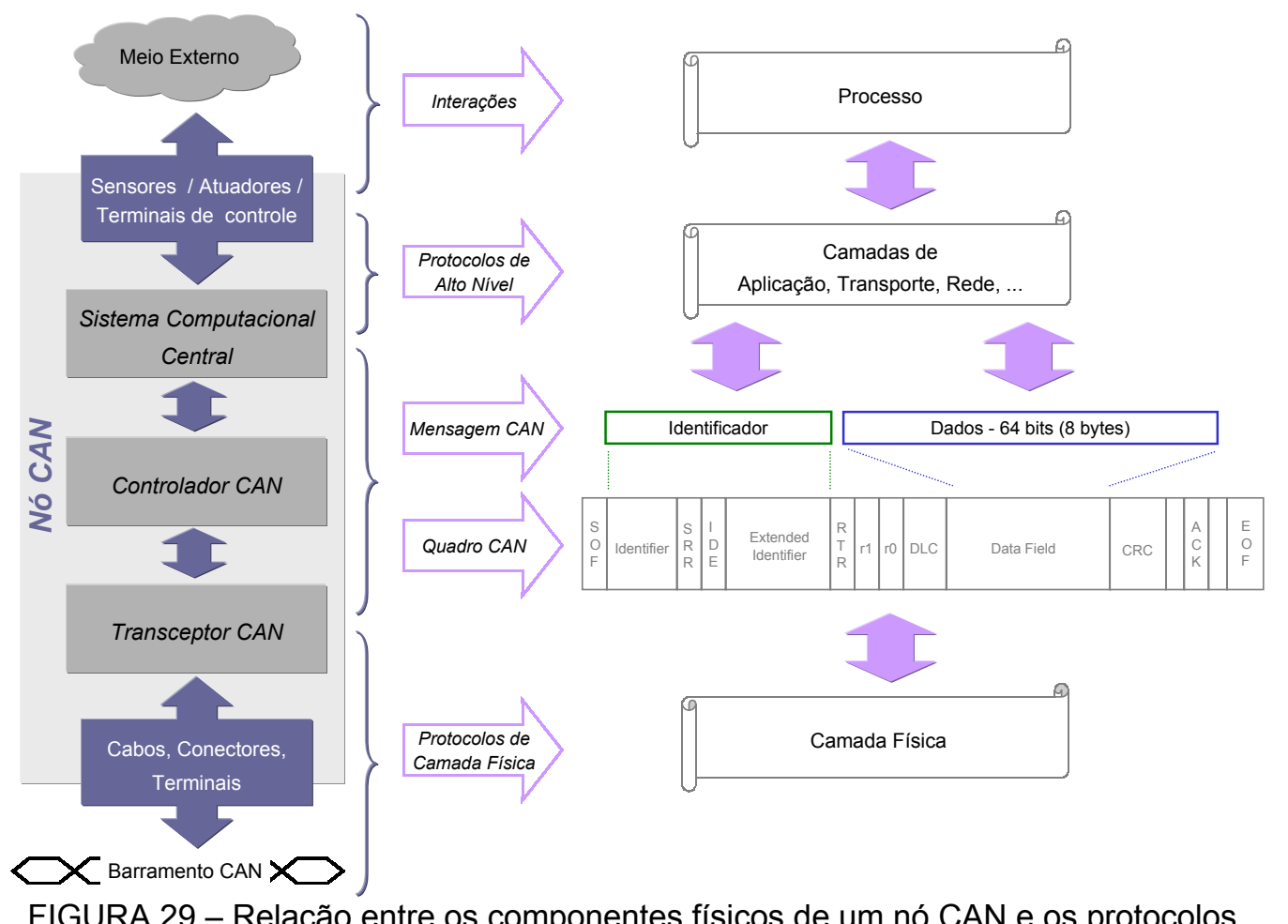

No mercado estão disponíveis Cl's com os três módulos - transceptor, controlador e sistema computacional - implementado internamente, assim como também, existem Cl's que implementam cada módulo separadamente.

Os transceptores e controladores são os elementos básicos para elaboração de redes CAN, pois determinam as características de operação de rede, como velocidade de transferência de dados (taxa de bits), imunidade a interferências, robustez, capacidade de carga (número de nós), custos, entre outras.

Como exemplo, na TABELA 6 são apresentados alguns transceptores CAN e na TABELA 7 são apresentados alguns controladores CAN, mais relevantes disponíveis no mercado. 
TABELA 6 - Transceptores CAN

\begin{tabular}{|c|c|c|}
\hline Fabricante & Dispositivo & Características \\
\hline Bosh & CF151 & Operação até 500k bits/s, circuito de proteção, 8 pinos. \\
\hline \multirow[t]{4}{*}{ Philips } & $82 \mathrm{C} 250$ & Operação até $1 \mathrm{M}$ bit/s, 110 nós, 8 pinos. \\
\hline & $82 \mathrm{C} 252$ & $\begin{array}{l}\text { Operação até } 125 \mathrm{k} \text { bits/s, tx/rx (transmissão/ recepção) } \\
\text { com único fio em caso de falha, } 15 \text { nós, modo de baixo } \\
\text { consumo, } 14 \text { pinos. }\end{array}$ \\
\hline & TJA1050 & Operação até $1 \mathrm{M}$ bit/s, 110 nós, 8 pinos. \\
\hline & TJA1054/53 & $\begin{array}{l}\text { Operação até } 125 \mathrm{k} \text { bits } / \mathrm{s}, \mathrm{t} \times / \mathrm{rx} \text { com único fio em caso de } \\
\text { falha, } 32 \text { nós, detecção de faltas, modo de baixo } \\
\text { consumo, temporizador de transmissão, } 14 \text { pinos. }\end{array}$ \\
\hline Infineon & TLE6252G & $\begin{array}{l}\text { Operação até } 125 \mathrm{k} \text { bits/s, tx/rx com único fio em caso de } \\
\text { falha, } 110 \text { nós, detecção de faltas, } 14 \text { pinos. }\end{array}$ \\
\hline
\end{tabular}

TABELA 7 - Controladores CAN

\section{Fabricante Dispositivo Características}

\begin{tabular}{|c|c|c|}
\hline Infineon & $81 C 90$ & $\begin{array}{l}\text { Full CAN 2.0A e 2.0B passivo, até } 1 \mathrm{M} \text { baud, buffer globa } \\
\text { de } 16 \text { mensagens ( } 12 \text { bytes), interfaces serial síncrona } \\
\text { (three-lead) e paralela } 8 \text { bits, } 2 \text { portas de E/S } \\
\text { (entrada/saída), temporizador para mensagens } \\
\text { recebidas, } 44 \text { pinos. }\end{array}$ \\
\hline Intel & 82527 & $\begin{array}{l}\text { Full CAN 2.0A e 2.0B, até } 1 \mathrm{M} \text { baud, buffer global de } 15 \\
\text { mensagens ( } 14 \mathrm{rx} / \mathrm{tx} \text { e } 1 \mathrm{rx}, 8 \text { bytes) com máscaras } \\
\text { (filtros), interfaces serial SPI e paralela } 8 \text { bits ou } 16 \text { bits } \\
\text { multiplexados, } 2 \text { portas de E/S, e drivers de saída } \\
\text { configuráveis, } 44 \text { pinos }\end{array}$ \\
\hline Microchip & MCP2510 & $\begin{array}{l}\text { Full CAN } 2.0 \mathrm{~A} \text { e } 2.0 \mathrm{~B} \text {, até } 1 \mathrm{M} \text { baud, buffer } 5 \text { mensagens } \\
\text { ( } 3 \text { tx e } 2 \text { rx, } 14 \text { bytes) com } 6 \text { máscaras (filtros), interfaces } \\
\text { serial SPI } 5 \mathrm{M} \text { bits/s, interrupções para controle opcional } \\
\text { de recepção, } 18 \text { pinos. }\end{array}$ \\
\hline Philips & SJA1000 & $\begin{array}{l}\text { BasicCAN e PeliCAN (CAN 2.0B com recursos como } \\
\text { filtros e recursos de diagnóstico), até } 1 \mathrm{M} \text { baud, FIFO } \\
\text { com } 13 \text { bytes para rx e } 13 \text { bytes para tx, acesso aos } \\
\text { controles de erros, } 28 \text { pinos. }\end{array}$ \\
\hline
\end{tabular}


Nas TABELAS 6 e 7 pode-se observar que os componentes representados apresentam requisitos para operação em ambientes agressivos como propriedades de detecção, sinalização, distinção de erros e detecção de faltas, além da possibilidade de continuar a comunicação em caso de rompimento de um dos dois fios do barramento ou curto-circuito com a fonte de alimentação (ou terra).

Os controladores avaliados possuem diferentes interfaces para se comunicar com outros componentes. As mais comuns notadas no levantamento são: interface serial SPI e interface Paralela. Outra interface presente é a interface serial I2C. Em relação a essas interfaces é importante observar que em projetos com controladores não integrados a sistemas computacionais, é necessário definir o tipo de interface que será utilizada para troca de dados entre estes dispositivos (microcontrolador/outro processador $\leftrightarrow$ controlador), para que haja compatibilidade e seja possível a implementação do circuito desejado.

Atualmente existe um grupo de Cl's que são denominados Microcontroladores $(\mu C)$, que têm sido utilizados amplamente em circuitos eletrônicos. Estes microcontroladores são sistemas computacionais implementados em um único $\mathrm{Cl}$, com $\mathrm{CPU}$, memórias voláteis e não voláteis, e estão disponíveis com uma infinidade de periféricos como contadores, comparadores, conversores analógicos e digitais, controladores de protocolo, transceptores, entre outros. Os microcontroladores permitem que sejam gravados programas computacionais (rotinas de programa) desenvolvidos externamente em aplicativos próprios. Através destes programas são implementadas as funções do microcontrolador em cada circuito.

Foi encontrada uma variedade grande de microcontroladores com controladores CAN integrados. Estes apresentaram características diversas, que devem ser analisadas segundo as necessidades de cada aplicação. Como exemplo, alguns microcontroladores pertencentes às famílias encontradas são apresentados na TABELA 8 
TABELA 8 - Microcontroladores com controlador CAN

\begin{tabular}{|c|c|c|}
\hline Fabricante & Dispositivo & Características \\
\hline Infineon & C167CR-LM & $\begin{array}{l}\text { Com controlador CAN compatível com } 82527 \text { (Intel); CPU } \\
\text { de } 16 \text { bits RISC com algumas aplicações Cl'SC, } 4 \mathrm{~K} \text { bytes } \\
\text { RAM e } 0,32 \text {, ou } 128 \mathrm{~K} \text { bytes ROM, entradas A/D, várias } \\
\text { portas de E/O digitais, } 144 \text { pinos. }\end{array}$ \\
\hline Intel & 87C196CA & $\begin{array}{l}\text { Com controlador CAN } 82527 \text { integrado (TABELA 7); CPU } \\
\text { de } 8 \text { bits, } 32 \mathrm{~K} \text { bytes EPROM e } 1280 \text { bytes RAM, seis } \\
\text { conversores A/D de } 10 \text { bits, várias E/Os. } 68 \text { pinos. }\end{array}$ \\
\hline Microchip & $18 \mathrm{Fxx} 8$ & $\begin{array}{l}\text { Com controlador MCP2510 integrado (TABELA 7); várias } \\
\text { configurações com diferentes capacidades de memória e } \\
\text { periféricos como conversores A/D, USART, PWM e } \\
\text { comparadores. }\end{array}$ \\
\hline Motorola & 68376 & $\begin{array}{l}\text { Com controlador CAN (TOUCAN: Full CAN 2.0A e 2.0B, } \\
\text { buffer de } 16 \text { mensagens) com diversas ferramentas de } \\
\text { diagnóstico como acesso ao quadro CAN e aos contadores } \\
\text { de erro; CPU de } 32 \text { bits, RAM de } 4 \mathrm{~K} \text { bytes, dezesseis } \\
\text { conversores D/A de } 10 \text { bits, interface SPI, } 160 \text { pinos. }\end{array}$ \\
\hline Philips & P8xC591 & $\begin{array}{l}\text { Baseados na popular família } 8051 \text {, com controlador CAN } \\
\text { SJA1000 integrado (TABELA 7); várias configurações com } \\
\text { diferentes capacidades de memória e elementos como } \\
\text { conversores A/D, USART e comparadores. }\end{array}$ \\
\hline
\end{tabular}

Como se pode observar na TABELA 8 , os microcontroladores, além do controlador CAN, possuem variadas capacidades de processamento e memória, entradas e saídas paralelas que podem ser utilizadas com sensores e atuadores com sinais compatíveis. Também possuem interfaces seriais, como USART e USB (Universal Seria Bus), que podem permitir a compatibilidade de equipamentos e integração ou desenvolvimento de interfaces com dispositivos de instrumentação mais elaborados (GPS, PC 104, computador portátil e atuador e sensor inteligentes).

Nos microcontroladores ou em outros sistemas computacionais, as interfaces paralelas para comunicação com outros dispositivos normalmente são mais rápidas que as seriais. Em contrapartida as interfaces seriais são mais simples de se utilizar e os componentes utilizam menos pinos para comunicação (2 ou 3 normalmente), e, consequentemente, os microcontrolador são menores ou têm pinos para outras funções. 


\section{IV.5.2. Dispositivos mais elaborados e interfaces}

No Brasil são encontrados apenas representantes de fabricantes de equipamentos com CAN, mas no mercado mundial existem diversos dispositivos com controlador CAN integrado principalmente para aplicações em automação industrial e automobilística, como por exemplo, transdutores (atuadores e sensores) CAN.

Computadores portáteis, como os notebooks, ainda não existem no mercado com controlador CAN integrado, mas existem interfaces externas, como cartões de interface PCMCIA, que possibilitam a utilização destes computadores em barramento CAN. Outra possibilidade para integração deste tipo de computador a barramentos CAN é a utilização de interface externa, como interfaces CAN/USB, CAN/RS232 ou CAN/RS485.

Os computadores-embarcáveis, como os computadores tipo PC104, são sistemas computacionais para tarefas dedicadas, possuem boa capacidade de processamento e armazenamento de dados, são compactos e de custo inferior, relativamente, aos microcomputadores pessoais comuns. Apresentam possibilidade de utilização de diversos programas e periféricos (interfaces visuais e teclas de controle). São encontrados no mercado com diversos tipos de interfaces internas integradas ao sistema, incluindo interfaces CAN. Apresentam grande potencial para projeto de ECU's segundo os padrões descritos neste trabalho.

Os computadores-de-mão, como os palmtops, são sistemas bastante compactos em relação a microcomputadores e computadores embarcáveis. Apresentam interface visual e programas de desenvolvimento de aplicativos bastante elaborados, que tornam fácil o desenvolvimento de aplicações. Possuem geralmente interfaces de comunicação via infra-vermelho ou interfaces serias segundo os padrões RS232 ou USB. Não existem modelos disponíveis com interface interna com controlador CAN, portanto para integração destes sistemas a barramentos CAN é necessário a utilização de interface externa, como interfaces CAN/USB ou CAN/RS232.

O padrão mais comum de comunicação de dados utilizado entre os receptores GPS e os coletores de dados, é o padrão de comunicação NMEA 0183. A norma deste padrão foi elaborada pela associação de normas NMEA e define características elétricas, protocolo de transmissão de dados, temporizações e tipos 
de mensagens. A versão 1 desta norma possui características elétricas baseadas no padrão RS232. Também é possível encontrar receptores GPS com interfaces segundo outros padrões, como padrões proprietários baseados no padrão USB ou no padrão RS485. Recentemente foi concluída a normatização de um novo padrão NMEA, denominado NMEA 2000, que é baseado no CAN. O padrão NMEA 2000 apresenta especificações para receptores GPS compatíveis com especificações dos padrões SAE J1939 e ISO 11783, e já estão disponíveis no mercado receptores GPS que possuem uma interface padrão para ser utilizado em sistemas com qualquer um destes três padrões.

A interface interna mais comum verificada nos dispositivos pesquisados é o padrão RS232. Outras interfaces que também se destacam são os padrões RS485 e USB. Os padrões RS232 e RS485 são padrões de camada física e sobre eles são utilizados alguns protocolos proprietários ou abertos de camadas superiores. $O$ USB é um padrão mais elaborado que os padrões RS232 e RS485, mas também necessita de alguns protocolos proprietários ou abertos de camadas superiores sobre ele. O padrão USB é mais utilizado atualmente para interligar computadores com periféricos, como impressora, mouse, CD-ROM, monitor, multimídia, fax, etc, mas sua utilização tem se ampliado sendo encontrado em computadores-de-mão, celulares, rádio digitais, cameras, GPS e até em sensores industriais.

\section{IV.5.3. Projeto de circuitos}

Como observado na Seção anterior, ainda não existem no mercado certos dispositivos com interface interna com controlador CAN integrado, sendo necessário uma interface externa para conectar o dispositivo a um barramento CAN. Assim, como exemplo de desenvolvimento de um nó CAN, foi desenvolvido um circuito eletrônico de interface entre os padrões RS232 e o CAN. A FIGURA 30 ilustra a utilização desta interface externa para permitir conectar dispositivos com interface interna RS232 à um barramento CAN. 


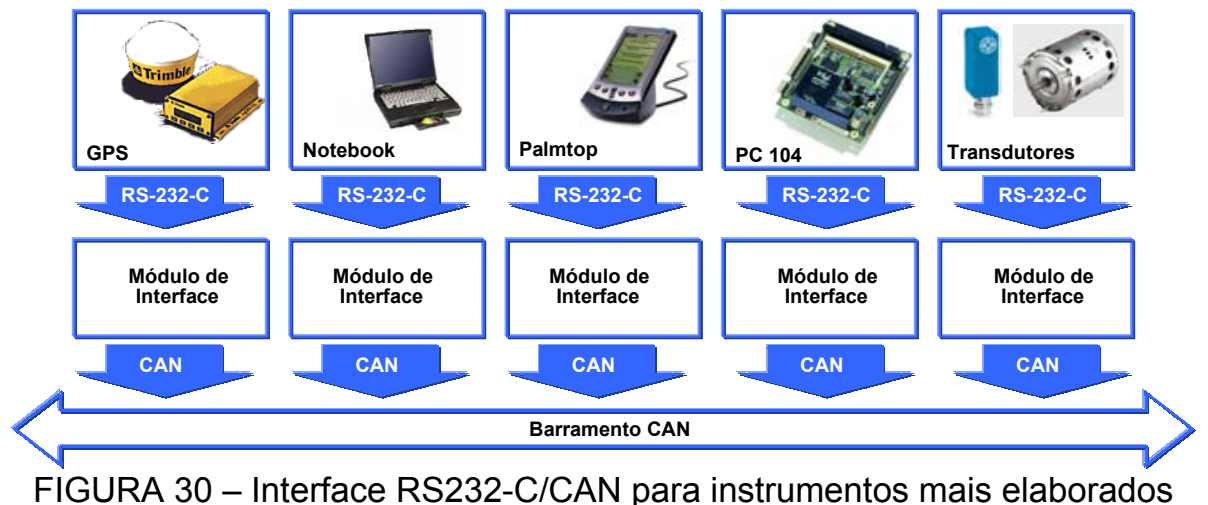

Inicialmente foi projetado e montado um circuito eletrônico básico baseandose nos Cl's: transceptor CAN, controlador CAN e microcontrolador com USART. Também utilizou-se um $\mathrm{Cl}$ transceptor RS232 para adaptar os níveis dos sinais elétricos da USART do microcontrolador para os níveis padrão RS232. Optou-se por utilizar controlador CAN não integrado ao microcontrolador para se ter uma maior liberdade de projeto, pois assim pode-se escolher um microcontrolador adequado entre os vários tipos existentes de diversos fabricantes.

Para teste da interface-protótipo, foi elaborada e implementada no microcontrolador uma rotina simples, para envio e recebimento de mensagens. Um fluxograma da rotina é apresentado na FIGURA 31. 


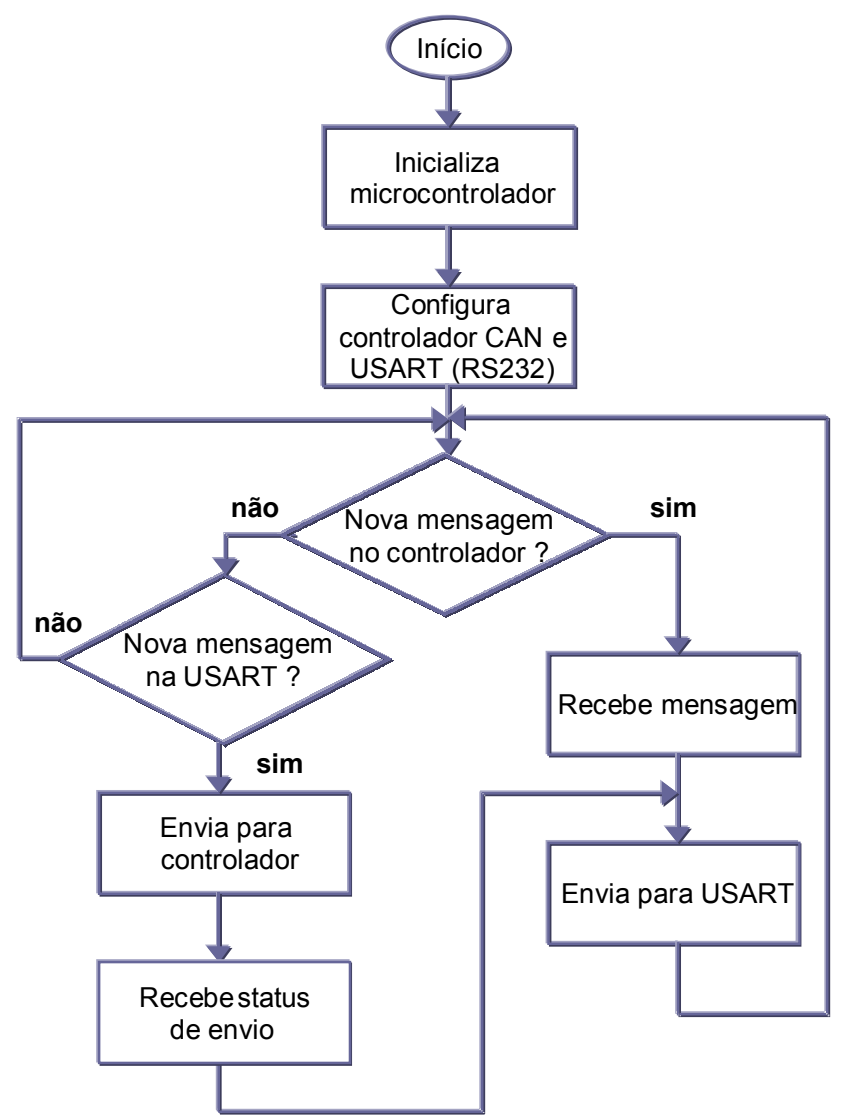

FIGURA 31 - Fluxograma simples da rotina para teste da interface-protótipo

A implementação da rotina foi comprometida por limitações do compilador baseado em linguagem $\mathrm{C}$, utilizado para desenvolvimento de programas para $\mathrm{o}$ microcontrolador. Algumas funções da biblioteca para ser utilizada com o controlador não funcionaram corretamente. Foi necessário substituir estas funções por rotinas na linguagem de baixo nível própria para o microcontrolador utilizado. Apesar desta dificuldade com os resultados dos testes, foi possível determinar alterações para melhorar a funcionalidade e o desempenho dos circuitos. Então o projeto foi atualizado, e em relação ao projeto inicial foram acrescidos à interface uma memória não volátil (EEPROM) de $4 \mathrm{~K}$ bits e isoladores ópticos. Um diagrama ilustrativo da interface é apresentado na FIGURA 32, e o esquemático (esquema elétrico) da interface é apresentado no ANEXO. 


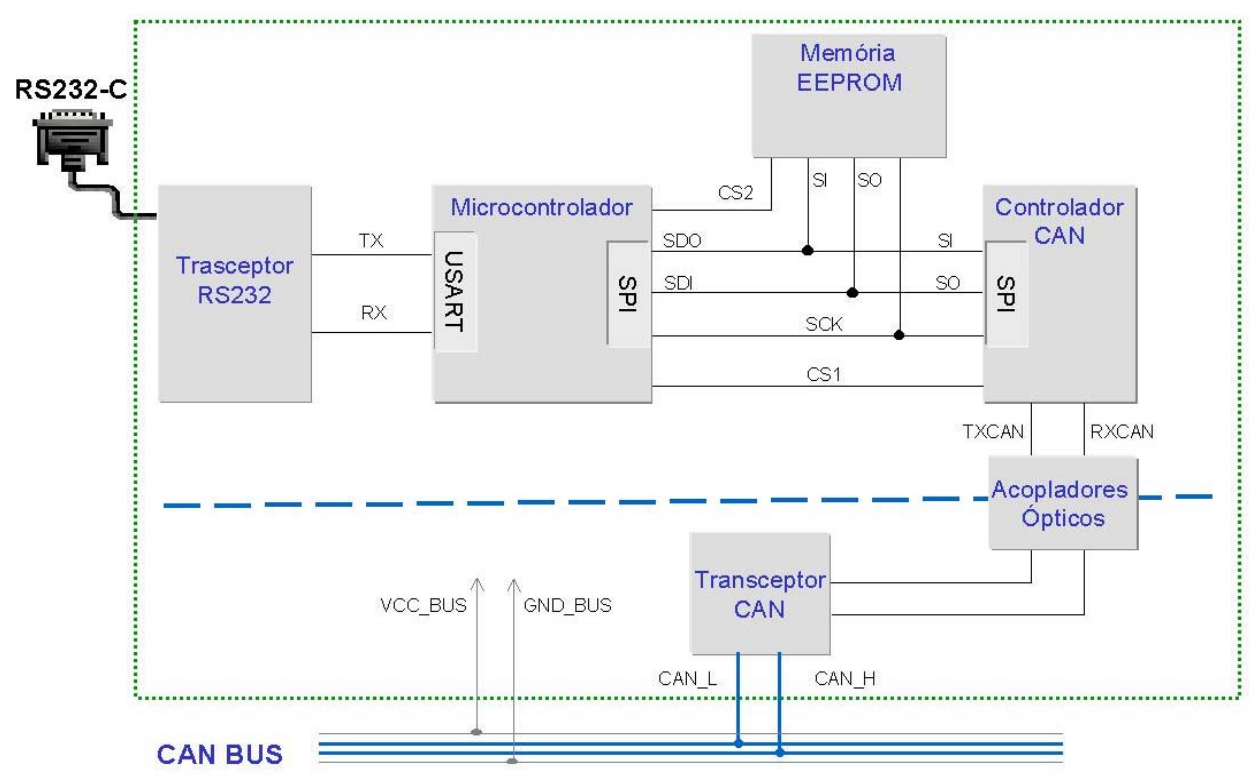

FIGURA 32 - Diagrama ilustrativo da interface RS232-C/CAN - opticamente isolada (esquemático apresentado no ANEXO)

Uma das principais condição para a escolha do microcontrolador refere-se a interface deste com o controlador CAN, ou seja, o microcontrolador e o controlador CAN escolhidos devem possuir interface compatível para troca de dados. No caso deste projeto optou-se por utilizar interface serial, pois é mais simples de implementar e utiliza menos pinos, tornando o circuito mais compacto. A interface escolhida foi a SPI, pois é uma das mais comuns nestes componentes.

Os controladores CAN, como o controlador utilizado, normalmente possuem dois modos básicos de operação. Um dos modos é o modo de configuração, no qual é possível definir a taxa de comunicação, a versão do protocolo a ser utilizada e os filtros e máscaras de mensagem. O outro modo de operação é o modo normal, no qual o controlador executa a comunicação normalmente, recebendo e enviando mensagens, e gerenciado erros.

A memória adicionada à interface permite que o usuário desta interface possa configurar, por exemplo, através de um terminal em um PC, parâmetros de comunicação RS232 (taxa de comunicação e os bits de controle - paridade e fim de quadro) e de comunicação CAN (taxa de comunicação, identificador do nó, identificador de mensagens a serem aceitas e versão do CAN utilizada - 2A ou 2B), e os parâmetros ficarem armazenados na memória não volátil. Desta forma a interface torna-se mais flexível, permitindo diferentes configurações. Escolheu-se uma memória com interface para componentes SPI. Esta interface foi escolhida por ser mais rápida (5M bits/s) que as interfaces USART e I2C (< 400k bits/s). 
Utilizando a interface SPI foi possível utilizar o mesmo barramento SPI do controlador CAN MCP2510, tornando o circuito mais compacto, como pode ser visto na FIGURA 32.

Os isoladores ópticos adicionados ao projeto promovem o isolamento elétrico entre o circuito de comunicação RS232 e o barramento CAN. Esta adição aumenta a proteção contra sobre-tensões que possam ocorrer no barramento CAN, e que poderiam danificar dispositivo conectado ao RS232. A escolha dos isoladores ópticos baseou-se em recomendações do fabricante do transceptor CAN utilizado. O principal parâmetro considerado foi o atraso provocado pelos isoladores que por recomendação deve ser inferior à 40 ns para taxa de comunicação do barramento superior a $500 \mathrm{k}$ bits $/ \mathrm{s}$.

Foi elaborado um terminal para PC com Labview para envio e recebimento de mensagens do barramento, mas pode-se utilizar outros aplicativos desenvolvidos em outras linguagens de programação, desde que preparados para comunicar com a interface. Para isto deve-se considerar que uma mensagem CAN é composta por 11 ou 29 bits de identificação e até 64 bits de dados, e a USART utilizada para comunicação de bits via RS232 opera com quadros de bits compostos por 1 bit de início de quadro, seguido por 8 bits de dados e 1 bit de fim de quadro. Assim, um protocolo deve ser implementado para que o aplicativo sendo executado no PC ou em outro dispositivo a ser conectado no barramento CAN, comunique-se com a interface. Como exemplo, no caso deste projeto definiu-se que quando uma mensagem CAN é recebida pelo barramento CAN e encaminhada para o PC via RS232, ou quando uma mensagem é gerada no aplicativo no PC e encaminhada via RS232 à interface, esta mensagem é fragmentada e enviada via RS232 em quadros de 8 bits precedida por dois quadros de controle. Definiu-se que um quadro de comando de 8 bits é enviado primeiramente para informar à interface ou ao aplicativo no PC (dependendo do sentido da comunicação) do conteúdo dos dados no barramento RS232. Este quadro de comando é seguido por um quadro de 8 bits informando o tamanho do quadro de dados da mensagem CAN fragmentada. Os quadros de controle são seguidos por quadros de 8 bits da mensagem CAN fragmentada. Desta forma, o receptor, sendo este a interface ou o aplicativo no PC, pode receber a mensagem fragmentada via RS232 e montá-la para a devida utilização. 
A interface-protótipo mostrou-se um circuito simples, porém eficiente, que pode permitir a integração de dispositivos com interface RS232 a redes baseadas no CAN, como redes ISO 11783 e redes LBS. Os inconvenientes maiores na utilização do RS232 são a taxa de comunicação e a carga útil de dados, já que os valores máximos possíveis são inferiores aos permitidos pelo CAN. Sendo assim, sistemas que demandam respostas rápidas podem ter a eficiência comprometida por atrasos de comunicação provocados pela interface.

Como exemplo de aplicação de uma interface como a projetada, cita-se a utilização para promover a conexão de um receptor GPS com padrão NMEA 0183, a um barramento ISO 11783 ou LBS. Também, pode ser utilizada para permitir o emprego de um pamltop para realização de diagnósticos em barramentos ISO 11783 ou LBS. No primeiro caso, a interface deverá possuir rotinas para conversão das menagens do GPS no formato NMEA 0183 (exemplo de mensagens: GGA, VTG e RTCM) para o formato do padrão do barramento utilizado. No segundo caso a interface deverá possuir rotinas para implementar o padrão do barramento utilizado e para realizar a fragmentação de mensagens de erros e de faltas detectados no barramento, para então, transmiti-las ao palmtop, que, por sua vez, deverá possuir um aplicativo próprio para processamento destas mensagens e exibição dos resultados. 


\section{CONCLUSÕES}

Atualmente, o protocolo CAN figura como um dos mais importantes protocolos que compõem padrões de barramentos de campo e de barramentos de para sistemas eletrônicos embarcados. A robustez, a confiabilidade e a flexibilidade conferida aos padrões desenvolvidos com este protocolo é reconhecida e têm sido responsáveis pelo crescente número de aplicações deste protocolo. Com isto a disponibilidade de circuitos integrados e de nós CAN é crescente e os custos de para implementação têm decrescido.

A pesquisa de circuitos integrados controladores, transceptores e microcontroladores revelou uma diversidade grande destes componentes, com capacidades e periféricos que potencializam o desenvolvimento de circuitos simples, mas com recursos que permitem implementação de redes sofisticadas. $O$ fato da maioria dos componentes, assim como os padrões desenvolvidos com o CAN, obedecerem as especificações das normas ISO 11898 e ISO 11519, tornam estas normas referências para o desenvolvimento de nós CAN.

As características do CAN e a variedade de circuitos integrados fornecem um excelente suporte ao desenvolvimento de aplicações em automação e controle na área agrícola. Este excelência pode ser reafirmada com este trabalho, assim como a excelência dos protocolos de alto nível que compõem as normas DIN 9684, SAE J1939 e ISO 11783.

A sistematização das informações realizada sobre o CAN e os padrões em questão, permitiu a geração de uma documentação referencial, que associada à sistematização da pesquisa de componentes, constitui um suporte para empresas da área agrícola para escolha ou desenvolvimento de padrões de comunicação para projetos de máquinas e implementos agrícolas. Também constitui suporte para outros projetos na área agrícola para sistemas com necessidade de uma rede para integração de dispositivos transdutores e controladores.

Também, a sistematização da pesquisa de interfaces presentes em dispositivos mais elaborados e com potencial para aplicação na área agrícola faz parte desta documentação referencial gerada, e fornece suporte para projetos de redes CAN com estes dispositivos (como GPS, computadores embarcáveis, computadores-de-mão, transdutores inteligentes), que atualmente estão fazendo 
parte do conjunto de ferramentas de trabalho no campo, principalmente sob o contexto da Agricultura de Precisão. A utilização de computadores-de-mão e computadores embarcáveis expande as possibilidades de interfaceamento, capacidade de armazenamento, autonomia de operação, e possibilita a utilização conjunta de sistemas de apoio a decisão, podendo ser considerada atualmente de grande auxílio na Agricultura de Precisão.

A utilização da ferramenta de modelamento gráfico e matemático Redes de Petri para modelamento e simulação do processo de endereçamento dinâmico dos padrões ISO 11783 e SAE J1939 mostrou-se simples e eficiente, facilitando o entendimento deste processo e gerando um modelo para auxiliar o desenvolvimento de rotinas para projetos de ECU's segundo os padrões em questão. Também o uso desta ferramenta sugestiona seu emprego em modelagens e simulação de outros processos para auxiliar projetos de redes CAN para aplicações agrícolas.

O desenvolvimento de sistemas baseados no CAN com características próprias para as necessidades da agricultura e do agricultor brasileiro, assim como o desenvolvimento de circuitos e programas que permitam integrar dispositivos de controle e automação à máquinas agrícolas com os padrões sistematizados, ainda constitui um desafio para as industrias nacionais de máquinas e implementos. 0 potencial tecnológico destes padrões é claro, assim como os benefícios do emprego destes padrões.

Fica claro que os esforços advindos da união entre empresas e grupos de pesquisa deram origem ao protocolo $\mathrm{CAN}$ e aos padrões para a área agrícola, sendo assim espera-se que este trabalho possa orientar não só empresas, como grupos de pesquisa no desenvolvimento e implementação destas tecnologias, contribuindo para que se tornem realidade na Agricultura do Brasil. 


\section{ANEXO}

A seguir é apresentado o esquemático do circuito da interface-protótipo RS232-C/CAN descrita na Seção IV.5.3. 


\section{REFERÊNCIAS BIBLIOGRÁFICAS}

3COM CORP. (2002). http://www.3com.com. (Jan.).

AGCO CORP. (2002). http//:www.agcocorp.com. (Mar.).

AGROCOM GMBH \& CO. AGRARSYSTEM KG. (2001). http://www.agrocom.com. (Dez.).

AMAZONEN-WERKE H.DREYER GMBH \& CO. KG. (2001). http//:www.amazone.de. (Dez.).

ASAE. SOCIETY FOR ENGINEERING IN AGRICULTURAL FOOD, AND BIOLOGICAL SYSTEMS. (1997). Precision agriculture: a position statement adopted by ASAE. St. Joseph, ASAE.

AUERNHAMMER, H. (2001). Precision farming - the environmental challenge. Computers and Electronics in Agriculture, v.30, Issues 1-3, p.31-43, Feb.

BAKER, K.; BRANDON, D.; FORMWALT, C.W. (1994) CAN physical layer for offroad equipment. In: ASAE INTERNATIONAL SUMMER MEETING, Kansas City, 1994. St.Joseph, ASAE. (ASAE Paper No. 941078).

BALASTREIRE, L.A. (1998). Estudo de caso: uma pesquisa brasileira em agricultura de precisão. In: CONGRESSO BRASILEIRO DE ENGENHARIA AGRÍCOLA, 27., Poços de Caldas, 1998. Mecanização e Agricultura de Precisão. Poços de Caldas, SBEA/UFLA, 1998. Cap.6, p.203-231.

BALDAN S/A IMPLEMENTOS AGRÍCOLAS. (2001). http://www.baldan.com.br. (Nov.).

BARBOSA, M.; FARSI, M.; RATCLIFF, K. (1999). An overview of controller area network. Computing \& Control Engineering Journal, v.10, n.3, p.113-120, June.

CASE CORP. (2001). http//:www.casecorp.com. (Out.).

CIA - CAN IN AUTOMATION. (2002). http://www.cia-can.com. (Jan.).

CORONA JUNIOR, N.; SARTORI, J.C.; INAMASU, R.Y. (1996). Rede local de instrumentos: aplicação de rádio digital à agropecuária.(CD ROM) In: CONGRESSO BRASILEIRO DE ENGENHARIA AGRÍCOLA, 25./ CONGRESO LATINOAMERICANO DE INGENIERIA AGRICOLA, 2., Bauru, 1996. Anais. Bauru, UNESP/Sociedade Brasileira de Engenharia Agrícola/ Asociación Latinoamericana de Ingenieria Agricola, 1996. (ref.EnA 362).

DARBON ELECTRONICS LTD. (2001). http://www.dearborn.co.uk. (Out.).

DEERE \& COMPANY. (2002). http//:www.deer.com. (Mar.). 
DEUTSCHES INSTITUT FÜR NORMUNG. (2002). http://www.en.din.de/. (Jan.)

ELECTRONIC INDUSTRIES ALLIANCE. (2001). http://www.eia.org/. (Nov.).

GAZZIRO, M., SOUSA, R. V., INAMASU, R. Y., TORRE-NETO, A. (2001) Sistema portátil de aquisição de dados baseado em computadores de mão no auxílio a SIG. In: BALASTREIRE, L.A. Avanços na agricultura de precisão no Brasil no período 1999-2001. Piracicaba: L. A. Balastreire, 2002. Cap. 5, p. 324-328. 1 CD-ROM. Trabalho apresentado no III Simpósio sobre Agricultura de Precisão, Piracicaba, SP, 2001.

HOFSTEE, J.W.; GOENSE, D. (1997). Simulation of a CAN-based tractorimplement field bus according to DIN 9684. Journal of Agricultural Engineering Research, v.68, p.89-100, May 1997.

. (1999). Simulation of a controller area network-based tractor-implement data bus according to ISO 11783. Journal of Agricultural Engineering Research, v.73, n.4, p.383-394, Aug.

INFINEON TECHNOLOGIES AG. (2001). http://www.infineon.com/. (Nov.).

INTEL CORP. (2002). http://www.intel.com/. (Jan.).

INTERNATIONAL STANDARDS ORGANIZATION. (2002). http://www.iso.org/ (Mar.).

JAHNS, G.; SPECKMANN, H. (1999). Development and application of an agricultural BUS for data transfer. Computers and Electronics in Agriculture, v. 23, n.3, p.219-237.

JUMPTEC INDUSTRIELLE COMPUTERTECHNIK AG. (2001). http//:www.jumptec.de. (Nov.).

KVASER CORP. (2001). http/l:www.kvaser.com. (Out.).

LANDTECHNIK-VEREINIGUNG. (2002). LBS: the mobile agricultural BUS. LBS Documentation, version 2.0 - 08. Frankfurt, 1998. http: //isotc.isso.ch. (dia Mar.).

LANG, F.et al. (1999). Development of a CAN based air seeder monitor. In: INTERNATIONAL CONFERENCE OF PRESION AGRICULTURE, 4., St.Paul, 1998. Proceedings. Madison, American Society of Agronomy. p.991-1000.

MICROCHIP INC. (2002). http://www.microchip.com. (Mar.).

MARCHESAN IMPLEMENTOS E MÁQUINAS AGRÍCOLAS "TATU" S/A. (2001). http://www.marchesan.com.br. (Oct.).

MOTOROLA INC. (2001). http://www.mot.com. (Oct.)

MANTOVANI, E.C.; QUEIROZ, D.M.; DIAS, G.P. (1998). Máquinas e operações utilizadas na agricultura de precisão. In: CONGRESSO BRASILEIRO DE 
ENGENHARIA AGRÍCOLA, 27., Poços de Caldas, 1998. Mecanização e Agricultura de Precisão. Poços de Caldas, SBEA/UFLA. Cap.4, p.109-157.

MUNACK, A.; SPECKMANN, H. (2001). Communication technology is the backbone of precision agriculture. Agricultural engineering international. CIGR Journal of Scientific Research and Development, .v.3, p.1-12, May.

MURATA, T. (1989). Petri nets: properties, analysis and applications. Proceedings of the IEEE, v.77, n.4, Apr.

NATIONAL INSTRUMENTS CORP. (2001). http://www.ni.com.br. (Oct.).

NEW HOLLAND CORP. (2002). http//:www.newholland.com. (Mar.).

OPEN DEVICENET VENDOR ASSOCIATION. (2002). http://www.odva.com. (Jan.)

NATIONAL MARINE ELECTRONIC ASSOCIATION. (2001). http://www.nmea.org/. (Nov.).

OMEGAS SOFTWARE SYSTEMS LTD. (2001). http://www.omegas.co.uk. (Oct.).

PC/104 CONSORTIUM. (2002). http//:www.pc104.org. (Jan.).

PHILIPS SEMICONDUCTORS. (2001). http://www.semiconductors.philips.com. (Nov.).

POCKET TECHNOLOGIES INC. (2001). www.pocket-technologies.com. (Nov.).

ROBERT BOSCH GMBH. (2002). http://www.bosh.de. (Fev.).

SOCIETY OF AUTOMOTIVE ENGINEERS. (2002). http://www.sae.org. (Jan.).

SARAIVA, A.M.; CUGNASCA, C.E. (1998). Sistemas para agricultura de precisão: equipamentos e programas. In: CONGRESSO BRASILEIRO DE ENGENHARIA AGRÍCOLA, 27., Poços de Caldas, 1998. Mecanização e Agricultura de Precisão. Poços de Caldas, SBEA/UFLA. Cap.5, p.159-202.

SOUSA, R.V.; INAMASU, R.Y.; TORRE-NETO, A. (2000). Protocolo CAN: um subsídio para implementação. (CD ROM) In: CONGRESSO BRASILEIRO DE ENGENHARIA AGRíCOLA, 29., Fortaleza, 2000. Anais. Fortaleza, Sociedade Brasileira de Engenharia Agrícola.

. (2001). Modelamento e simulação com redes de petri aplicados a projeto de redes CAN para máquinas agrícolas. (CD ROM) In: CONGRESSO BRASILEIRO DE ENGENHARIA AGRÍCOLA, 30., Foz do Iguaçú, 2001. Anais. Foz do Iguaçú, Sociedade Brasileira de Engenharia Agrícola.

(2001a). Levantamento e sistematização de padrões desenvolvidos para máquinas e implementos agrícolas baseados no protocolo CAN. (CD ROM). In: SIMPÓSIO SOBRE AGRICULTURA DE PRECISÃO, 3., Piracicaba, 2001. Anais. Piracicaba, Escola Superior de Agricultura Luiz de Queiroz. 
(2001b). Levantamento e sistematização de padrões desenvolvidos para máquinas e implementos agrícolas baseados no protocolo CAN para projeto de interface. In: CONGRESSO BRASILEIRO DA SOCIEDADE BRASILEIRA DE INFORMÁTICA APLICADA À AGROPECUÁRIA E AGROINDÚSTRIA, 3., 2001, Foz do Iguaçu. Trabalhos apresentados... Foz do Iguaçu: SBIAGRO, 2001. p. 60. Resumo. Editores: Marcos Aurélio Lopes, André Luiz Zambalde. Anais.

SPECKMANN, H. (2000). Providing measured position data for agricultural machinery. Computers and Electronics in Agriculture, v.25, Issues 1-2, p.87106, Jan.

STEPPER, M. R. (1993). J1939 high speed serial comunication, the next generation network for heavy duty vehicles. In: SAE FUTURE TRANSPORTATION TECHNOLOGY CONFERENCE, San Antonio, 1993. Warrendale, SAE. P.1-20 (SAE Technical Paper Series, No. 931809).

STONE, M. L. (1997). Dynamic address configuration in SAE J1939. SAE Transactions, p.310-315, Sept. (Apresentado no SAE SYMPOSIUM ON OFFHIGHWAY EQUIPMENT, Milwaukee, 1997).

. (1997a). High speed networking in construction and agricultural equipment. In: SAE SYMPOSIOUM ON FUTURE TRASPORTATION ELECTRONICS: MULTIPLEXING, Dearbon, 1994. S.I., SAE. p.1589-1598. (SAE, 941662).

. (2001). http://bioen.okstate.edu/Home/mstone/pindex.html. (Oct.).

STONE, M.L.; ZACHOS, M. (1993). Application of J1939 networks in agricultural equipament. In: ASAE INTERNATIONAL WINTER MEETING, St Joseph, 1993. Chicago, ASAE. (ASAE paper no. 931535).

STRAUSS, C.et al. (1999). Applications of the CAN and ISO 11783 protocols to a planter monitor. (CD ROM) In: WORLD MULTICONFERENCE ON CIRCUITS, SYSTEMS, COMMUNICATIONS AND COMPUTERS, Danvers, 1999. Proceedings. Athens. World Scientific and Engineering Society.

TEXAS INSTRUMENTS INC. (2001). http://www.ti.com. (Aug.).

TORRE, A.N. (1995). Estudo e implementação de um sistema de monitoramento remoto de variáveis endafo-ambientais. São Carlos. 146 p. Tese (Doutorado) - Instituto de Física de São Carlos, Universidade de São Paulo.

TRIMBLE NAVIGATION LTD. (2001). http://www.trimble.com. (Oct.).

VECTOR INFORMATIK GMBH. (2001). http://www.vector-informatik.de. (Mar). 


\section{BIBLIOGRAFIA COMPLEMENTAR}

BURNS, A.; TINDELL, K.; WELLINGS, A.J. (1995). Calculating controller area network (CAN) message response times. Control Engineering Pratice, v.3, n.8, p.1163-1169, Aug.

BUSCHMEIER, R.; WEIB, H.; HALD, J.A. (1993). Operator Interface for a standardized open MAB system. In: ASAE Internatinal Winter Meeting, Chicago, 1993. St Joseph, ASAE. (ASAE Paper n.931623).

CAMPBELL, J. (1990). Rs-232 tecnicas de interface. Trad.por Niuton Braga. Rio de Janeiro, Ebras.

ESRI CORP. (2001). http://www.esri.com. (Oct.).

INAMASU, R. Y.; FRANÇA, G. E.; TORRE-NETO, A.; MANTOVANI, E. C.; CRUVINEL, P. E.; GOMIDE, R. L.; LUCHIARI JR., A.; RABELLO, L. M.; SOUSA, R. V. (2001) Condutividade elétrica do solo: primeiros mapas do Brasil. In: BALASTREIRE, L. A. Avanços na agricultura de precisão no Brasil no período 1999-2001. Piracicaba: L. A. Balastreire, 2002. Cap. 2, p. 32-37. 1 CD-ROM. Trabalho apresentado no III Simpósio sobre Agricultura de Precisão, Piracicaba, SP, 2001.

PALMBRASIL. (2001). http://www.palmbrasil.com.br. (Out.).

PATCHWORK TECHNOLOGY LIMITED. (2001). http://www.patchwork.co.uk. (July).

SERÔNDIO, C; CUNHA, J.B.; MORAIS, R.; COUTO, C.; MONTEIRO, J. A. (2001). A networked platform for agricultural management systems. Computers and Electronics in Agriculture, v.31, Issue 1, p.75-90, Mar.

STAFFORD, J.V.; LE BARS, J.M.; AMBLER, B. (196). A hand-held data logger with integral GPS for producing weed maps by field walking. Computers and Electronics in Agriculture, v.14, n.2/3, p.235-247.

STRAUSS, C. (2001). Implementação e avaliação de uma rede experimental baseada em CAN para aplicações agrícolas. São Paulo. 59 p. Dissertação (Mestrado) - Escola Politécnica, Universidade de São Paulo.

TANENBAUM, A.S. (1997). Redes de computadores. 3.ed. Rio de Janeiro, Campus.

WANG, Z.; LU, H.; STONE, M.L. (1992). A message priority assignment algorithm for can based networks. In: COMPUTER SCIENCE CONFERENCE, New York, 1992. s.I., Association for computing machinary. p.25-32.

YOUNG, S. C.; SOKOL, D.G.; STROSSER, R.P. (1993). Utilization of CAN technology in a distributed control system. In: ASAE INTERNATIONAL WINTER MEETING, Chicago. St.Joseph, ASAE. ( ASAE Paper n.931535) 